PNL-2834

UC-95d

\title{
Manual of Procedures for the Operation of Bench-Scale Anaerobic Digesters
}

R. R. Spencer

December 1978

Prepared for the U.S. Department of Energy under Contract EY-76-C-06-1830

Pacific Northwest Laboratory Operated for the U.S. Department of Energy by Battelle Memorial Institute 


\title{
NOTICE
}

This report was prepared as an account of work sponsored by the United States Government. Neither the United States nor the Department of Energy, nor any of their employees, nor any of their contractors. subcontractors, or their employees, makes any warranty, express or implied, or assumes any legal liability or responsibility for the accuracy, completeness or usefulness of any information, apparatus, product or process disclosed, or represents that its use would not infringe privately owned rights.

The views, opinions and conclusions contained in this report are those of the contractor and do not necessarily represent those of the United States Government or the United States Department of Energy.

\author{
PACIFIC NORTHWEST LABORATORY \\ operated by \\ BATTELLE \\ for the \\ UNITED STATES DEPARTMENT OF ENERGY \\ Under Contract EY-76-C-06-1830
}

\author{
Printed in the United States of America \\ Availabie from \\ National Technical Information Service \\ United States Department of Commerce \\ 5285 Port Royal Road \\ Springfield, Virginia 22151
}

Price: Printed Copy 5 . $\because$ Microfiche $\$ 3,00$

$\begin{array}{cc}\text {-Pages } & \text { NTIS } \\ & \text { Selling Price } \\ 001-025 & \$ 4.00 \\ 026-050 & \$ 4.50 \\ 051-075 & \$ 5.25 \\ 076-100 & \$ 6.00 \\ 701-125 & \$ 6.50 \\ 126-150 & \$ 7.25 \\ 151-175 & \$ 8.00 \\ 176-200 & \$ 9.00 \\ 201-225 & \$ 9.25 \\ 226-250 & \$ 9.50 \\ 251-275 & \$ 10.75 \\ 276-300 & \$ 11.00\end{array}$


PNL -2834

UC-95d

\section{4}

\section{MANUAL OF PROCEDURES FOR \\ THE OPERATION OF BENCH- \\ SCALE ANAEROBIC DIGESTERS}

R.R. Spencer

December 1978

Prepared for the U.S. Department of

Energy under Contract EY-76-C-06-1830

Pacific Northwest Laboratory

Richland, Washington 99352 

TABLE OF CONTENTS

$\underline{\text { Page }}$

INTRODUCTION. . . . . . . . . . . . . . 1

ENVIRONMENTAL REQUIREMENTS. . . . . . . . . . . 2

$\mathrm{pH}$. . . . . . . . . . . . . . . . . 2

Chemical Addition. . . . . . . . . . . 3

Temperature. . . . . . . . . . . . . 5

Mixing . . . . . . . . . . . . . . . 6

Anaerobic Conditions . . . . . . . . . 6

Nutrients. . . . . . . . . . . 6

ANAEROBIC DIGESTERS .............. . 7

Digester Vessels . . . . . . . . . . . 7

Temperature Control. . . . . . . . . . 9

Gas Recirculation Mixing . . . . . . . . . 9

Feeding/Sampling System. . . . . . . . . . 11

Leak Testing.............. 12

GAS COLLECTION SYSTEM .............. 14

Description. . . . . . . . . . . . . . 14

Calibration of Gas Collection Columns. . . 14

Gas Measurement. . . . . . . . . . 16

Preparation of Salt Solution . . . . . . 18

DIGESTION SUBSTRATES. . . . . . . . . . . . . 19

Sewage Sludge. . . . . . . . . . . 19

Glucose. . . . . . . . . . . . . 20

Acetate. . . . . . . . . . . 20

Preparation of Nutrient-Rich

Dilution Water........... . 21

OPERATIONAL PROCEDURES. . . . . . . . . . . . 23

Operational Procedure No.1......... 24

Operational Procedure No. 2. . . . . . . 27

LABORATORY RECORD BOOK. ........... . 29

PERSONAL HYGIENE AND SAFETY . . . . . . . 30

ANALYTICAL PROCEDURES . . . . . . . . . . . 32

$\mathrm{pH}$. . . . . . . . . . . . . . . . 32

Alkalinity . . . . . . . . . . . . . 34

Chemical Oxygen Demand (Soluble) . . . . 36

Sludge Solids. . . . . . . . . . . . 39

Volatile Acids .. . . . . . . . . . 41

Sludge Filtration. . . . . . . . . . 44

APPENDIX A - DRAWINGS/SPECIFICATIONS. . . . . 46

Digester Elevation View. . . . . . . . . 47

Digester Plan View . . . . . . . . . . 47

Gas Recirculation Schematic. . . . . . 48 
TABLE OF CONTENTS (Cont'd.)

$\underline{\text { Page }}$

APPENDIX B - OPERATING AND MAINTENANCE

INSTRUCTIONS . . . . . . . . . . . . . . . . . . 49

Temperature Controller. . . . . . . . 50

Heating Mantle. . . . . . . . . . . 53

Variable Transformer. . . . . . . . . 54

Pump Drive Unit. . . . . . . . . . . 57

Pump Heads and Tubing. . . . . . . . . 70

Mercurial Barometer . . . . . . . . 75

APPENDIX C - GENERAI INFORMATION . . . . . . . 84

Conversion Chart. . . . . . . . . . . . 85

Periodic Table of the Elements. . . . . . 86 
NOTE

Manufacturers' names and literature are cited for the convenience of the reader; citation does not imply endorsement by Pacific Northwest Laboratory. 



\section{INTRODUCTION}

The successful operation of any laboratory-scale biological system is often a difficult and frustrating experience. This is especially true when dealing with the anaerobic digestion process. Because of the stringent environmental requirements associated with anaerobic digesters, efficient operation of bench-scale units requires rigid monitoring and control. The purpose of this manual is to present the methods and procedures which are followed in bench-scale anaerobic digestion studies at Pacific Northwest Laboratory (PNL). Among the topics discussed are operating parameters, a description of the experimental system, typical digestion substrates, operational procedures, analytical techniques, and safety considerations. The document serves as a technical guide to PNL personnel assigned to a U.S. Department of Energy sponsored program evaluating the effect of powdered activated carbon on the anaerobic digestion of sewage sludge.

It should be noted that the methods described in this manual do not necessarily represent the best or only means of conducting the research. They are merely procedures that have been found to be successful at PNL. It is hoped that this information may be useful to other researchers who are contemplating or pursuing bench-scale studies of their own. 
ENVIRONMENTAL REQUIREMENTS

In anaerobic digestion, organic materials are stabilized in a series of two stages mediated by two different groups of microorganisms -- the acid formers and the methane formers. These two classes of bacteria are very different from each other in their physiology and environmental requirements. However, in a typical anaerobic digestion system both sets of microorganisms are placed within the same physical and chemical environment. Therefore, the design and operation of an anaerobic treatment system is based primarily on providing optimum environmental conditions for the slowest growing and most sensitive group of bacteria -- the methane formers.

$\stackrel{\mathrm{pH}}{-}$

One of the most important ervironmental conditions is the maintenance of proper $\mathrm{pH}$ in the digesters. Rigid control of $\mathrm{pH}$ is required because methane bacteria are extremely sensitive to slight changes in $\mathrm{pH}$. Every effort should be made to maintain the $\mathrm{pH}$ in the range of 6.6-7.4, with an optimum value of 7.0 . At $\mathrm{pH}$ below 6.2 , the acidic conaitions produced can become quite toxic to the methane formers. Thus, major drops in pH must be avoided if effective treatment is to be provided.

Control of $\mathrm{pH}$ is normally accomplished by the bicarbonate buffer system. For most municipal waste sludges, bicarbonate ion is the principal form of alkalinity when volatile acid concentration is low. If volatile acids begin to increase, they are neutralized by the bicarbonate ion, and bicarbonate alkalinity decreases. In normal operation, the bicarbonate buffer is 
reformed when the methane bacteria ferment the volatile acid salts. The process of buffer destruction and formation during the digestion of glucose is illustrated in the following equations:

(1) $\mathrm{C}_{6} \mathrm{H}_{12} \mathrm{O}_{6} \stackrel{\text { acid formers }}{\longrightarrow} 3 \mathrm{CH}_{3} \mathrm{COOH}$

(2) $3 \mathrm{CH}_{3} \mathrm{COOH}+3 \mathrm{HCO}_{3}^{-} \longrightarrow 3 \mathrm{CH}_{3} \mathrm{COO}^{-}+3 \mathrm{H}_{2} \mathrm{O}+3 \mathrm{CO}_{2}$

(3) $3 \mathrm{CH}_{3} \mathrm{COO}^{-}+3 \mathrm{H}_{2} \mathrm{O} \stackrel{\text { methane formers }}{\longrightarrow} 3 \mathrm{CH}_{4}+3 \mathrm{HCO}_{3}^{-}$

The first equation shows the breakdown of glucose by acid forming bacteria to produce acetic acid. In the second reaction the acid is neutralized by bicarbonate ion, and forms a volatile acid salt. If sufficient buffer is not available, acid accumulation will cause a drop in $\mathrm{pH}$, and the formation of methane via the third rection is inhibited. However, if the third reaction can proceed, the bicarbonate ion consumed in the second equation is reproduced, and the equilibrium between buffer destruction and formation is maintained.

Chemical Addition

In operating a laboratory digester it is sometimes necessary to add an external source of alkalinity to the system to prevent failure of the process due to low pH. Generally, this is required only during startup or when operating at solids residence times of less than 5 days. A minimum bicarbonate alkalinity of $1000 \mathrm{mg} / 1$ should always be maintained in a unit to ensure effective pH control. According to McCarty* bicarbonate alkalinity can be estimated from the total alkalinity and volatile acid concentration as follows:

$$
\mathrm{BA}=\mathrm{TA}-[(0.71)(\mathrm{VA})]
$$

*P. I. McCarty. "Anaerobic Waste Treatment Fundamentals. Part II. Environmental Requirements and Control," Public Works, Vol. 95 , No. 10, p. 125, October 1964 . 
in which

$$
\begin{aligned}
& \mathrm{BA}=\text { bicarbonate alkalinity, } \mathrm{mg} / \mathrm{l} \text { as } \mathrm{CaCO}_{3} \\
& \mathrm{TA}=\text { total alkalinity, mg/l as } \mathrm{CaCO}_{3} \\
& \mathrm{VA}=\text { volatile acid concentration, } \mathrm{mg} / \mathrm{I} \text { as acetic acid. }
\end{aligned}
$$

Increasing the bicarbonate alkalinity is normally accomplished by the addition of sodium bicarbonate $\left(\mathrm{NaHCO}_{3}\right)$. The following equation can be used to calculate the amount of $\mathrm{NaHCO}_{3}$ required to increase the total alkalinity a specific amount.

$$
\text { gm } \mathrm{NaHCO}_{3}=\left(1.68 \times 10^{-6}\right)(\Delta \mathrm{TA})(\mathrm{V})
$$

in which

$$
\begin{aligned}
\Delta \mathrm{TA} & =\text { desired increase in total alkalinity, } \mathrm{mg} / \mathrm{l} \text { as } \mathrm{CaCO}_{3} \\
\mathrm{~V} & =\text { volume of substrate in digester, } \mathrm{ml}
\end{aligned}
$$

The laboratory digesters are normally operated with a substrate volume of $3500 \mathrm{ml}$. Based on this volume, the following table lists the amount of $\mathrm{NaHCO}_{3}$ required to achieve various increases in the total alkalinity.

$\begin{array}{cc}\text { Alkalinity }\left(\mathrm{mg} / \mathrm{I} \text { as } \mathrm{CaCO}_{3}\right) & \mathrm{NaHCO}_{3} \stackrel{(\mathrm{gm})}{ } \\ 100 & 0.6 \\ 200 & 1.2 \\ 300 & 1.8 \\ 400 & 2.4 \\ 500 & 2.9 \\ 600 & 3.5 \\ 700 & 4.1 \\ 800 & 4.7 \\ 900 & 5.3 \\ 1000 & 5.9 \\ 1100 & 6.5 \\ 1200 & 7.1 \\ 1300 & 7.6 \\ 1400 & 8.2\end{array}$




$\begin{array}{cc}\text { Alkalinity }\left(\mathrm{mg} / 1 \text { as } \mathrm{CaCO}_{3}\right) & \mathrm{NaHCO}_{3}(\mathrm{gm}) \\ 1500 & 8.8 \\ 1600 & 9.4 \\ 1700 & 10.0 \\ 1800 & 10.6 \\ 1900 & 11.2 \\ 2000 & 11.8 \\ 2250 & 13.2 \\ 2500 & 14.7 \\ 2750 & 16.2 \\ 3000 & 17.6 \\ 3250 & 19.1 \\ 3500 & 20.6 \\ 3750 & 22.0 \\ 4000 & 23.5 \\ 4250 & 25.0 \\ 4500 & 26.5 \\ 4750 & 27.9 \\ 5000 & 29.4\end{array}$

Excessive addition of $\mathrm{NaHCO}_{3}$ can cause inhibition of the digestion process due to the toxic effect of the sodium cation. In an attempt to avoid this problem, $\mathrm{NaHCO}_{3}$ is generally not added in sufficient quantity to increase the total alkalinity above 6000 $\mathrm{mg} / \mathrm{l}$. If at this alkalinity the digester $\mathrm{pH}$ is still low, lime $(\mathrm{CaOH})$ should be added. From experience the following lime additions are recommended for a substrate volume of $3500 \mathrm{ml}$ :

\begin{tabular}{|c|c|}
\hline $\mathrm{pH}$ & Lime $(\mathrm{gm}$ \\
\hline 6.8 & 1.0 \\
\hline 6.7 & 2.0 \\
\hline 6.6 & 2.5 \\
\hline 6.5 & 3.0 \\
\hline 6.4 & 3.5 \\
\hline 6.3 & 4.0 \\
\hline 6.2 & 4.5 \\
\hline 6.1 & 5.0 \\
\hline & 5.5 \\
\hline
\end{tabular}

Note: Lime additions may result in the formation of insoluble calcium carbonate according to the following reaction:

$$
\mathrm{Ca}(\mathrm{OH})_{2}+\mathrm{CO}_{2} \rightarrow \mathrm{CaCO}_{3}+\mathrm{H}_{2} \mathrm{O}
$$


The consumption of carbon dioxide associated with this reaction will likely produce a vacuum in the digestion system. In order to avoid the possible suction of salt solution into the digesters from the gas collection columns, the systems should be pressurized with nitrogen gas following the addition of lime.

Whenever making chemical additions it should be remembered that alkali and alkaline-earth cations such as those of sodium, potassium, calcium, and magnesium can cause inhibition of the anaerobic process. Care must be taken to avoid exceeding the toxic concentrations listed below.*

\begin{tabular}{|c|c|c|c|}
\hline \multirow[b]{2}{*}{ Cation } & \multicolumn{3}{|c|}{ Concentration (mg/1) } \\
\hline & Moderately & Inhibitory & Strongly Inhibitory \\
\hline Sodium (Na+) & 3500 & -5500 & 8,000 \\
\hline Potassium $\left(\mathrm{K}^{+}\right)$ & 2500 & -4500 & 12,000 \\
\hline Calcium $\left(\mathrm{Ca}^{++}\right)$ & 2500 & -4500 & 8,000 \\
\hline Magnesium $\left(\mathrm{Mg}^{++}\right)$ & 1000 & -1500 & 3,000 \\
\hline
\end{tabular}

Temperature

It is generally accepted that two temperature ranges exist for anaerobic treatment -- the mesophilic range $\left(29^{\circ}-38^{\circ} \mathrm{C}\right)$ and the thermophilic range $\left(49^{\circ}-57^{\circ} \mathrm{C}\right)$. Although treatment proceeds more rapidly at thermophilic temperatures, the additional heat requirement probably offsets this advantage. Therefore, digestion of wastewater sludge is practically always performed in the mesophilic range, a temperature of $35^{\circ} \mathrm{C}$ commonly considered optimal. In this study, an operating temperature of $35^{\circ} \mathrm{C}$ has been selected 
for all units. Every effort should be made to maintain the temperature between $34^{\circ}$ and $36^{\circ} \mathrm{C}$. A temperature change of 2 or 3 degrees can disrupt the dynamic balance between the acid and methane formers. Because the acid formers respond more rapidy than the methane bacteria, acid production will likely exceed acid consumption following a variation in system temperature. The resulting acid buildup may result in digester upset. Mixing

All of the digestion units are equipped with variable speed gas recirculation mixing devices designed to keep the digester contents completely mixed. wot only does mixing keep the microorganisms in continuous contact with their food supply, but also it helps provide a constant environment throughout the digester. Pockets of highly concentrated toxic materials do not develop in the system. Instead, the concentrations of inhibitory materials are maintained at minimum levels.

Anaerobic Conditions

Even small quantities of oxygen can be harmful to the methane formers and other anaerobic bacteria. Therefore, the digesters are completely sealed from the atmosphere. Nutrients

The bacteria responsible for anaerobic digestion require nitrogen, phosphorus, and other nutrients for efficient growth. Municipal waste sludge generally contains these required materials, and thus usually provides a favorable environment for growth. However, if synthetic substrates (e.g., glucose, acetate) are to be digested, a specially prepared nutrient-rich dilution water must be added with the feed. Preparation of the dilution water is described in the section of this manual entitled "Digestion Sub- 


\section{ANAEROBIC DIGESTERS}

\section{Digester Vessels}

The digestion units consist of pyrex reaction flasks. Each vessel is cylindrically shaped with a rounded bottom, and has a volume of four liters. The top of each flask is a separate piece connected to the main body by a ground glass interface. The sections are secured together with a circular clamp. The top of each vessel contains four ground glass fitted openings to which various appurtenances are attached. A schematic diagram of a digester, including supporting equipment, is presented in Figure 1. Detailed drawings of a digester, specifying tuoing and stopper sizes, are provided in Appendix A.

Experience has shown that the greased, ground glass joints do not proviaje an air tight seal even when the digesters are subjected to only low pressure differentials. Thus, a silicone rubber sealent (RTV) is applied to the exposed surfaces of all joints on the digestion vessels. Prior to applying the sealent, surfaces should be thoroughly cleaned with a solvent, such as acetone or MIBK. Approximately 24 hours is required for the RTV to completely dry. A more effective seal is obtained if, during this period, the digesters are subject to a slight vacuum.

It is very important the correct volume of substrate (normally $3500 \mathrm{ml}$ ) is maintained in each digester. Therefore, a thin strip of tape is applied to the outside of each vessel to mark the proper liquid level. Substrate levels should be checked at least twice each week and adjusted as required. This procedure shall be documented in the daily log section of the laboratory record book. 


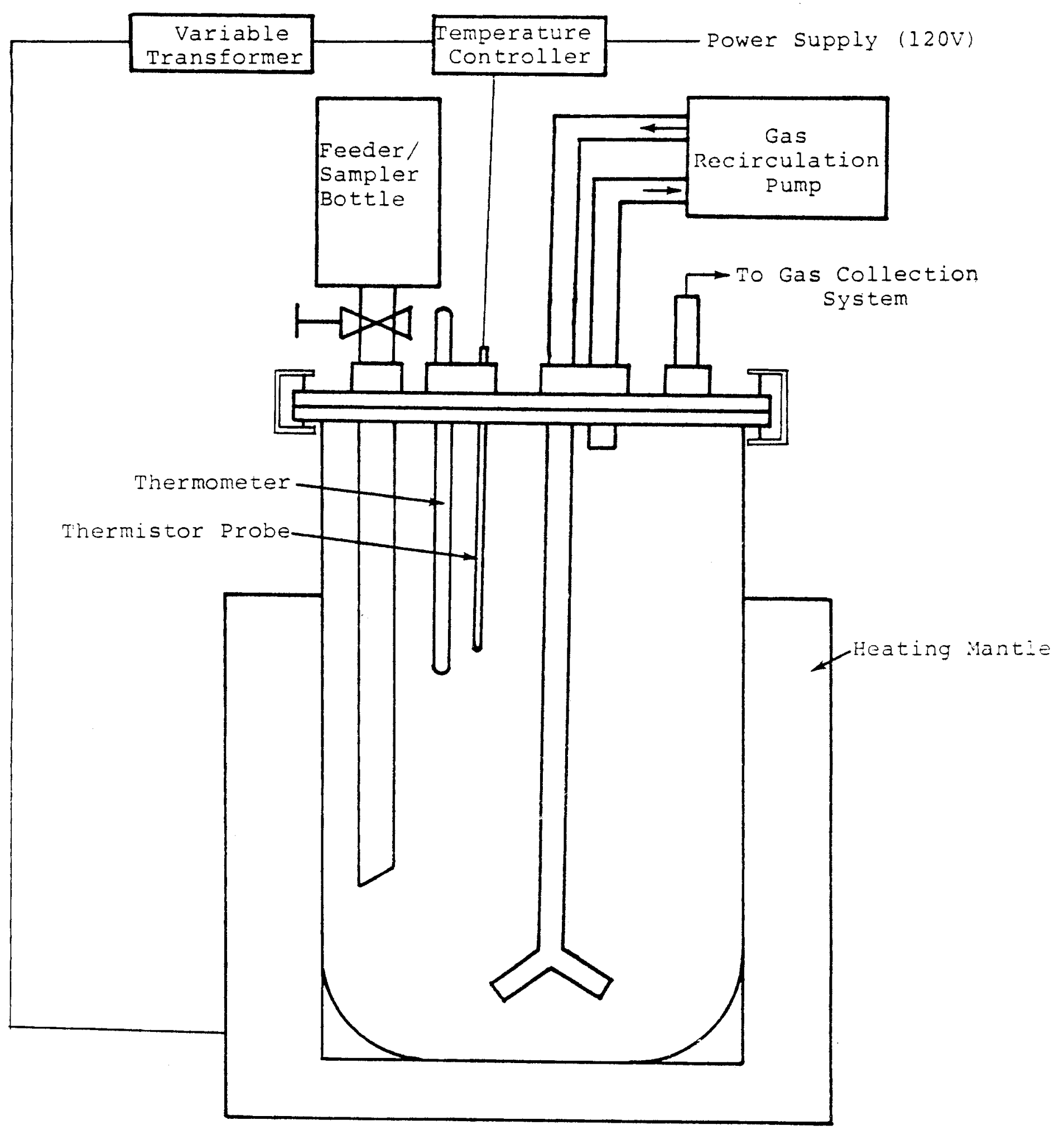

FIGURE 1. BENCH SCALE DIGESTION UNIT 
Temperature Control

Each digestion flask is equipped with an electrically operated heating mantle. A temperature controller connected to the heating mantle automatically switches power "on" or "off" as required to maintain a constant temperature in the digester. Temperature changes are detected by a thermistor probe inserted through the top of each digestion vessel. Electrical power to the heating mantle is supplied via a variable transformer. By moderating the input wattage the rate of heating is reduced, allowing more precise temperature control. Operating and maintenance instructions for the temperature controllers, heating mantles, and variable transformers are included in Appendix B.

Each digestion unit includes a thermometer for monitoring system semperature. All digesters must be maintained at $35 \pm 1^{\circ} \mathrm{C}$. Temperatures should be checked at least twice each day, at the beginning and end of each work shift. In order to ensure representative values, temperatures shall be measured only when the gas recirculation pumps have been operating for at least 10 minutes. The data, including date, time, and temperature, shall be recorded on the appropriate log sheet. If the setting on a temperature controller is readjusted, this should be indicated by including an arrow after the temperature entry. An arrow $\uparrow$ indicates the setting was increased, while an arrow $\downarrow$ signifies it was decreased. Gas Recirculation Mixing

Positive displacement tubing pumps are used to recirculate overhead gases through the digesters for mixing. In each digestion unit, gas is withdrawn from the space above the substrate, transferred through a pump, and then injected via a glass tube into the 
bottom of the vessel. A plastic "Y" connector is attached to the glass tube to aid in distributing the gas flow. Rising gas bubbles produce the mixing action in the digester.

Each variable speed drive unit operates two pump heads, each head providing gas flow for one digester. Electrical power to each pump drive is controlled by an automatic timer. As many as four pump drives may operated by a single timer. The timers can be set to turn power either "on" or "off" at 15 minute intervals during a 24 hour period. Generally, timers are set to activate the pump drives for one 15 minute period each hour. In this manner, sufficient mixing is provided to prevent stratification and the formation of thermal gradients, while at the same time, the digester contents are not subject to over-mixing. Operating and maintenance instructions for the pump drives and pump heads are included in Appendix B.

Due to the semi-continuous operation of the gas recirculation pumps, silicone tubing is normally used in the pump heads. This material has a life expectancy about three times that of tygon. Pump head tubing should be replaced at least once each week when using silicone tubing, and every other day when using tygon. Routine replacement is imperative since ruptured tubing can cause air to be introduced into the digesters. About 11 inches of tubing is required for each pump head. Tubing specifications and instructions for replacement are given in Appendix $B$. The replacement of tubing should be noted in the "daily log" section of the laboratory record book. 
Feeding/Sampling System

Sampling and feeding of the digesters are accomplished through a $12 \mathrm{~mm}$ OD glass tube inserted through the top of each vessel. The tubes extend to within about four inches of the bottom of the flasks. The upper end of each glass tube is attached to a "feeder/sampler" bottle by about six inches of tygon tubing. The feeder/sampler bottles are made of plastic, approximately $800 \mathrm{ml}$ in volume, and are fitted with a bottom adapter to the tubing, permitting isolation of the feeder/sampler bottles from the digestion vessels.

The actual operations performed in sampling and feeding a digester are quite simple. In order to draw a sample, the gas collection system is adjusted to provide a pressure head of about two feet in the digester. The hose clamps isolating the vented feeder/

- sampler bottle from the digestion vessel are then opened, displacing sludge into the bottle due to the pressure differential. When the required volume of sludge has been transferred, the hose clamps are shut, and sample collection is complete. Feeding of a digester is accomplished with the gas collection system vented to the atmosphere. The hose clamps to the feeder/sampler bottle are opened, and substrate flows by gravity into the digestion vessel.

As mentioned above, the sampling of a digester required pressure modification in the system. Pressure is indicated by the relative height of the liquid levels in the gas collection column and the confining solution reservoir. If sufficient pressure for sampling has not been provided by digester gas production, the necessary pressure can be created by either of two methods: 1) positioning the reservoir so that its liquid level exceeds the level in the column, or 2) pressurizing with nitrogen gas via the vent line. 
The first method is perferable, especially during data collection periods, since it does not change the composition of the digester gas. If, however, the second method is selected, care should be taken to isolation the digester from the gas collection system during pressurization in order to avoid placing excessive stress on the digester seals.

The feeding/sampling operation shall be documented in the "sludge transfer record" section of the laboratory record book. Leak Testing

Accurate measurement of gas production is absolutely essential in this project. Even small inconsistencies (20-30 $\mathrm{ml}$ per hr) can contribute significant error to the total gas production. For this reason it is extremely important that the digestion systems be continuously monitored for gas leakage. Care should be taken to routinely replace the pump head tubing, and to ensure that the associated plastic connectors are securely fastened. Potential leak sites, such as those around rubber stoppers and tubing penetrations, should be routinely inspected with soap solution. Also, each digester should be pressure tested prior to starting a test run, immediately preceding a data collection period, or whenever gas leakage is suspected. Testing is accomplished by injecting a sufficient quantity of nitrogen gas to lower the liquid level in the gas collection column to a point below the $50.0 \mathrm{~cm}$ mark. (As mentioned in the previous section, care should be taken to isolate the digester from the gas collection column during pressurization.) With the entire digestion system pressurized and the gas recirculation pump operating, an initial reading on the gas collection column should be obtained. After a 20 minute period the column 
should be reread. Any perceptible increase in liquid level indicates gas leakage. Soap solution should be applied to identify the exact location of a suspected leak, and repairs made as soon as possible. The results of leak testing should be noted in the "daily log" section of the laboratory record book. 


\section{GAS COLLECTION SYSTEM}

Description

The gas production in the anaerobic digesters is collected in plexiglass columns by the displacement of a saturated salt solution. Tygon tubing is used to transfer the overhead gases from the digestion vessels to the gas collection columns. Each transfer line is equipped with a vent line to permit sampling of the digester gas, and to allow for periodic system pressure release. Another section of tygon tubing connects the bottom of each gas collection column to a confining solution reservoir. A diagram illustrating the gas collection system is provided in Figure 2. Calibration of Gas Collection Columns

Prior to starting the project, all of the gas collection columns were calibrated volumetrically. Each column was found to have a uniform diameter. Thus, a factor was obtained relating liquid level in each column to collected gas volume. Transparent tape marked off in $0.1 \mathrm{~cm}$ increments was vertically applied to the columns to facilitate the reading og liquid levels. Actual calibration was accomplished by initially filling each column with water, and then draining incremental volumes into a graduated cylinder of volumetric flask. The change in liquid level was then recorded versus the volume of water withdrawn. The calibration factors determined by this method are as follows: 


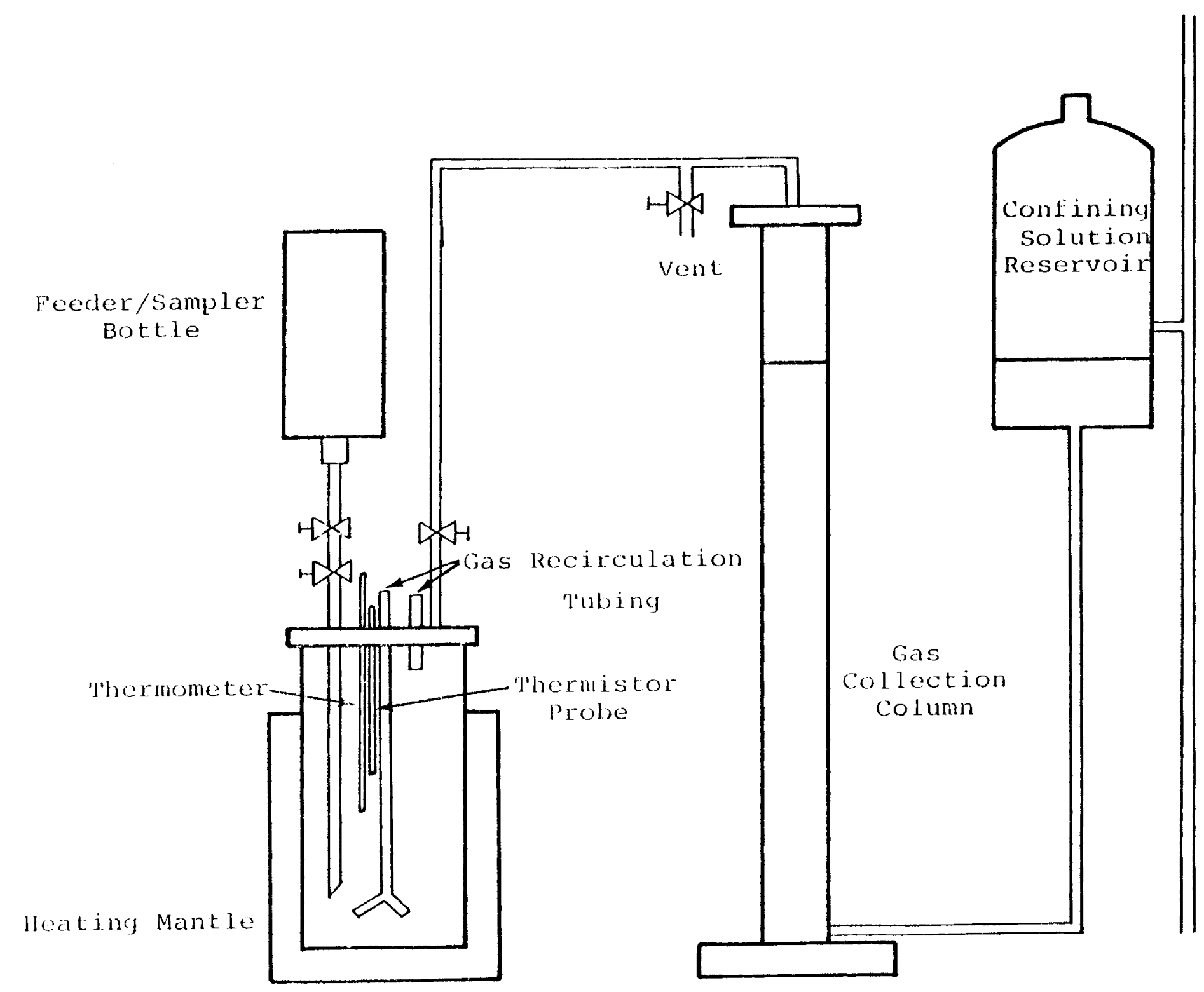

FIGURE 2. BENCH SCALE DIGESTION SYSTEM 


$\begin{array}{cc}\text { Column No. } & \text { Factor }(\mathrm{ml} / \mathrm{cm}) \\ 1 & 104.1 \\ 2 & 103.4 \\ 3 & 103.7 \\ 4 & 103.2 \\ 5 & 103.6 \\ 6 & 103.6 \\ 7 & 82.6 \\ 8 & 82.1 \\ 9 & 81.1 \\ 10 & 80.5 \\ 11 & 81.2 \\ 12 & 102.9 \\ 13 & 103.2 \\ 14 & 102.8\end{array}$

\section{Gas Measurement}

Measurement of gas production in a digester is based on the volume of gas accumulated in its gas collection column. Initially, the column is "zeroed" by opening the vent valve and adjusting the height of the confining solution reservoir so that the liquid level in the column is at the zero mark. The liquid level in the reservoir should be maintained at the same level as in the column in order to provide atmospheric pressure in the digestion system. After zeroing the column, the vent valve is closed. The production of gas in the digester then causes displacement of liquid from the gas collection column to the confining solution reservoir. At the end of the measurement period the volume of gas collected is determined by noting the change in liquid level in the column. Iike the initial zeroing, the final reading is obtained with the liquid levels in the gas collection column and confining solution reservoir equalized. Each gas volume measurement must be converted to an equivalent volume at standard temperature $\left(0^{\circ} \mathrm{C}\right)$ and pressure $(760 \mathrm{~mm} \mathrm{Hg})$. Thus, the gas volume at STP is calculated as follows: 
gas volume (mI) a $\operatorname{STP}=\frac{H \times F \times P \times 273}{760 \times \mathrm{T}}$

where

$$
\begin{aligned}
\mathrm{H}= & \text { liquid level reading on column }(\mathrm{cm}) \\
\mathrm{F}= & \text { conversion factor relating gas volume to liquid level } \\
& (\mathrm{ml} / \mathrm{cm}) \\
\mathrm{P}= & \text { atmospheric pressure }(\mathrm{mm} \mathrm{Hg}) \\
\mathrm{T}= & \text { temperature of gas in column }\left({ }^{\circ} \mathrm{K}\right), \text { where }{ }^{\circ} \mathrm{K}={ }^{\circ} \mathrm{C}+273
\end{aligned}
$$

This equation can be simplified by multiplying the conversion factor, F, by 273 divided by 760. This new quantity shall be designated, A, and can be computed for each of the gas collection columns as follows:

$\begin{array}{cc}\text { Column No. } & \text { A } \\ 1 & 37.4 \\ 2 & 37.2 \\ 3 & 37.3 \\ 4 & 37.1 \\ 5 & 37.2 \\ 6 & 37.2 \\ 7 & 29.7 \\ 8 & 29.5 \\ 9 & 29.2 \\ 10 & 28.9 \\ 11 & 29.2 \\ 12 & 37.0 \\ 13 & 37.1 \\ 14 & 37.0\end{array}$

Using the conversion factor, A, gas volume at standard temperature and pressure is calculated by the following modified equation:

$$
\text { gas volume (mI) a STP }=\frac{\mathrm{H} \times \mathrm{A} \times \mathrm{E}}{\mathrm{T}}
$$

Atmospheric pressure (F) and temperature ( $T$ ) readings must be recorded whenever gas volume is measured. Atmospheric pressure can be determined by using the mercurial barometer located in PSL 506. Instructions for using the barometer are located in Appendix B. The temperature of the gas in the coliection columns is assumed to 
be the same as the ambient air temperature in the laboratory. Ambient temperature can be obtained from the mercury thermometer attached to the barometer apparatus.

Preparation of salt Solution

A saturated salt solution is used as the displacing solution in the gas collection columns. This liquid is specially prepared to. minimize gas solubility. The solution is prepared as follows:

1. Add about $3000 \mathrm{ml}$ of water to a $4000 \mathrm{ml}$ beaker.

2. Place the beaker on a combination magnetic stirrer/hot plate and continuously mix.

3. Add $0.175 \mathrm{gm}$ Evans Blue dye and completely dissolve.

4. Slowly add 1050 gm of sodium chloride (technical grade), making sure not to interfere with the operation of the magnetic stirring bar.

5. Heat the solution to about $50^{\circ} \mathrm{C}$ and continue mixing until all of the salt is dissolved. As the salt dissolves, add water to bring the final volume to $3500 \mathrm{ml}$.

6. Turn off hot plate.

7. Add concentrated sulfuric acid $\left(\mathrm{H}_{2} \mathrm{SO}_{4}\right)$, dropwise, to adjust the $\mathrm{pH}$ to about 3 .

8. Transfer the solution to a one gallon poly bottle for storage. Note:

The Evans Blue dye may precipitate from solution during storage. Mix the salt solution by shaking to redissolve the dye prior to adding to the gas collection system. 


\section{DIGESTION SUBSTRATES}

\section{SEWAGE SLUDGE}

Raw sludge is generally used as feed for the laboratory digesters. However, digested sludge is required occasionally for seeding the units (i.e., supplying the anaerobes necessary for the digestion process). Sludge is procured from the Richland, Washington sewage treatment plant. Raw sludge is obtained from the transfer line between the primary clarifier sludge hoppers and the digestion tanks. Sludge is transferred every hour on the hour for a duration of about five minutes. It is during this pumping period that the raw sludge sample must be collected. Digested sludge is obtained at the discharge pipe to the sludge drying beds. It is usually pumped on $\mathrm{y}_{\mathrm{y}}$ on Monday afternoons between 1:00 and 3:00pm. If digested siudge is required at another time, special arrangements can be made to withdraw sludge directly from the primary digester. However, this should be done only if absolutely necessary as this procedure can be quite messy and requires the assistance of a treatment plant operator. Sludge pumping times should be verified by calling the treatment plant at (509) 943-9161, Ext. 225 .

All sludge is to be collected in 5-15 gallon poly bottles. Because the sludge volume expands during storage, bottles should not be filled more than $3 / 4$ full. The bottles shall be immediately capped after filling and then transported to the laboratory. To retard biological degradation, the sludge should be kept in the cold room $\left(10^{\circ} \mathrm{C}\right)$ located in PSL 516. Sludge should not be stored longer than five days prior to its use. 
As required for digester feed, an appropriate amount of sludge is to be added to the one gallon Waring blender. The blender should then be operated at low speed for about five minutes. The exact length of time of blending should be based on increasing the temperature of the sludge to approximately $30^{\circ} \mathrm{C}$. Thus, blending not only homogenizes the sludge, but also increases its temperature so that thermal shock to the digestion units is minimized.

GLUCOSE

In some of the test runs the digesters utilize a glucose substrate (D-glucose anhydrous, $\left.\mathrm{C}_{6} \mathrm{H}_{12} \mathrm{O}_{6}\right)$. A glucose concentration of 0.5 percent is usually not exceeded in the digestion units. Operation at higher concentrations has proved unsuccessful, presumably due to the rapid conversion of glucose to organic acids, resulting in a sudden high volatile acid concentration and low $\mathrm{pH}$.

The glucose is dissolved in a specially prepared nutrientrich dilution water prior to being fed to the system. The dilution water should be heated to $35-40^{\circ} \mathrm{C}$ to minimize thermal shock to the digestion units. Preparation of the dilution water is described at the end of this chapter. ACETATE

Occasionally, sodium acetate $\left(\mathrm{NaC}_{2} \mathrm{H}_{3} \mathrm{O}_{2} \cdot 3 \mathrm{H}_{2} \mathrm{O}\right)$ is used as a substrate in the digesters. Difficulty has been experienced obtaining good digestion with acetate feed. Some success was achieved with a 1.13 percent sodium acetate substrate.

Like the glucose, sodium acetate is dissolved in a specially prepared nutrient-rich dilution water prior to 
being fed to the digesters. Again, the dilution water should be heated to $35-40^{\circ} \mathrm{C}$ to minimize thermal shock to the digestion units. Preparation of the dilution water is described below. Preparation of Nutrient-Rich Dilution Water

This dilution water provides sufficient nutrients for the digestion of a 0.6 percent glucose $\left(\mathrm{C}_{6} \mathrm{H}_{12} \mathrm{O}_{6}\right)$ solution or a 1.4 percent sodium acetate $\left(\mathrm{NaC}_{2} \mathrm{H}_{3} \mathrm{O}_{2} \cdot 3 \mathrm{H}_{2} \mathrm{O}\right)$ solution. The procedure must be carefully followed in the sequence given to avoid precipitation of salts. The following instructions are for the preparation of 24 liters of dilution water.

1. Add $33.3 \mathrm{ml}$ of trace salt solution to a 2 liter flask.

2. Add about $1000 \mathrm{ml}$ of water and continuously mix using

a magnetic stirrer.

3. Add each of the following with mixing. Do not add a compound until the previous compound is in solution.
a. $\quad 13.6 \mathrm{gm} \mathrm{KH} \mathrm{KH}_{4}$
b. $\quad 8.3 \mathrm{gm} \mathrm{NaH} \mathrm{PO}_{4} \cdot \mathrm{H}_{2} \mathrm{O}$
c. $\quad 5.3 \mathrm{gm}\left(\mathrm{NH}_{4}\right)_{2} \mathrm{SO}_{4}$
d. $49.2 \mathrm{gm} \mathrm{NH} 4 \mathrm{Cl}$
e. $\quad 4.4 \mathrm{gm} \mathrm{CaCl} 2$
f. $\quad 8.1 \mathrm{gm} \mathrm{MgCl}_{2} \cdot 6 \mathrm{H}_{2} \mathrm{O}$

4. Dissolve $3.60 \mathrm{gm}$ of yeast extract in $100 \mathrm{ml}$ of water, with heating and stirring. Do not allow to boil. When cool, add to the flask.

5. Add the solution to a 6.5 gallon poly bottle containing 23 liters of water. (Note: The water should have been allowed to stand for at least 12 hours to allow for dissipation of residual chlorine.) Mix the contents thoroughly and transfer to a dispensing container. 
6. Preparation of trace salt solution.

The trace salts are added to distilled water in amounts given below and made to two liters with distilled water. Compounds should be added in the order shown, and each compound should not be added until the previous one is in solution.
a. $\quad 64.8 \mathrm{gm} \mathrm{FeCl}_{3} \cdot 6 \mathrm{H}_{2} \mathrm{O}$
b. $\quad 9.5 \mathrm{gm} \mathrm{MnCl}_{2} \cdot 4 \mathrm{H}_{2} \mathrm{O}$

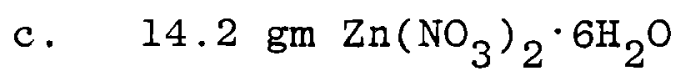
d. $\quad 4.1 \mathrm{gm} \mathrm{CuCl}{ }_{2} \cdot 2 \mathrm{H}_{2} \mathrm{O}$
e. $\quad 5.7 \mathrm{gm} \mathrm{CoCl} l_{2} \cdot 6 \mathrm{H}_{2} \mathrm{O}$
f. $\quad 2.3 \mathrm{gm} \mathrm{Na}_{2} \mathrm{~B}_{4} \mathrm{O}_{7} \cdot 1 \mathrm{OH}_{2} \mathrm{O}$
g. $353.0 \mathrm{gm} \mathrm{Na}_{3}$ Citrate
h. $\quad 4.2 \mathrm{gm}\left(\mathrm{NH}_{4}\right)_{6} \mathrm{Mo}_{7} \mathrm{O}_{24} \cdot 4 \mathrm{H}_{2} \mathrm{O}$

7. Total nutrient concentrations in the prepared dilution water are as follows:
$\mathrm{N}=559 \mathrm{mg} / \mathrm{l}$
$\mathrm{Fe}=9.3 \mathrm{mg} / 1$
$\mathrm{P}=207 \mathrm{mg} / \mathrm{l}$
$\mathrm{Mn}=1.8 \mathrm{mg} / \mathrm{I}$
$\mathrm{K}=163 \mathrm{mg} / \mathrm{I}$
$\mathrm{Zn}=2.2 \mathrm{mg} / 1$
$\mathrm{Na}=115 \mathrm{mg} / 1$
$\mathrm{Cu}=1.1 \mathrm{mg} / 1$
$\mathrm{S}=53 \mathrm{mg} / 1$
Co $=0.98 \mathrm{mg} / \mathrm{I}$
$\mathrm{Ca}=66 \mathrm{mg} / \mathrm{l}$
$B=0.18 \mathrm{mg} / 1$
$\mathrm{Mg}=40 \mathrm{mg} / \mathrm{I}$
Mo $=1.6 \mathrm{mg} / 1$ 


\section{OPERATIONAL PROCEDURES}

The following operational procedures describe the sequence in which the activities of digester sampling, feeding, chemical addition, gas measurement, and sludge analysis are to be performed. Operational procedure No. 1 is applicable during the data collection period. Operational procedure No. 2 is applicable only during the preceding acclimation period, and contains no instructions for gas production measurements or extensive sludge testing. It is emphasized that both sets of procedures provide only the order in which the various operating steps are conducted. For a more detailed description of individual procedural steps refer to the appropriate section in this manual. 
Operational Procedure No. I

(Applicable During Data Collection Period)

NOTE: Those steps marked with an asterisk (*) shall be omitted if the alkalinity, volatile acids, and COD analyses are not required.

1. Check to see that the gas recirculation pumps are operating. The pumps must be operated a minimum of 15 minutes prior to proceeding to step No. 4. Mixing should continue during steps 4,5 , and 6 .

2. Transfer the required amount of raw sludge from the storage bottle in the cold room to the blender.

3. Buffer the $\mathrm{pH}$ meter.

4. Record the laboratory ambient air temperature and atmospheric pressure. Measure the gas volumes in the gas collection columns.

5. Adjust the pressure in each gas collection system to about two feet of water. (If nitrogen gas is used, ensure that the gas valve on the top of each digester is closed during pressurization.)

6. Discharge the appropriate amount of digested sludge to the feeder/sampler bottles. Following this operation, check that both of the clamps that isolate each digester from its feeder/sampler bottle are shut.

7. Zero the gas collection columns and resume gas collection.

8. Secure the cap on each feeder/sampler bottle and mix by shaking. Then immediately transfer approximately $25 \mathrm{ml}$ of sludge from each bottle to a preweighed crucible. Resecure the caps on the bottles. Promptly weigh the crucibles and place them in the oven. 
9. Transfer approximately $40 \mathrm{ml}$ of sludge from each feeder/ sampler bottle to a $50 \mathrm{ml}$ centrifuge tube. Then immediately measure the $\mathrm{pH}$ of each siudge sample.

*10. Centrifuge about $40 \mathrm{ml}$ of each sludge sample at about 10,000 rpm for 10 minutes. While centrifuging, preparations can be made for the alkalinity and COD tests.

*11. Distribute the centrate samples for the alkalinity, COD, and volatile acid analyses.

*12. Perform the alkalinity test.

13. Dispose of the sluage remaining in the feeder/sampler bottles.

14. Blend the raw sludge feed until its temperature increases to about $30^{\circ} \mathrm{C}$. While the blender is operating, calculate and weigh out any required chemical additions.

15. Transfer the blended raw sludge to a plastic bottle (feed bottle). Mix the bottle by shaking, then transfer a 20-30 ml volume of sampie into a preweighed crucible, and cover.

16. Fill half of the feeder/sampler bottles with the required volume of feed sludge. Care should be taken to keep the feed sludge well-mixed so that each digester receives substrate of the same consistency.

17. Mix the remaining contents of the feed bottle by shaking, then transfer a $20-30 \mathrm{ml}$ volume of sample into a preweighed crucible, and cover.

18. Fill the remaining feeder/sampier bottles with feed sludge.

19. Mix the remaining contents of the feed bottle by shaking, then transfer a $20-30 \mathrm{ml}$ volume of sample into a preweighed crucible, and cover. 
20. Add any required chemicals, including carbon or flyash, to the feeder/sampler bottles. Rinse each carbon/flyash storage vial with $5 \mathrm{ml}$ of distilled water to insure complete transfer of the contents. Secure the caps on the feeder/sampler bottles, then shake thoroughly to completely disperse the additives. (Caution: When mixing sodium bicarbonate, occasionally vent the bottle to prevent a pressure buildup.) Reconnect the feeder/sampler bottles to the digesters, and remove the caps.

21. Check to see that the gas recirculation pumps are operating. Pump operation should continue a minimum of 15 minutes following the completion of step 23 .

22. Measure the gas volumes in the gas collection columns, then vent the systems. The amounts of gas collected should be added to the gas volumes measured in step 4. Each sum represents total gas production for the period ending at the time specified in step 24.

23. Discharge the raw sludge feed into the digesters, then shut the clamps isolating each digester from its feeder/ sampler bottle.

24. Zero the gas collection columns and resume gas collection.

25. Weigh the three crucibles containing feed sludge and place them in the oven.

26. Remove the feeder/sampler bottles and rinse with tap water, then reconnect them to the system.

*27. Complete the volatile acid and COD analyses. 
Operational Procedure No. 2

(Applicable During Acclimiation Period)

NOTE: Those steps marked with an asterisk (*) shall be omitted if the alkalinity analysis is not required.

I. Check to see that the gas recirculation pumps are operating. The pumps must be operated a minimum of 15 minutes prior to proceeding to step No. 4. Mixing should continue during steps 4 and 5 .

2. Transfer the required amount of raw sludge from the storage bottle in the cold room to the blender.

3. Buffer the $\mathrm{pH}$ meter.

4. Adjust the pressure in each gas collection system to about two feet of water. (If nitrogen gas is used, ensure that the gas valve on the top of each digester is closed during pressurization.)

5. Discharge the appropriate amount of digested sludge to the feeder/sampler bottles. Following this operation, check that both ofthe clamps that isolate each digester from its feeder/sampler bottle are shut.

6. Transfer approximately $75 \mathrm{ml}$ of sludge from each bottle to a $100 \mathrm{ml}$ beaker.

7. Measure the $\mathrm{pH}$ of each sludge sample.

*8. Centrifuge about $40 \mathrm{ml}$ of each sludge sample at about 10,000 rpm for 10 minutes. While centrifuging, preparations can be made for the alkalinity test.

*9. Perform the alkalinity test.

10. Blend the raw sludge until its temperature increases to about $30^{\circ} \mathrm{C}$. While the blender is operating, calculate and weigh out any chemical additions, and dispose of the sludge remaining in the feeder/sampler bottles. 
11. Transfer the blended raw sluage to a plastic bottle (feed bottle).

12. Fill the feeder/sampler bottles with the required volume of feed sludge. Care should be taken to keep the feed bottle well mixed (by shaking) so that each digester receives substrate of the same consistency.

13. Add any required chemicals, including carbon, to the feeder/ sampler bottles. Rinse each carbon/flyash storage vial with $5 \mathrm{ml}$ of distilled water to insure complete transfer of the contents. Secure the caps on the feeder/sampler bottles, then shake thoroughly to completely disperse the additives. (Caution: When mixing sodium bicarbonate, occasionally vent the bottle to prevent a pressure buildup.) Reconnect the feeder/sampler bottles to the digesters, and remove the caps.

14. Check to see that the gas recirculation pumps are operating. Pump operation should continue a minimum of 15 minutes following the completion of step 16 .

15. Vent the gas collection systems.

16. Discharge the raw sludge feed into the digesters, then shut the clamps isolating each digester from its feeder/ sampler bottle.

17. Shut the vent valves on the gas collection system.

18. Remove the feeder/sampler bottles and rinse them with tap water, then reconnect them to the system. 


\section{LABORATCRY RECORD BOOK}

All test data shall be recorded directly in the official laboratory record book. Data shall not be written on scratch paper and then later entered into the book. In this manner errors in transcribing are minimized. Additionally, all entries shall be made in ink. No erasures are permitted. If an error is made, simply cross out the incorrect value with a single line, and insert the proper entry next to the one that is crossed out. Be sure to write legibly. The laboratory record book is worthless if it is not readable. The book shall be reviewed on a daily basis by the Project Engineer, and at least once each week by the Project Manager.

A very important section in the laboratory record book is the adily log. It shall include a brief description of the project work accomplished during the day, and comments on the operational status of the test systems. Tasks that should always be included in the daily log are the checking and adjustment of substrate levels, leak testing, equipment breakdown and repair, and replacement of pump tubing. The person who conducts a work item is responsible for recording the performance of that task in the log. The log should be checked for completeness at the end of each work day by the Project Engineer. 
PERSONAL HYGIENE AND SAFETY

Operation of the bench scale anaerobic digesters generally requires frequent handling of municipal sewage sludge. It is a well known fact that the microorganisms present in sludge can cause infection and disease. Contact with these "bugs" can be made during many of the daily work routines. In order to protect oneself from this health hazard, various safety procedures are required.

Rubber gloves, safety glasses, and a laboratory coat should be worn whenever direct contact with sludge is a possibility. Examples of instances when these protective devices are required, include the sampling and feeding of the digesters, and the procurement of sludge at the sewage treatment plant. Safety glasses are required to be worn in the laboratory at all times, regardless of the type of work being performed.

After working with sludge the hands should be washed with soap and hot water before eating or otherwise putting anything from hand to mouth. A stiff bristle brush can be used if necessary. It is desirable to keep the fingernails cut short.

Open sores, cuts, or other breaks in the skin are particularly dangerous. When suffering such an injury, the wound should be cleaned and disinfected immediately. During working hours, treatment can be obtained at the first aid station located in PSI 1120. Covering the wound with a bandage and changing the bandage frequently are necessities. 
All persons assigned to the anaerobic digestion project are required to be immunized against typhoid, tetanus, and polio. These immunizations can be obtained at the Benton County Health Department located at 1005 Goethals Drive in Richland.

Several safety considerations regarding work in the anaerobic digester laboratory (PSL 506) should be noted. Methane gas may be present in the laboratory atmosphere, especially following venting of the digesters. For this reason, smoking or any activity which produces a flame (e.g., Bunsen burner) is prohibited. Also, an eyewash fountain is located at the sink on the west wall of the laboratory. If chemicals are splashed into the eyes, the eyes should be immediately irrigated with water. Irrigation should continue until medical help arrives. A safety shower is located in the hallway between PSI 506 and PSL 510 . 
AINALYTICAI PROCEDURES

I. $\mathrm{pH}$

Reference: (Standard Methcds, 14th Edition, Page 460)

Apparatus

1. Electronic pH meter

2. Combination electrode

Reagents

1. $\mathrm{pH} 7$ buffer solution

2. $\mathrm{pH} 4$ buffer solution

Procedure

1. Check liquid level in combination electrode to insure that level is in upper (wide) portion of probe. If required add electrode filling solution (4 MKCl saturated with AgCl).

2. Remove electrode from distilled water and dry by gentle wiping with a soft cloth.

3. Standardize the instrument with the electrode immersed in the $\mathrm{pH} 7$ buffer solution. The temperature compensator on the meter should be adjusted to the temperature of the buffer.

4. Remove electrode from the buffer, rinse thoroughly with distilled water, and dry.

5. Immerse electrode in the $\mathrm{pH} 4$ buffer solution. Adjust temperature compensator if required. The $\mathrm{pH}$ reading should be between 3.9 and 4.1 . If the reading is outside this range, replace the electrode.

6. Rinse electrode throughly with distilled water, dry, and immerse in the sample.

7. Measure the sample temperature and set the temperature compensator.

8. Note and record the $\mathrm{pH}$ and temperature.

9. Rinse electrodes with distilled water and dry prior to next sample reading. 
NOTES :

1. Keep the combination electrode immersed in distilled water when not in use.

2. The $\mathrm{pH}$ meter should be standardized at least once each day, and whenever accuracy of instrument is in doubt.

3. Instrument should always be in "standby" mode when it is not in use, or whenever the electrode is not immersed in. solution.

4. Plug on upper portion of electrode should be open. If closed, pressure changes can cause probe to rupture.

5. Sludge samples should not be stirred. Loss of carbon dioxide due to stirring will result in an apparent $\mathrm{pH}$ value which is too high.

6. Measurement of $\mathrm{pH}$ should be made as soon as possible after sampling .

7. Report $\mathrm{pH}$ values to nearest $0.05 \mathrm{pH}$ unit. 
II. Alkalinity

Reference: (Standard Methods, 14th Edition, Page 278)

Apparatus

1. Centrifuge and $50 \mathrm{ml}$ centrifuge tubes.

2. $250 \mathrm{ml}$ beakers.

3. Magnetic stirrer.

4. Volumetric pipet.

5. $50 \mathrm{ml}$ Burette.

6. $\mathrm{pH}$ meter.

\section{Reagents}

1. Sulfuric Acid $\left(\mathrm{H}_{2} \mathrm{SO}_{4}\right), 0.1 \mathrm{~N}$. Dilute $100 \mathrm{ml}$ of $1.00 \mathrm{~N}$ sulfuric acid stock solution to 1.0 liter in a volumetric flask.

2. Sodium hydroxide $(\mathrm{NaOH}), 1.00 \mathrm{~N}$. Standard stock solution. Standardization

1. Each preparation of $0.1 \mathrm{~N} \mathrm{H}_{2} \mathrm{SO}_{4}$ titrant should be standardized against the $1.00 \mathrm{NaOH}$ standard solution. Standardization should also be performed whenever there is reason to believe that the concentration of the sulfuric acid may be different than that previously determined.

2. Add about $100 \mathrm{ml}$ of distilled water to a $250 \mathrm{ml}$ beaker. Then pipet exactly $3.0 \mathrm{ml}$ of $1.00 \mathrm{~N} \mathrm{NaOH}$ into the beaker.

3. Place the beaker on a magnetic stirrer and continuously mix.

4. Immerse the $\mathrm{pH}$ electrode in the solution.

5. Titrate to a $\mathrm{pH}$ of 7.0 with the $\mathrm{H}_{2} \mathrm{SO}_{4}$ titrant. Record the amount of titrant required.

6. Calculate the normality of the $\mathrm{H}_{2} \mathrm{SO}_{4}$ as follows:

Normality of $\mathrm{H}_{2} \mathrm{SO}_{4}=\frac{3.0}{\text { mIs of titrant }}$

7. The normality of the sulfuric acid determined by standardization should be used in all alkalinity calculations.

$\underline{\text { Procedure }}$

1. Centrifuge the sludge sample at approximately $10,000 \mathrm{rpm}$ for at least 10 minutes. The supernatant obtained from this operation should be used for both the total alkalinity and the volatile acids test. 
2. Add about $100 \mathrm{ml}$ of distilled water to a $250 \mathrm{ml}$ beaker. Then pipet $15.0 \mathrm{ml}$ of supernatant sample into the beaker.

3. Place the beaker on a magnetic stirrer and continuously mix during titration.

4. Immerse the $\mathrm{pH}$ electrode in the solution.

5. Titrate to a pH of 3.7 with $0.1 \mathrm{~N} \mathrm{H}_{2} \mathrm{SO}_{4}$. Record to amount of titrant required.

6. Calculate total alkalinity as follows:

Total Alkalinity $\left(\frac{\mathrm{mg}}{1}\right.$ as $\left.\mathrm{CaCO}_{3}\right)=\frac{\mathrm{A} \times \mathrm{N} \times 50,000}{\mathrm{mls} \text { of sample }}$

where $\mathrm{A}=\mathrm{mls}$ of $\mathrm{H}_{2} \mathrm{SO}_{4}$ used

$$
\mathrm{N}=\text { normality of } \mathrm{H}_{2} \mathrm{SO}_{4}
$$

7. Bicarbonate alkalinity can be estimated from the total alkalinity and volatile acids concentration as follows:

Bicarbonate Alkalinity $\left(\frac{\mathrm{mg}}{1}\right.$ as $\left.\mathrm{CaCO}_{3}\right)=\mathrm{TA}-0.71 \mathrm{VA}$

where $\mathrm{TA}=$ total alkalinity, mg/l as $\mathrm{CaCO}_{3}$

$$
\mathrm{VA}=\text { volatile acid concentration, } \mathrm{mg} / \mathrm{l} \text { as acetic acid }
$$

Notes

1. Values for alkalinities should be reported to three significant figures.

2. The correct sampie size can be estimated from the following table:

Estimated Total Alk. $\left(\frac{\mathrm{mg}}{\mathrm{l}}\right)$ Sample Size (ml)

$\begin{array}{lr}\text { Less than } 1000 & 100 \\ 1000-2000 & 50 \\ 2000-3000 & 25 \\ 3000-6000 & 15 \\ 6000-10,000 & 10\end{array}$


III. Chemical Oxygen Demand (Solubie)

Reference: (Standard Methods, 13th Edition, Page 495)

Apparatus

1. Reflux apparatus, including $250 \mathrm{ml}$ erlenmeyer flasks, condensers, and hot plates.

2. Centrifuge and $50 \mathrm{ml}$ centrifuge tubes.

3. $25 \mathrm{ml}$ or $50 \mathrm{ml}$ Burette.

4. Volumetric pipette.

5. $25 \mathrm{ml}$ and $50 \mathrm{ml}$ graduated cylinders.

$\underline{\text { Reagents }}$

1. Standard potassium dichromate solution, $0.240 \mathrm{~N}$. Dissolve exactly $12.259 \mathrm{gm} \mathrm{K}_{2} \mathrm{Cr}_{2} \mathrm{O}_{7}$, primary standard grade, previously dried at $103^{\circ} \mathrm{C}$ for 2 hours, in distilled water and dilute to 1.0 liter in a volumetric flask.

2. Sulfuric acid reagent. Dissolve $22 \mathrm{gm}$ silver sulfate $\left(\mathrm{Ag}_{2} \mathrm{SO}_{4}\right)$ in a 9 pound bottle of concentrated sulfuric acid.

3. Standard ferrous ammonium sulfate titrant. Dissolve $39 \mathrm{gm} \mathrm{Fe}\left(\mathrm{NH}_{4}\right)_{2}\left(\mathrm{SO}_{4}\right)_{2} 6 \mathrm{H}_{2} \mathrm{O}$ in distilled water in a 1.0 liter volumetric flask. Add $20 \mathrm{ml}$ concentrated $\mathrm{H}_{2} \mathrm{SO}_{4}, \mathrm{CoOl}$, and dilute to 1.0 liter.

4. Ferroin indicator solution.

5. Mercuric sulfate $\left(\mathrm{HgSO}_{4}\right)$.

6. Sulfamic acid.

$\underline{\text { Standardization }}$

1. The standard ferrous ammonium sulfate titrant should be standardized against the standard potassium dichromate solution each time a COD analysis is performed.

2. Dilute exactly $10.0 \mathrm{ml}$ of standard $\mathrm{K}_{2} \mathrm{Cr}_{2} \mathrm{O}_{7}$ solution to about $100 \mathrm{ml}$ in a $250 \mathrm{ml}$ erlenmeyer flask.

3. Add $30 \mathrm{ml}$ of the sulfuric acid reagent and cool.

4. Add 3 drops ferroin indicator.

5. Titrate with ferrous ammonium sulfate titrant to a reddish brown endpoint. Record the amount of titrant required. 
6. Calculate the normality of the standard ferrous ammonium sulfate as follows:

Normality $=\frac{2.5}{\mathrm{mls} \mathrm{Fe}\left(\mathrm{NH}_{4}\right)_{2}\left(\mathrm{SO}_{4}\right)_{2}}$

\section{Procedure}

1. Centrifuge the sludge sample at approximately $10,000 \mathrm{rpm}$ for exactly 10 minutes.

2. Place $0.4 \mathrm{gm} \mathrm{HgSO}_{4}$ in a refluxing flask. Similarly add $0.4 \mathrm{gm} \mathrm{HgSO} 4$ to each of two other flasks, which will serve as blanks.

3. Pipet a suitable amount of supernatant sample to the refluxing flask. (Note: Only soluble COD is being measured. Care should be taken to avoid transferring any particulate material with the sample.) The correct sample size can be determined from the following table:

\begin{tabular}{cc} 
Estimated COD (mg/l) & Sample Size (ml) \\
\hline $5000-12,000$ & 1.0 \\
$4000-6,000$ & 2.0 \\
$3000-4,000$ & 3.0 \\
$2000-3,000$ & 4.0 \\
$1000-2,000$ & 5.0 \\
$500-1,000$ & 10.0 \\
$200-500$ & 20.0
\end{tabular}

4. Dilute with distilled water to provide a volume of 20 $\mathrm{ml}$ in the flask.

5. Add $20 \mathrm{ml}$ of distilled water to each of the two flasks serving as blanks. These will be carried through the analysis in the same manner as the flask containing the sample.

6. Mix the contents of each flask by swirling.

7. Add exactly $10.0 \mathrm{ml}$ of standard potassium dichromate solution to each flask.

8. Add several glass beads to each container. (Note: Glass beads should have been previously ignited at $600^{\circ} \mathrm{C}$ for 1 hour.)

9. Attach each flask to a condenser and start the cooling water.

10. Slowly add $30 \mathrm{ml}$ of sulfuric acid reagent through the open end of each condenser, mixing thoroughly by swirling, while adding the acid. (Note: Mix the reflux mixture thoroughly before heat is applied; if this is not done, local heating occurs in the bottom of the flask and the mixture may be blown out of the condenser.) 
11. Apply heat to refluxing flasks. Once the mixture begins to boil, reflux for two hours.

12. Cool and then wash down each condenser with distilled water.

13. Dilute the mixture in each flask to about $150 \mathrm{ml}$ with distilled water, then cool to room temperature. (Note: cooling of the mixtures can be hastened by placing the flasks in a water bath.)

14. Add 3 drops ferroin indicator to each flask.

15. Titrate with standard ferrous ammonium sulfate to an endpoint characterized by a sharp color change from blue-green to reddish brown. Record the amount titrant required.

16. Calculate the soluble $\operatorname{COD}$ as follows:

$\operatorname{COD}(\mathrm{mg} / \mathrm{l})=\frac{(\mathrm{A}-\mathrm{B}) \times \mathrm{N} \times 8000}{\mathrm{ml} \text { sample }}$

where $\mathrm{A}=\operatorname{mls} \mathrm{Fe}\left(\mathrm{NH}_{4}\right)_{2}\left(\mathrm{SO}_{4}\right)_{2}$ used for blank

$B=\operatorname{mls} \mathrm{Fe}\left(\mathrm{NH}_{4}\right)_{2}\left(\mathrm{SO}_{4}\right)_{2}$ used for sample

$\mathrm{N}=$ normality of $\mathrm{Fe}\left(\mathrm{NH}_{4}\right)_{2}\left(\mathrm{SO}_{4}\right)_{2}$

Notes

1. If upon addition of the ferroin indicator the sample turns a reddish brown color, then too large a sample was used. The analysis must be repeated using a smaller sample size.

2. Values for COD's should be reported to three significant figures.

3. The $\mathrm{HgSO}_{4}$ may be conveniently measured using a reagent spoon - one level spoonful being approximately equal to $0.4 \mathrm{gm}$.

\section{Safety Precautions}

This procedure requires the handling of concentrated sulfuric acid and mercuric sulfate powder, and the boiling of strong sulfuric acid solutions. Sulfuric acid is very corrosive to skin tissue. Mercuric sulfate is extremely toxic and can be introduced into the body by ingestion, breathing, and adsorption through the skin. If improperly handled, both of these materials can present a serious safety hazard to the analyst. The following iist describes specific safety precautions that should be observed when performing this procedure.

1. Rubber apron, face shield, and rubber gloves are required to be work when handing concentrated sulfuric acid. 
2. Rubber gloves, laboratory coat, and safety glasses must be worn during all other steps of the procedure.

3. In reference to step 10 , the $30 \mathrm{ml}$ of concentrated sulfuric acid should be added to each reflux flask in about $5 \mathrm{mi}$ portions. Care should be taken to mix by swirling between each addition. More rapid addition may cause boiling and a sudden release of acid vapors. As an added precaution, the condenser opening should be pointed away from the face during this step.

4. Remember to add boiling beads to each refluxing flask prior to heating (see Step 8). Failure to do so may lead to a sudden and violent vaporation. Release of the acid mixture through the condenser opening, and breakage of the flask may occur.

5. Ensure that the cooling water is flowing at a sufficient rate to prevent vapors from escaping during refluxing. Insufficient condenser cooling may allow the release of toxic fumes, and possible breakage of the reflux flask.

6. In reference to step 12, make sure that each reflux flask has cooled to room temperature before rinsing the condenser with distilled water. The addition of water to an acid solution that is not fully cooled may cause the mixture to boil. 
IV. Sludge Solids

Reference: (Standard Methods, 14th Edition, Page 96)

\section{Apparatus}

1. Crucibles, $50 \mathrm{ml}$ capacity.

2. Analytical balance, capable of weighing to $1.0 \mathrm{mg}$.

3. Drying oven, $103^{\circ} \mathrm{C}$.

4. Muffle furnace, $550^{\circ} \mathrm{C}$.

5. Desiccator.

\section{Procedure}

1. Ignite a clean crucible at $550^{\circ} \mathrm{C}$ for 1 hour in a muffle furnace.

2. Cool in a desiccator. Weigh to nearest $1 \mathrm{mg}$ and record as "Dish Weight." Store crucible in desiccator until ready for use.

3. Place 20-30 ml of well-mixed sludge sample in the crucible.

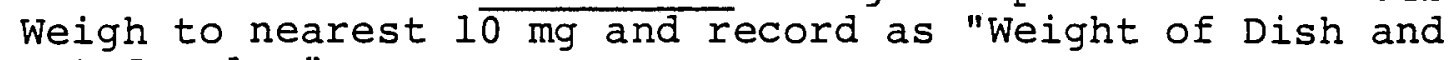
Wet Sample."

4. Compute "Weight of Wet Sample" by subtracting "Dish Weight" from "Weight of Dish and wet Sample."

5. Evaporate the sample in an oven set at $103^{\circ} \mathrm{C}$ for approximately 10 hours.

6. Cool in a desiccator. Weigh to nearest $1 \mathrm{mg}$ and record as "Weight of Dish and Dry Solids."

7. Compute "Weight of Dry Solids" by subtracting "Dish Weight" from "Weight of Dish and Dry Solids."

8. Ignite the crucible and dried residue in a furnace set at $550^{\circ} \mathrm{C}$ for 1 hour.

9. Cool in a desiccator to room temperature. Weigh to nearest $1 \mathrm{mg}$ and record as "Weight of Dish and Ash."

10. Compute "Weight of Ash" by subtracting "Dish Weight" from "Weight of Dish and Ash." 
11. Calculate total soliàs, volatile solids, and fixed solids as follows:

Total Solids $=\frac{\text { Weight of Dry Solids } \times 100}{\text { weight of wet Sample }}$

\% Volatile Solids $=$ (Weight of Dry Solids - weight of Ash) X 100 Weight of Wet sample

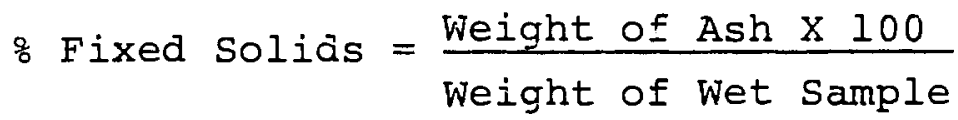

\section{Notes}

1. If a sludge sample contains powdered activated carbon the contribution of the carbon to the weight of the sample in each step of the analysis must be deducted. In this manner the computed solids composition will reflect only the true nature of the sludge. The fraction of carbon remaining at each step in the procedure can be determined by performing the solids analysis on a powdered carbon sample. By weight difference, the percentages of the carbon remaining after drying and ignition can be calculated. A series of samples should be run for each carbon type, and average values determined. Knowing the initial carbon concentration, the experimentally determined factors can be applied to substract the effect of carbon in the analysis. This procedure can be used to adjust for any other additive (e.g., flyash, clay) that may be present in the sludge.

2. Be sure that each sludge sample is thoroughly mixed and is representative of the material being sampled.

3. Due to the nonuniform nature of raw sludge, these samples should be analyzed in triplicate.

4. During ignition be certain that samples are exposed to a temperature of $5 \overline{50}^{\circ} \mathrm{C}$ for at least 1 hour.

5. Values for $\frac{\circ}{\circ}$ solids should be reported to 3 significant figures. 
V. Volatile Acids

Reference: (Standard Methods, 14th Edition, Page 527)

Apparatus

1. Centrifuge and $50 \mathrm{ml}$ centrifuge tubes.

2. Buchner Funnels, with fritted discs, $30 \mathrm{ml}$ capacity.

3. Separatory funnel, 2.0 liter.

4. Beakers, $50 \mathrm{ml}$.

5. Vacuum flask, $250 \mathrm{ml}$.

6. Volumetric pipette.

7. Graduated cylinder, $50 \mathrm{ml}$.

\section{Reagents}

1. Silicic acid, 50 to 200 mesh. Remove fines by slurrying the acid in distilled water and decanting the supernatant after settling for 15 minutes. Repeat several times. Dry the washed acid in an oven at $103^{\circ} \mathrm{C}$ until absolutely dry, then store in a desiccator.

2. Chloroform-butanol reagent: Mix $1200 \mathrm{ml}$ reagent-grade chloroform, $400 \mathrm{mI} \mathrm{n}$-butanol, $160 \mathrm{mI} 1.0 \mathrm{~N} \mathrm{H}_{2} \mathrm{SO}_{4}$, and $160 \mathrm{ml}$ distilled water in a 2.0 liter separatory funnel. Let the aqueous and organic layers separate. Drain off the lower organic layer through a filter paper into a dry bottle.

3. Phenolphthalein indicator solution: Dissolve $80 \mathrm{mg}$ phenolphthalein in $100 \mathrm{ml}$ absolute methanol.

4. Sulfuric acid $\left(\mathrm{H}_{2} \mathrm{SO}_{4}\right)$, concentrated.

5. Standard sodium hydroxide $(\mathrm{NaOH}), 0.02 \mathrm{~N}$ : Dilute $20 \mathrm{ml}$ 1.0 $\mathrm{N}$ NaOH stock solution to 1.0 liter with absolute methanol.

6. Standard sodium hydroxide $(\mathrm{NaOH}), 0.005 \mathrm{~N}$ : Dilute $5.0 \mathrm{ml}$ $1.0 \mathrm{~N}$ NaOH stock solution to 1.0 liter with absolute methanol.

Standardization

1. The nomalities of basic alcohol solutions decrease with time, particularly when subjected to repeated exposure to the atmosphere. Therefore, the $\mathrm{NaOH}$ titrants should be standardized before being used, and at least weekly thereafter when volatile acid tests are being performed. 
2. Add about $100 \mathrm{ml}$ of distilled water to a $250 \mathrm{ml}$ beaker. For the $0.02 \mathrm{~N}$ titrant, pipet exactly $4.0 \mathrm{ml}$ of approximately $0.1 \mathrm{~N} \mathrm{H}_{2} \mathrm{SO}_{4}$ into the beaker. For the $0.005 \mathrm{~N}$ titrant, pipet exactly $1.0 \mathrm{ml}$ into the beaker. (Note: Exact normality of $\mathrm{H}_{2} \mathrm{SO}_{4}$ should have been determined as specified in the Alkalinity procedure.)

3. Place the beaker on a magnetic stirrer and continuously $\operatorname{mix}$.

4. Immerse the $\mathrm{pH}$ electrode in the solution.

5. Titrate to a $\mathrm{pH}$ of 7.0 with the $\mathrm{NaOH}$ titrant. Record the amount of titrant required.

6. Calculate the normality of the $\mathrm{NaOH}$ as follows:

Normality of $\mathrm{NaOH}=\frac{\mathrm{mls}_{\mathrm{S}} \text { of } \mathrm{H}_{2} \mathrm{SO}_{4} \times \text { normality of } \mathrm{H}_{2} \mathrm{SO}_{4}}{\mathrm{mls} \text { of titrant }}$

7. The normality of the $\mathrm{NaOH}$ titrant determined by standardization should be used in all volatile acid calculations.

Procedure

1. Centrifuge the sludge sample at approximately 10,000 rpm sor at least 10 minutes. The supernatant obtained from this operation should be used for both the volatile acids and total alkalinity tests.

2. Place 10 to $15 \mathrm{ml}$ of supernatant in a $50 \mathrm{ml}$ beaker.

3. Add concentrated $\mathrm{H}_{2} \mathrm{SO}_{4}$, dropwise, to obtain a $\mathrm{pH}$ of 1.0 to 1.2 .

4. Place about 12 grams of silicic acid in a fritted glass funnel and apply suction to pack the column. (Note: 12 grams can be conveniently estimated by filling the funnel to level between the designations "ASTM" and "30 $\mathrm{ml}$ " on the side of the funnel.)

5. With a pipet, distribute $5.0 \mathrm{ml}$ of acidified sample as uniformly as possible over the surface of the column. Apply suction momentarily to draw the sample into the silicic acid. Release the vacuum as soon as the last portion of the sample has entered the column.

6. Quickly add $65 \mathrm{ml}$ of chloroform-butanol reagent and apply suction.

7. Discontinue the suction just before the last of the reagent enters the column. 
8. Remove the funnel and purge the sample with nitrogen gas for at least 1 minute, and continue purging during titration. Purging with nitrogen will prevent contact with atmospheric carbon dioxide and also $\mathrm{mix}$ the sample during titration.

9. Add a half a dropper full of phenolphthalein indicator to the liquid in the vacuum flask.

10. Titrate the sample with standard NaOH to the phenolphthalein end point (light purple). Use the $0.02 \mathrm{~N}$ titrant if the volatile acids concentration in the sample is estimated to be greater than $500 \mathrm{mg} / 1$. The 0.005 $\mathrm{N}$ titrant should be used for concentrations less than 500 $\mathrm{mg} / 1$.

11. Repeat the above procedure using a blank consisting of $5.0 \mathrm{ml}$ of acidified distilled water, extract with reagent and titrate in a similar manner. Use the same standard $\mathrm{NaOH}$ solution as was used in the sample titration.

12. Calculate total volatile acids as follows:

Total Volatile Acids ( $\frac{\mathrm{mg}}{\mathrm{l}}$ as Acetic Acid)

$$
=\frac{(A-B) \times N \times 60,000}{m l \text { sample }}
$$

where

$$
\begin{aligned}
& A=\mathrm{ml} \mathrm{NaOH} \text { used for sample } \\
& \mathrm{B}=\mathrm{ml} \mathrm{NaOH} \text { used for blank } \\
& \mathrm{N}=\text { normality of } \mathrm{NaOH}
\end{aligned}
$$

Notes

1. At least once each week a standard $2100 \frac{\mathrm{mg}}{\mathrm{l}}$ acetic acid solution should be tested. Based on an average recovery of 95 percent, the experimentally determined value should range between 1900 and $2100 \mathrm{mg} / 1$ as acetic acid. If the acid concentration is outside this range the cause of the deviation should be determined.

2. The standard $2100 \frac{\mathrm{mg}}{\mathrm{t}}$ acetic acid solution can be prepared by diluting exactly $1.0 \mathrm{ml}$ of glacial acetic acid (reagent grade) to $500 \mathrm{ml}$ in a volumetric flask.

3. The shade of the phenolphthalein endpoint will vary between analysts. Error is reduced if each set of sample is tested by only one analyst, and if he consistently titrates to the same endpoint (color). 
VI. Sludge Filtration

\section{Apparatus}

1. Buchner funnel, $51 / 2$ inch diameter, porcelain, with fixed perforated plate.

2. Plastic support screen, cut to cover perforated plate of Buchner funnel.

3. Vacuum flask, $4000 \mathrm{ml}$, with $100 \mathrm{ml}$ graduated cylinder secured in flask.

4. No. 2 Whatman Filter paper, $12.5 \mathrm{~cm}$ diameter.

5. Vacuum gage, 0-30 inches Hg vacuum.

6. Stop watch.

\section{Procedure}

1. Filtration assembly should be set up as shown in Figure 3 .

2. Obtain approximately $150 \mathrm{ml}$ of sludge sample.

3. Measure the total solids content of the well-mixed sample.

4. Allow the sludge sample to come to laboratory ambient temperature. Measure and record the ambient temperature.

5. Transfer a well-mixed sludge sample to a $100 \mathrm{ml}$ graduated cylinder. Fill to the $100 \mathrm{ml}$ mark.

6. Add the $100 \mathrm{ml}$ of sludge to the Buchner funnel and allow time for a cake to form (about 10 seconds).

7. Apply vacuum to the system and immediately start the stop watch.

8. Record the volume of filtrate collected at the following time intervals: $1,2,3,4,5,6,8,10,12,15,20,25$, and 30 minutes.

9. During the test periodically observe the reading on the vacuum gage. Record the range of values observed during the test period.

10. Calculate the specific resistance of the sludge as described below.

Calculation

1. Plot $t / V$ vs $V$, where $t$ is the time in seconds, and $V$ is the volume of filtrate collected in milliliters.

2. Determine the slope of the line. The slope is designated as $b\left(\mathrm{sec} / \mathrm{cm}^{6}\right)$. 
3. Specific conditions of the test:

$$
\begin{aligned}
\mathrm{A}= & \text { area of filter paper }\left(\mathrm{cm}^{2}\right), 123 \mathrm{~cm}^{3} \text { for } 12.5 \mathrm{~cm} \\
& \text { diameter paper } \\
\mathrm{P}= & \text { average vacuum pressure }\left(\mathrm{gm} / \mathrm{cm}^{2}\right), \mathrm{gm} / \mathrm{cm}^{2}=34.6 \mathrm{x} \text { in } \mathrm{Hg} \\
\mathrm{C}= & \text { total solids content of initial sludge }(\mathrm{gm} / \mathrm{ml}), \mathrm{gm} / \mathrm{ml}= \\
& 0.01 \mathrm{x} \frac{8}{\mathrm{~s} l} \\
\mu= & \text { filtrate viscosity (poises), poise }=\mathrm{gm} / \mathrm{cm} \mathrm{sec,}, \\
& \text { poises }=0.01 \mathrm{x} \text { centipoises. }
\end{aligned}
$$

\begin{tabular}{|c|c|c|c|}
\hline $\begin{array}{l}\text { Temp. } \\
\left({ }^{\circ} \mathrm{C}\right) \\
\end{array}$ & $\begin{array}{c}\text { Viscosity } \\
\text { (Poise) }\end{array}$ & $\begin{array}{l}\text { Temp. } \\
\left({ }^{\circ} \mathrm{C}\right)\end{array}$ & $\begin{array}{l}\text { Viscosity } \\
\text { (Poise) }\end{array}$ \\
\hline 15 & 0.0114 & 23 & 0.0094 \\
\hline 16 & 0.0111 & 24 & 0.0091 \\
\hline 17 & 0.0108 & 25 & 0.0089 \\
\hline 18 & 0.0106 & 26 & 0.0087 \\
\hline 19 & 0.0103 & 27 & 0.0085 \\
\hline 20 & 0.0100 & 28 & 0.0084 \\
\hline 21 & 0.0098 & 29 & 0.0082 \\
\hline 22 & 0.0096 & 30 & 0.0080 \\
\hline
\end{tabular}

The filtrate viscosity $(\mu)$ can be assumed to be the same as that of water at the same temperature. Use the following chart to determine viscosity:

4. Compute the specific resistance, $r$ :

$$
r\left(\sec ^{2} / g m\right)=\frac{(2)(P)\left(A^{2}\right)(b)}{(u)(C)}
$$




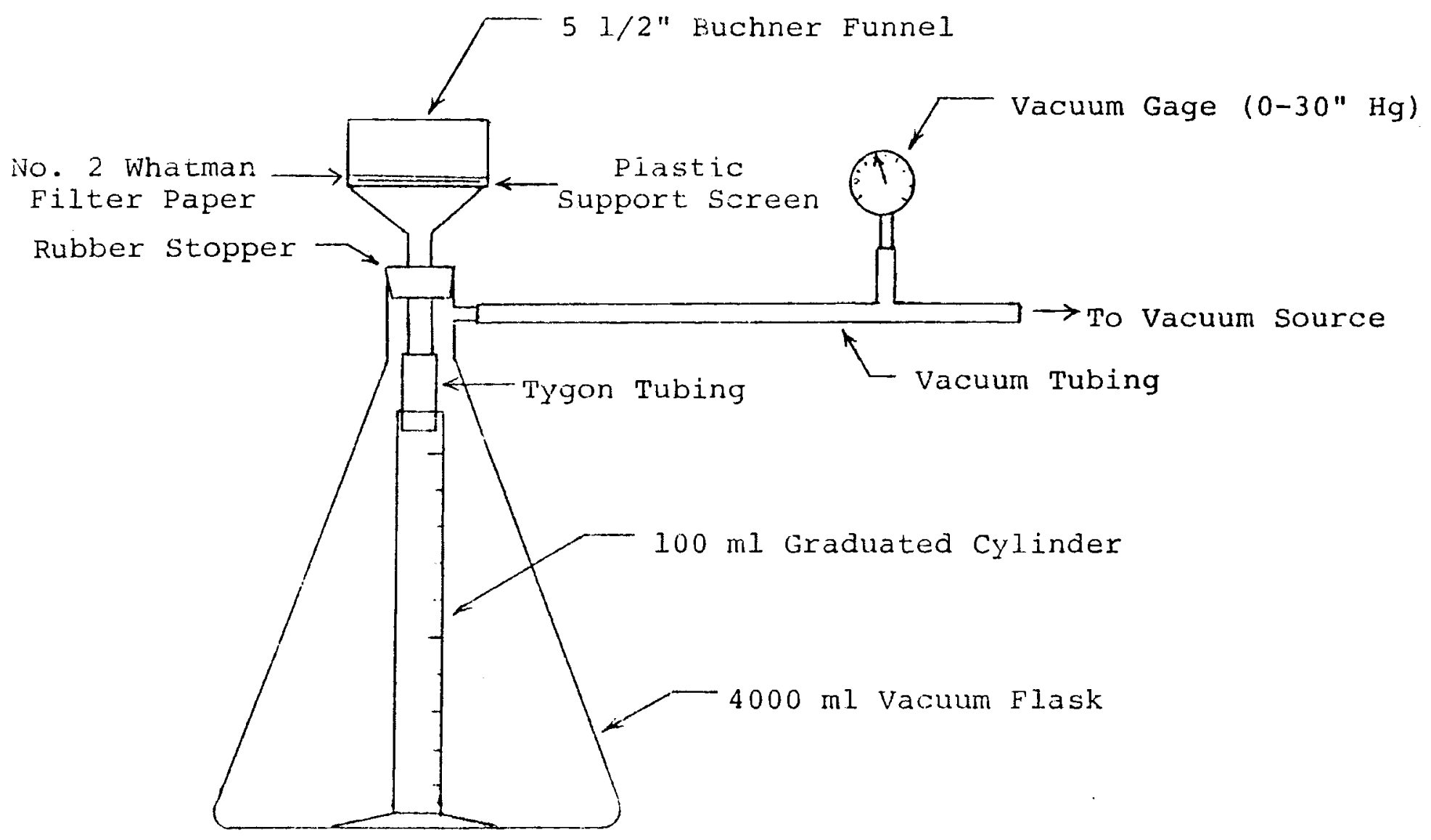

FIGURE 3. SLUDGE FILTRATION ASSEMBLY 
VII. Sludge Centrifugation

Apparatus

1. Centrifuge and $50 \mathrm{ml}$ centrifuge tubes.

2. Stopwatch.

3. Equipment for total suspended solids analysis.

4. Equipment for total solids analysis.

\section{Procedure}

1. Obtain about $75 \mathrm{ml}$ of sludge sample.

2. Perform total solids analysis (see section IV) on a wellmixed portion of the sample.

3. Transfer about $35 \mathrm{ml}$ of well-mixed sample to a $50 \mathrm{ml}$ centrifuge tube.

4. Place the tube in the centrifuge. Counterbalance as necessary with tubes containing water. Prepare the centrifuge for operation.

5. Turn the large dial on the front of the centrifuge to 10 , and immediately start the stopwatch. This is the start of the test. After exactly 15 seconds have elapsed, turn the dial to 20. Continue increasing the setting by intervals of 10 every 15 seconds until the dial reads 50 .

6. Continue operating at a dial setting of 50 until exactly 7 minutes have elapsed since the start of the test, then turn the main toggle switch to the off position. (Important: During slowdown do not utilize the braking system or in any other way interfere with the natural deceleration of the centrifuge head.)

7. When the centrifuge head has come to a complete stop, remove the tubes and analyze the centrate for total suspended solids and total solids.

8. The efficiency of centrifugation is determined by computing percent recovery.

where:

$$
\% \text { recovery }=\frac{c_{i}-C_{c}}{c i-C_{c}+C_{s}} \times(100)
$$

$$
\begin{aligned}
C_{i}= & \text { total solids present in initial sludge sample (\%) } \\
C_{c}= & \text { total solids present in centrate after centri- } \\
& \text { fugation }(\%) \\
C_{s}= & \text { total suspended solids present in centrate after } \\
& \text { centrifugation }\left(\frac{\circ}{\circ}\right) .
\end{aligned}
$$




\section{$\bullet$}


APPENDIX A

DRAWINGS / SPECIF ICATIONS 


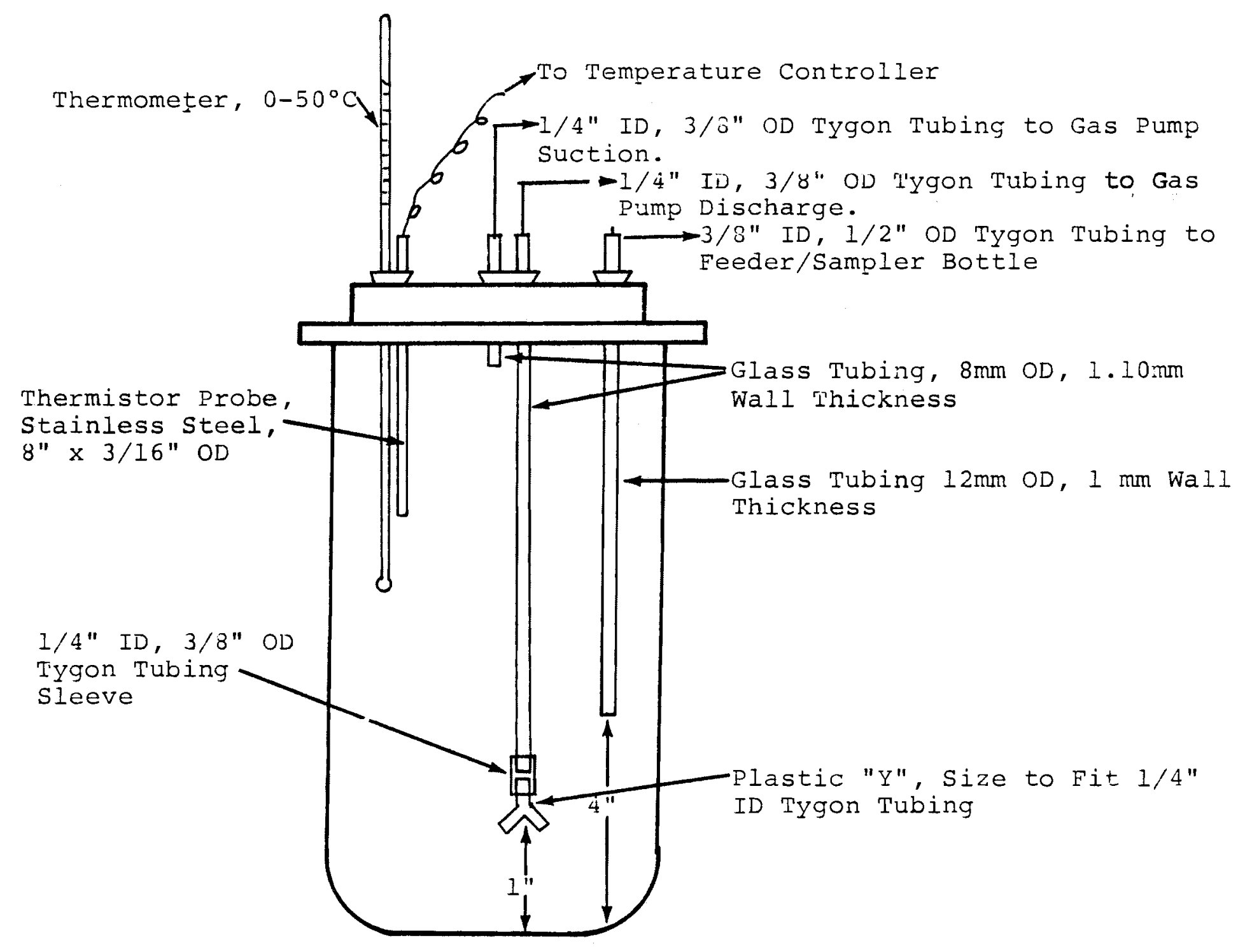

DIGESTER ELEVATION VIEW

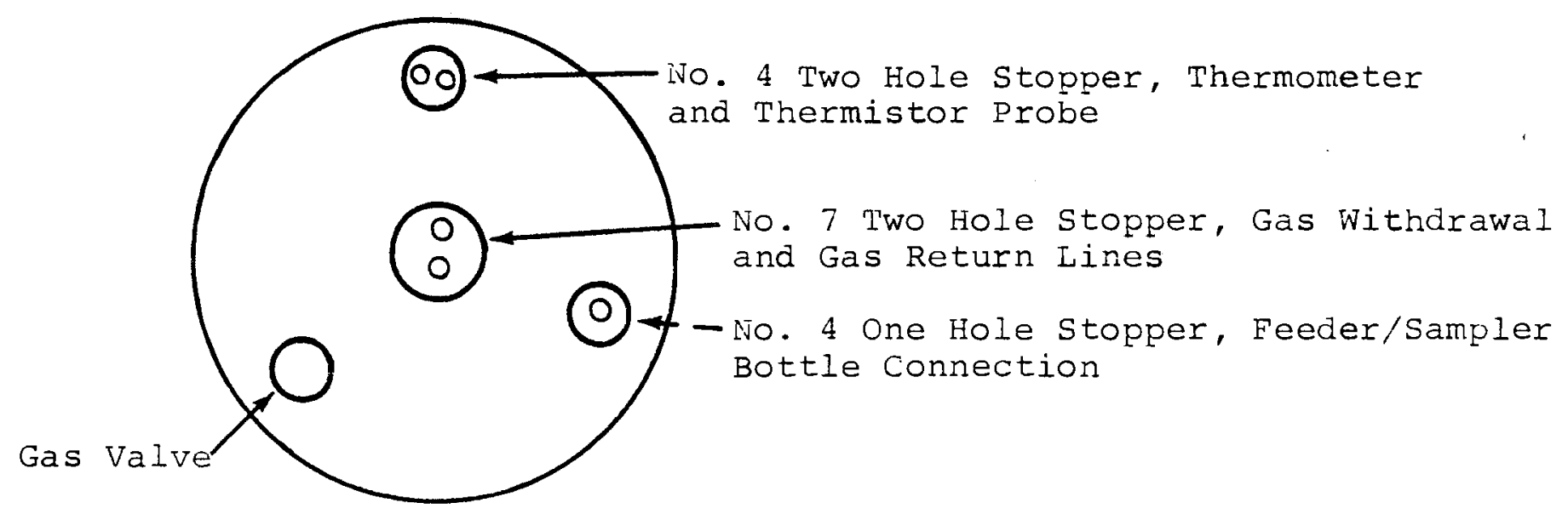




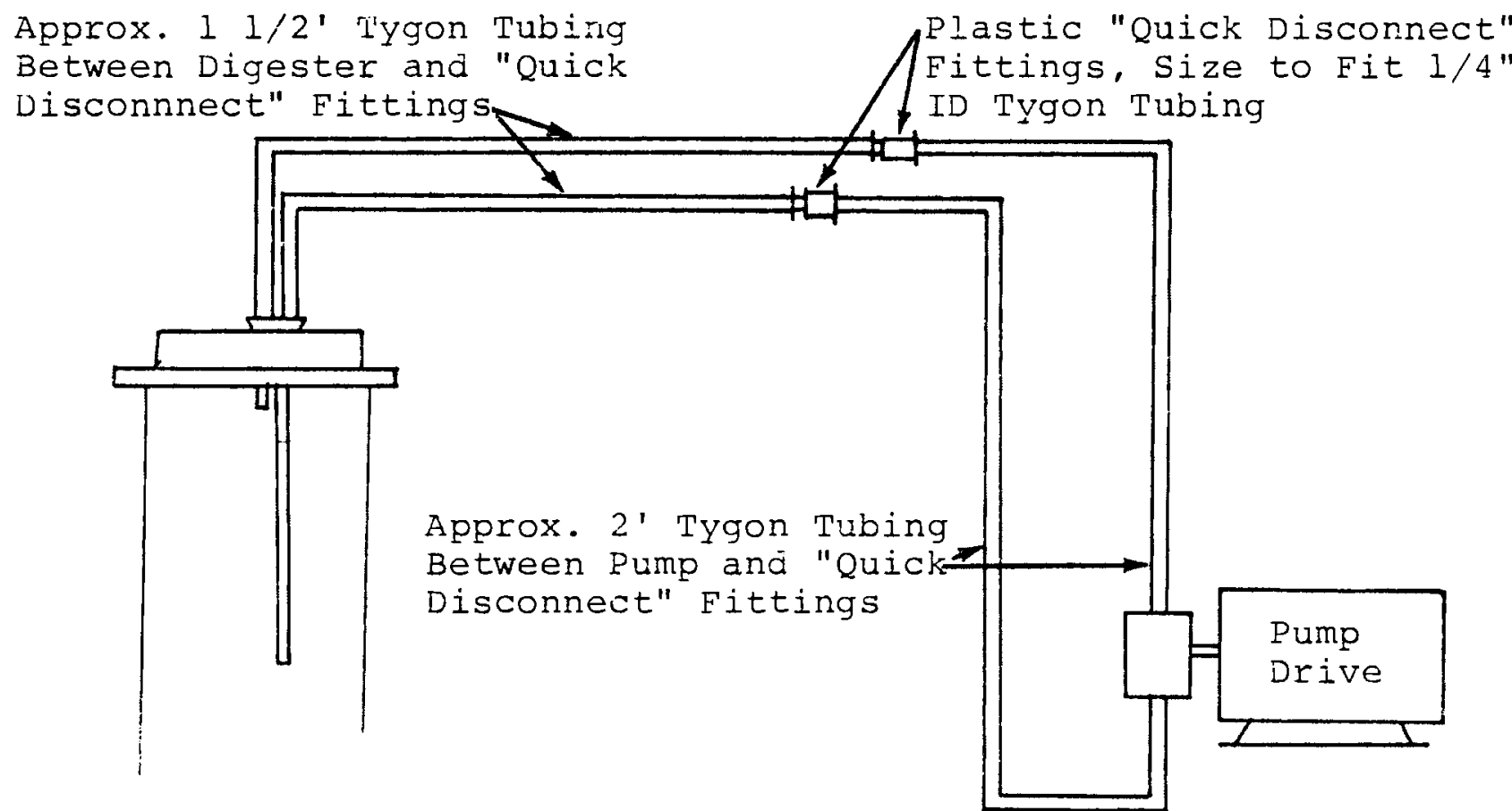


APPENDIX B

OPERATING AND MAINTENANCE INSTRUCTIONS 


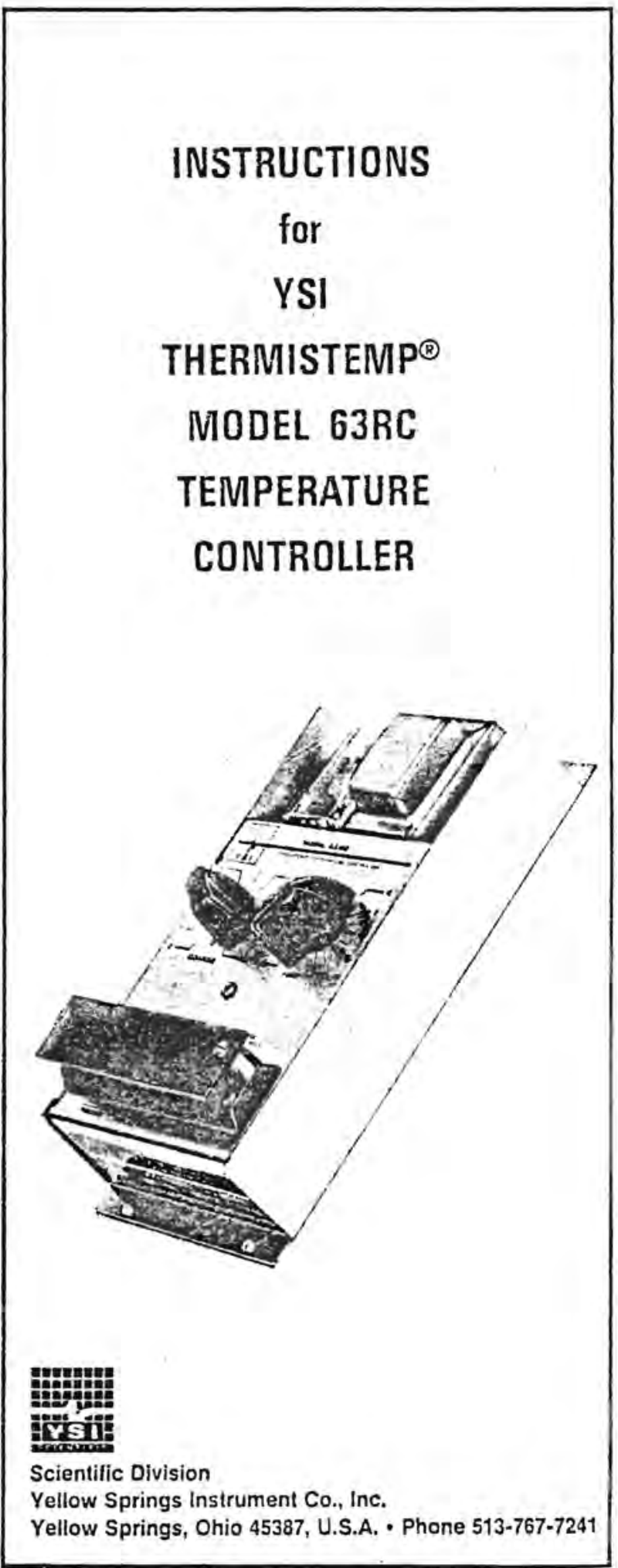

Reprinted with Permission from Yellow Springs Instrument $\mathrm{Co}$. , Inc. 


\section{GENERAL DESCRIPTION}

The YSI Model 63RC Temperature Controller is a compact, sensitive electronic controlier capable of maintaining temperautre within narrow limits. Since both coarse and fine controls are provided, the instrument can be set very precisely over a wide range of temperature.

Temperature is sensed by means of a thermistor probe which forms one leg of an alternating current bridge. If the temperature of the probe deviates from the setting of the controller, the bridge becomes unbalanced, and the unbalance voitage or error signal is amplified to operate a control relay. The contacts of the control relay are used to switch the external load on or off in accordance with the demands of the controller. Because of the sensitive probe and the high amplification the "dead zone" of the controller is very narrow; that is, a very slight temperature deviation from the contiol point will cause the load to be switched on or off.

\section{SPECIFICATIONS 63AC}

\author{
-20 to $120^{\circ} \mathrm{C}$ Probes $601,611,621,631,641$. \\ ( 0 to $250^{\circ} \mathrm{F}$ ) 651.661 (green center lead)
}

95 to $260^{\circ} \mathrm{C}$ Probes $602,612,622,632,642$. (200 to $\left.500^{\circ} \mathrm{F}\right) \quad 652.662$ (red center !ead)

.75 to $40^{\circ} \mathrm{C}$ Probes $603,613,623,633,643$. $\left(-100\right.$ to $\left.100^{\circ} \mathrm{F}\right) 653,663$ (blue center lead)

Dead Zone: Less than $0.05^{\circ} \mathrm{C}\left(0.1^{\circ} \mathrm{F}\right)$

Controls: Coarse and fine, ratio to approximately 20 to 1 . calibrated in arbitrary units. 0-100. Remove knobs to convert to screwdriver adjustment.

Relay: Single pole, double-throw: contacts rated 10 amperes at 117 VAC: 5 amperes at 230 VAC. non-inductive load.

Power: 117 or 230 volts. $50-60 \mathrm{~Hz}, 5$ watts.

\section{INSTALLATION}

The probe may be located up to several hundred feet from the controller. Almost any wire may be used for distances up to 20 feet: for runs of greater length. No. 14 wire in conduit is recommended.

Important: Ouserve polarity. The outside (shield braid) conductor of the probe must be connected to the PROBE GND terminal. As supplied, shield terminates in black pigtail.

Probe placement is important when close control is desired. If the probe is located close to the source of heat which is being controlled, often the temperature will be heid to narrower limits than the dead zone of the controller. If the thermal load on the system varies widely, locating the probe at a greater distance from the heater will result in better average temperature stability, but at the cost of somewhat greater undershoot and over-shoot about the control point.

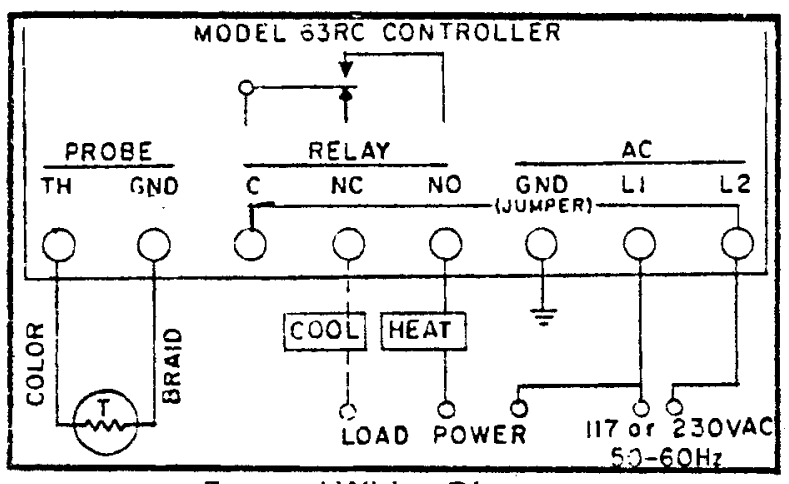

External Wiring Diagram

\section{GUARANTEE}

The YSI Model 63RC temperature controller and temperature probes carry a one-year unconditional guarantee on all workmanship and components. Damage through misuse, accident, or tampering will be repaired at nominal charge, if possible. If you are experiencing difficulty with any YSI product, even if the guarantee has expired. it may be returned to any authorized YSI dealer or to the YSI factory.

ITEM 000920 P/NA.41525.J OCT.75 PRINTEDINU.S.A. B.K. 
Reprinted with Permission from GLAS-COL APPARATUS COMPANY

711 Hulman Street

Terre Haute, Indiana 47802

Tel: (812) 235-6167

\section{CARE AND OPERATION OF THE GLAS-COL HEATING MANTLE}

With proper care and operation, the Glas-Col Mantle will give long and efficient service. Chemical spillage, overheating and general misuse will greatly reduce the life of the mantle.

The Glas-Col mantlel consists of a simple insulated electrical resistance heater and requires only an electrical power supply. However, use of a variable transformer or an automatic controller is recommended to prevent overheating and to effect accurate temperature control. In some instances, it may be desirable to use a variable transformer and an automatic device together for very accurate control. Instructions for connection and operation of this arrangement are available from Glas-Col on request.

For maximum safety, the three-prong plug of the cord on the Series M, TM and STM mantles should always be inserted into a grounded outlet. Since the exterior of Series $O$ mantles is an insulator, these mantles are furnished with two wire cords.

Maintenance of the Glas-Col mantle on a regular schedule is not required. Of course, any damage which occurs to the mantle should be repaired immediately. Glas-Col mantles should be protected from chemical spillage and corrosive atmospheres so far as practical. Damage from spillage on Series $M$ or TM mantles can be reduced greatly by using the Glas-Col Splash Guard or Poncho safety shield.

The only limitation in the operation of the Glas-Col mantle is the maximum heating zone temperature limit of $450^{\circ} \mathrm{C}$ for the glass fabric in Series $\mathrm{O}, \mathrm{M}$ and TM mantles and $650^{\circ} \mathrm{C}$ for Series S, STM and RFM mantles. Most Series O, M and TM mantles are equipped with iron constantan thermocouples to measure this temperature. Under normal conditions $650^{\circ} \mathrm{C}$ will not be exceeded and, therefore, Series S, STM and RFM mantles do not have thermocouples except on special order.

Overheating of Series $O$ spherical and hemispherical mantles can be prevented effectively by using the appropriate Glas-Col support. (Cat. No. $0-524$ thru $0-550$ extension supports, $0-505$ and $0-510$ tripod supports). The use of these supports is the only method approved by Glas-Col and we cannot assume responsibility for mantles damaged as a result of being supported otherwise. For example - on ring stands, cork rings, lab jacks, etc.

In Series $O$ spherical mantles of 12-liters capacity and larger, there are three heating circuits - two in the lower half and one in the upper half. The heat input in each circuit should be controlled with a suitable variable transformer. The two lower circuits furnish heat for boiling the liquid contents, while the upper circuit prevents condensation of the vapors. It will rarely be necessary to operate the upper circuit on more than 60 or 70 Volts. For low boiling liquicis the upper circuit need not be used. When the flask is more than half full of liquid, the two bottom circuits may be operated at the rated voltage. When the liquid level falls below the halfway mark in the flask, the voltage in the upper circuit of the lower half should be reduced to 70 or less. This will prevent superheating of the vapors, and overheating of the glass fabric in this circuit.

A similar procedure should be followed when using a Series M, TM, S or STM mantle with a Series MO heating top.

Glas-Col Apparatus Company is not responsible for damage to apparatus due to improper installation or through attempts to operate the apparatus beyond its rated capacity, intentional or otherwise. Glas-Col warrants products of its manufacture to be free from defects in material and workmanship and agrees to repair or replace without charge any products found defective upon examination at the factory. With proper installation, avoidance of contamination and excess temperature, Glas-Col mantles should provide efficient operation and long service life.

For full details and prices on all standard Glas-Col heatirg mantles for the laboratory, request Bulletin 73-L. For special heating applications, contact our Engineering Department. 

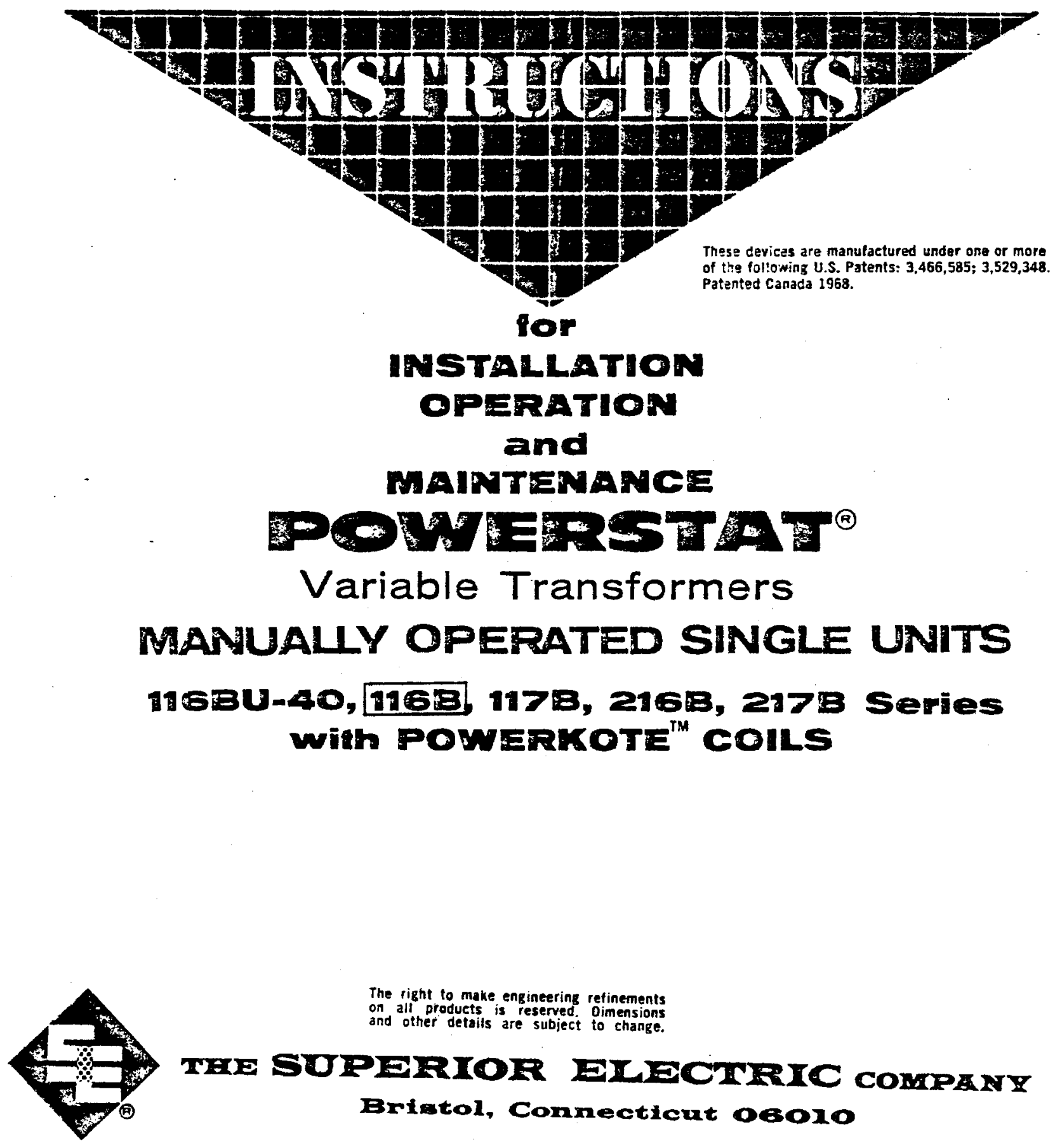

The right to make engineering refinements

on all products is reserved Oimensions

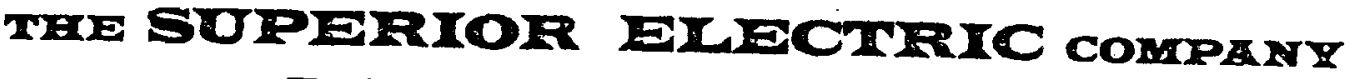
Briatol, Comnecticut oeoro

$S E-147218$

MS2105G148

Printed in U.S.A.

Reprinted with Permission from The Superior Electric co. 


\section{INSPECTION}

A POWERSTAT Variable Transformer is a precision product packed with care. When unpacking, examine carefully for any shipping damage. Inspect the brush contact with particular care. The "Damage and Shortage" instructions packed with the unit outline the procedure to follow if any parts are damaged or missing.

\section{PRECAUTIONS}

- Be absolutely certain triat the line voltage, phase and frequency are correct for the unit.

- If riot already provided, incorporate fuses in the hot output leads as recommended in the circuit diagram.

- Prevent the radiator from striking sharpiy against its stop because this tends to weaken the entire structure.

\section{CONNECTIONS AND RATINGS}

COIL TO TERMINAL CONNECTIONS for all POWERSTAT Variable Transformers included in these instructions are given in Figures $A, B$ and $C$.

DERATING OF OUTPUT CURRENT AT AMBIENT TEMPERATURES ABOVE $50^{\circ} \mathrm{C}$ is shown in Figure $\mathrm{D}$. At ambient temperatures between $-20^{\circ} \mathrm{C}$ and $+50^{\circ} \mathrm{C}$ use the current ratings given in the charts.

DERATING OF OUTPUT CURRENT WHEN OPERATING ON LOW INPIJT VOLTAGE TAP for $216 B$ units is shown in Figure $E$.

MAXIMUM TIME UNITS MAY BE SUEJECTEO TO VARIOUS OVERLOADS is shown by the "naximum on time" curve in Figure $F$. When used with repetitive overloads, the units must be allowed sufficient "off" time as indicated by the "minimum off
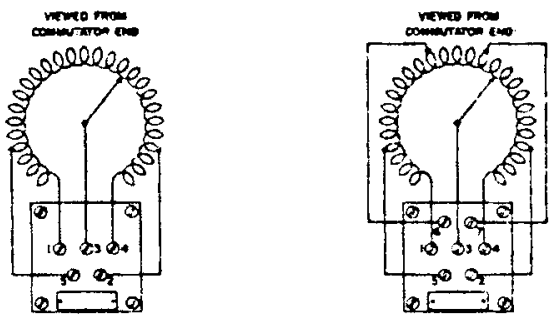

FIGURE A II6B TYPES

FIGURE $B$ 216B TYPES time" curve to prevent excessive steadystate temperatures. For overloads where "on" time is less than the maximum shown, the "off" time can be calculated using the following equation:

$$
\left(\frac{\text { OVERLOAO CURRENT }}{\text { RATED CURRENT }}\right)^{2}-1=\frac{\text { OFF TIME }}{\text { ON TIME }}
$$

\begin{tabular}{|l|c|c|}
\hline \multirow{2}{*}{$\begin{array}{c}\text { BASIC } \\
\text { UNIT }\end{array}$} & \multicolumn{2}{|c|}{$\begin{array}{c}\text { RECOMMENDED FUSE } \\
\text { (AMPERES) }\end{array}$} \\
\cline { 2 - 4 } & $\begin{array}{c}\text { COMSTANT } \\
\text { CURRENT } \\
\text { LOAD }\end{array}$ & $\begin{array}{c}\text { CONSTANT } \\
\text { IMPEDANCE } \\
\text { LOAD }\end{array}$ \\
\hline $116 B \backslash 40$ & 25 & 30 \\
\hline $116 \mathrm{~B}$ & $10 \dagger \dagger$ & 15 \\
\hline $117 \mathrm{~B}$ & 15 & $15 \dagger \dagger$ \\
\hline $216 \mathrm{~B}$ & $4 \dagger \dagger$ & 5 \\
\hline $217 \mathrm{~B}$ & 5 & $8 \dagger \dagger$ \\
\hline
\end{tabular}

HCord-and-plug units supplied with these fuses.

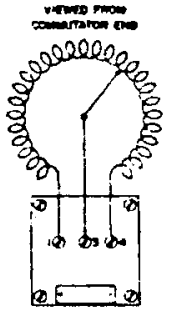

FIGURE C

116BU-40. 117B AND 2178 TYPES

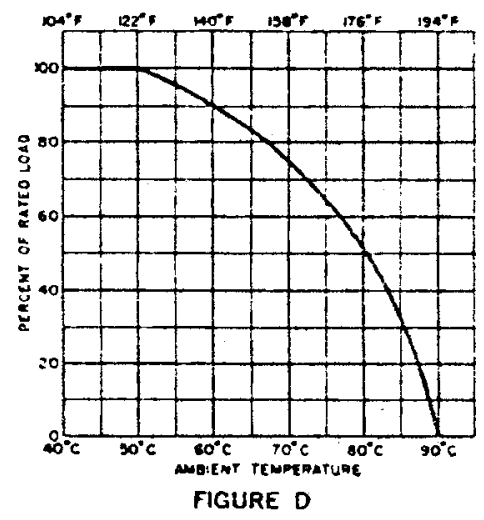

FIGURE D
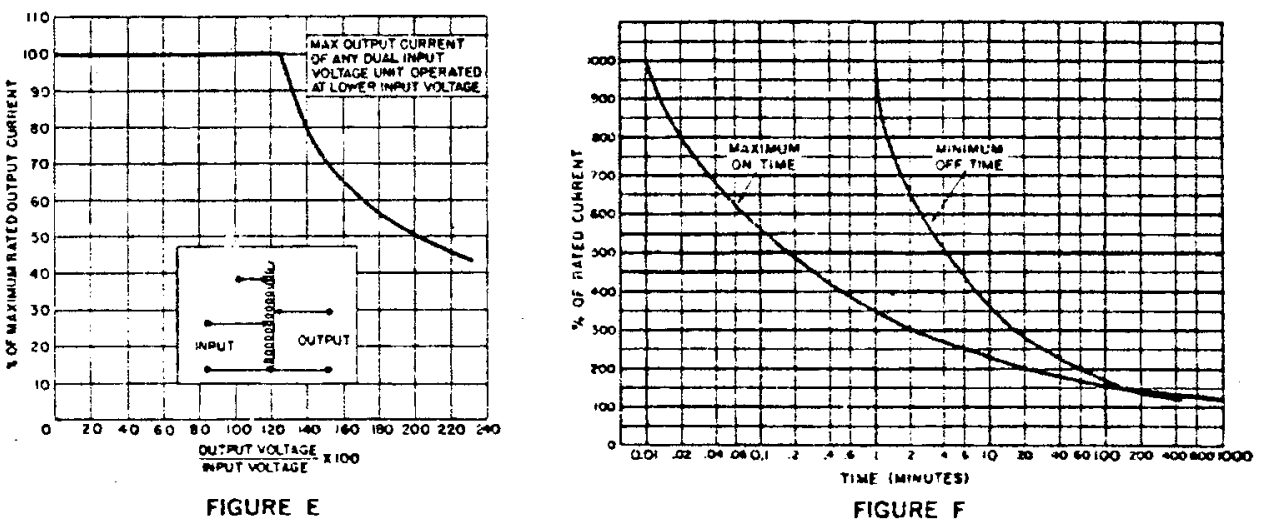


\begin{tabular}{|c|c|c|c|c|c|c|c|c|c|c|c|c|}
\hline \multirow[b]{4}{*}{ TYPE } & \multicolumn{2}{|c|}{ INPUT } & \multicolumn{5}{|c|}{ DUTPUT } & \multirow{4}{*}{$\begin{array}{l}\text { KMOS } \\
\text { RoTA- } \\
\text { TIOA }\end{array}$} & & & & \\
\hline & \multirow[b]{3}{*}{ volts } & \multirow[b]{3}{*}{ HERTZ } & \multirow[b]{3}{*}{ volts } & \multirow{2}{*}{\multicolumn{2}{|c|}{$\begin{array}{l}\text { CONSTANT } \\
\text { CURAENT } \\
\text { EOAD }\end{array}$}} & \multirow{2}{*}{\multicolumn{2}{|c|}{$\begin{array}{l}\text { CONSTANT } \\
\text { IMPEDANCE } \\
\text { LOAO }\end{array}$}} & & \multicolumn{4}{|c|}{ TERMIMALS } \\
\hline & & & & & & & & & \multicolumn{2}{|c|}{$\begin{array}{l}\text { KNOS ON } \\
\text { RABIATOR ENO }\end{array}$} & \multicolumn{2}{|c|}{$\begin{array}{l}\text { XNOB ON } \\
\text { BASE ENO }\end{array}$} \\
\hline & & & & $\begin{array}{l}\text { Max. } \\
\text { AMP. }\end{array}$ & $\operatorname{mix}_{\text {KVA }}$ & $\begin{array}{l}\operatorname{Max} . \\
\text { MAp. }\end{array}$ & $\max _{x y i}$ & & INPUT & OUTPUT & INPUT & OUTPuT \\
\hline \multirow{2}{*}{$1168 U .40$} & \multirow{2}{*}{40} & \multirow{2}{*}{60} & \multirow{2}{*}{$0-40$} & \multirow{2}{*}{25} & \multirow{2}{*}{1.0} & \multirow{2}{*}{30} & \multirow{2}{*}{1.2} & CW & $1-4$ & 1.3 & $1-4$ & $3-4$ \\
\hline & & & & & & & & $\mathrm{CCW}$ & $1-4$ & 3.4 & $1-4$ & $1 \cdot 3$ \\
\hline \multirow{4}{*}{ 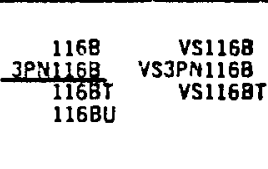 } & \multirow{4}{*}{120} & \multirow{4}{*}{$50 / 60$} & \multirow{2}{*}{0.120} & \multirow{2}{*}{10} & \multirow{2}{*}{1.2} & \multirow{2}{*}{13} & \multirow{2}{*}{1.6} & CW & 1.4 & 1.3 & $1-4$ & 3.4 \\
\hline & & & & & & & & $\operatorname{cen}$ & 1.4 & 3.4 & $1-4$ & $1-3$ \\
\hline & & & \multirow{2}{*}{0.140} & \multirow{2}{*}{10} & \multirow{2}{*}{1.4} & \multirow{2}{*}{ - } & \multirow{2}{*}{ - } & CW & $1-2 !$ & $1.3 ?$ & $4-5$ & $3-4$ \\
\hline & & & & & & & & $\mathrm{CCW}$ & $4-5$ & $3-4$ & 1.2 & $1-3$ \\
\hline $\begin{array}{ll}2 P F 1178 & \text { VS2PF1178 } \\
3 P N 1178 & \text { VS3PN117B }\end{array}$ & 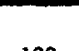 & sa & 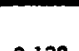 & I & , & 19 & 10 & CW & $1-49$ & $1-3 n$ & $1-4$ & 3.4 \\
\hline $\begin{array}{l}\text { 1178T VS117BT } \\
11780\end{array}$ & 120 & 60 & 0.120 & 12 & 1.4 & 10 & 1.8 & ccw & 1.4 & $3-4$ & $1-4$ & $1 \cdot 3$ \\
\hline & & & 000 & 35 & 00 & $=$ & 19 & $\mathrm{CW}$ & 1.4 & $1-3$ & 1.4 & $3-4$ \\
\hline & & & $0-240$ & 3.5 & 0.84 & 3 & 1.2 & CCW & $1-4$ & 3.4 & $1-4$ & 1.3 \\
\hline $\begin{array}{rr}2168 & \begin{array}{r}\text { VS216B } \\
\text { 3PN2168 }\end{array} \text { VS3PFV2168 }\end{array}$ & 240 & $20 / 60$ & 0.290 & 25 & 000 & 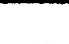 & 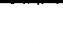 & CW & $1-2 \%$ & 1-3! & 4-5 & $3-4$ \\
\hline $\begin{array}{l}2168 \mathrm{BT} \\
216 \mathrm{BU}\end{array}$ & & & 0.600 & 3.2 & 0.50 & - & - & CCW & 4.5 & $3-4$ & 1.2 & 1.3 \\
\hline & חר & $50<5$ & חר? & 398 & 0 nt & . & 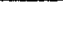 & $\mathrm{CW}$ & 1.6 & $1-3$ & 4.7 & $3-4$ \\
\hline & 120 & $30 / 00$ & $0-200$ & 3.3 & 0.421 & - & - & $\mathrm{CCW}$ & 4.7 & 3.4 & 1.6 & 1.3 \\
\hline $\begin{array}{ll}2 P F 2178 & \text { VS2PF2178 } \\
3 P N 2178 & \text { VS3PN2178 }\end{array}$ & 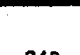 & 60 & 90 & 5 & ? & $\pi$ & -7 & CW & $1.4 ?$ & $1-3 \%$ & 1.4 & $3-4$ \\
\hline $\begin{array}{l}2178 T-V S 2178 T \\
21780\end{array}$ & $x+4$ & 00 & 0.240 & J & 1.2 & & 1.8 & CCW & $1-4$ & 3-4 & $1-4$ & $1-3$ \\
\hline
\end{tabular}

- Maximum output current in output voltage range from 0 to 25 percent above line voltage. At higher output voltages output current must be reduced according to rating curve Figure $E$.

†Maximum KVA at maximum output voltage. Maximum KVA at lower output voltages may be calculated from rating curve Figure $E$.

rCord and plug units wired this way when shipped.

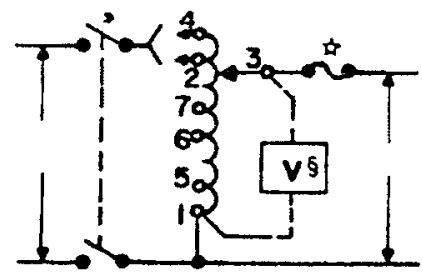

- Switch on Cord and Plus types oniy.

afiuses recommended on all units. See fusing chert for ratings.

छVoitmeter on "Vs" types oniy.

\section{MAINTENANCE}

When installed and operated in accordance with these instructions, a POWERSTAT Variable Transformer should require no servicing except possible replacement of the brush assembly. The brushes should be inspected periodically and replaced if they are badly worn. Use only the correct Superior Electric replacement brush assembly. The brushes must be of a special material if proper operation is to be attained.

\begin{tabular}{c|c}
\hline \multicolumn{2}{c}{ REPLACEMENT BRUSH ASSEMBLY } \\
\hline SERIES & $\begin{array}{c}\text { BRUSH } \\
\text { ASSEMBLY NO. }\end{array}$ \\
\hline $116 B U-40$ & RB116B-40 \\
\hline $116 \mathrm{~B}$ & RB116B \\
\hline $117 \mathrm{~B}$ & RB117B \\
\hline $216 \mathrm{~B}$ & RB216B \\
\hline $217 \mathrm{~B}$ & RB217B \\
\hline
\end{tabular}




\section{VARIABLE SPEED}

MASTERFLEX

PUMP DRIVES

7545 Series Variable Speed Drive Standard Pump Head No. 7017 Add-On Pump Head No. 7017-20

Cole Parmer Instrument Co. 7425 N. Oas Park Avenue Chicago, Illinois 60648

A-1299-4

EDITION 4675

Reprinted with Permission from Cole Parmer Instrument Co. 


\section{DESCRIPTION}

Masterflex variable speed drives are available in several configurations; the drive and controller alone or packaged in kits containing an assortment of pump heads. Several gear ratios are offered, and the systems can be purchased for use on either $115 \mathrm{~V} \mathrm{AC}$ or $230 \mathrm{~V} A C$, 50-60 HZ. All of the systems use the same type of solid state speed control circuit, with some differences between the $115 \mathrm{~V}$ and $230 \mathrm{~V}$ units.

The drives connect directiy to the pump heads. The Masterflex pumps are carefully engineered peristaltic pumps that accept a continuous length of tubing for contamination free pumping. The liquid only contacts the tubing and not the other pump parts. The pump can be used for gases, liquids, and vacuum applications. They are completely self-priming. A highly efficient three roller rotor assembly is used within a uniquely designed, polycarbonate housing. As many as ten pumps can be operated with one drive, depending on the type of tubing and speeds desired.

\section{OPERATION}

Operation of the variable speed drive is simple: select and install the desired pump head and tubing, connect the drive to the controller, and connect the controller line cord to a grounded, three wire AC receptacle. Adjust the speed control knob to the desired speed. If necessary, use the reversing switch to change the direction of the pump's rotation (stop the pump before changing the direction).

A few cautionary notes must be added. The speed control knob graduations are for reference only; 
they are not calibrated. Some drives will not start to rotate until the knob is at position ' 4 '. This is caused by component tolerances and is a normal condition. Speeds slower than the stated minimum speed can be obtained but they are not recommended. The motor would operate at a higher temperature, and the speed regulation circuit would allow greater fluctuations in the speed and hence the pump flow. Care should be taken, when using the rotation reversing switch, to make sure that the pump is brought to a full stop before reversing rotation. Failure to bring the pump to a full stop may cause an overload condition that will resuli in blowing the controller fuse and perhaps other electronic components. Do not replace the fuse with one of a higher rating. That would increase the possibility of component failure.

\section{MULTIPLE HEAD USAGE}

The variable speed drives and pump heads have been designed so that the drives can operate several heads, at once; the number dependent on the drive and type of tubing used. A list is provided with the drives and the recommended maximum number of pump heads that each can operate. This assumes that standard Tygon, Silicone, or Viton tubing is used. 'Food Grade' Tygon tubing requires approximately twice the torque as the standard Tygon, and this reduces the capacity of the drives by fifty percent. Hence, 7545-10 drives, using Food Grade Tyoon should be limited to five heads. Standard heads attach directly to the drive, while Add-Cn reads attach only to other heads, either Standard or Add-On. Use a Standard head as the firs $t$ channel and Add-On rieads for additiona? channels in multiple channel applications. 


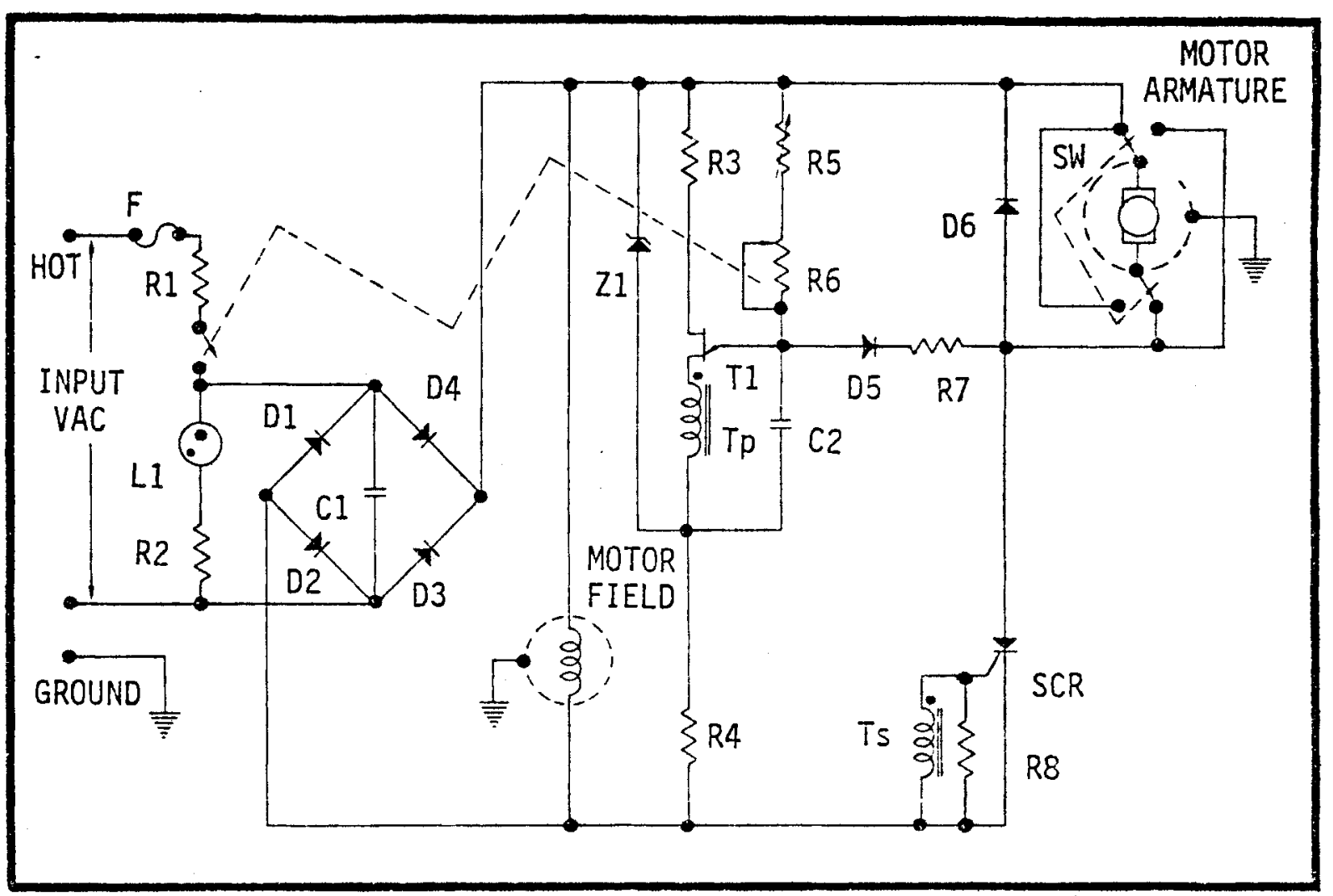

VARIABLE SPEED MASTERFLEX SCHEMATIC 
CONTROLLER PARTS LIST NO. 1

$230 \vee$ AC 50-60 HZ (7546, 7546-10)

\begin{tabular}{|c|c|c|}
\hline SYMBOL & PART NO. & ITEM \\
\hline $\mathrm{F}$ & $B-1115-8$ & 0.75 A-SLO-BLOW FUSE \\
\hline R1 & $B-1113-52$ & 2 OHM 10W \\
\hline R2 & $B-1113-43$ & $56 \mathrm{~K}$ \\
\hline R3 & B-11:3-108 & $680 \mathrm{OHM}$ \\
\hline R4 & B-1113-111 & $8 K, 8 w$ \\
\hline R5 & $B-1117-10$ & $4.7 \mathrm{~K}$ TRIM \\
\hline R6 & $B-1117-2$ & 25K SPEED CONTROL \\
\hline R7 & $B-1113-110$ & $82 \mathrm{k}, 5 \%$ \\
\hline R8 & $B-11: 3-2$ & 47 OHM \\
\hline LI & $A-1067$ & NEON LAMP \\
\hline D1 to D4 & $B-1119-7$ & $2.5 \mathrm{~A}, 1000 \mathrm{~V}$ DIODE \\
\hline $\mathrm{D} 5, \mathrm{D} 6$ & $B-1119-2$ & 1.0A, 10COV DIODE \\
\hline $\mathrm{Cl}$ & $B-1114-29$ & 0.1 MFD. $400 \mathrm{~V}$ \\
\hline C2 & $B-1114-19$ & 0.47 MFD $250 \mathrm{~V}$ \\
\hline $\mathrm{Z1}$ & $8-1126-7$ & 12V, 1W, ZENER \\
\hline $\mathrm{T} 1$ & $B-1118-2$ & UNIJUNCTION 2N1671 \\
\hline TP TS & $A-1103$ & PULSE TRANSFORMER \\
\hline SCR & $8-1120-6$ & SCR $\quad 2 A, 600 \mathrm{~V}$ \\
\hline
\end{tabular}


CONTROLLER PARTS LIST NO. 2

115V AC 50-60 HZ (7545, 7545-10)

\begin{tabular}{|l|l|l|}
\hline SYMBOL & PART NO. & \multicolumn{1}{|c|}{ ITEM } \\
\hline F & B-1115-3 & 1.5 A SLO-BLOW FUSE \\
\hline R1 & B-1113-64 & 4 OHM 10W \\
\hline R2 & & 0 OHM \\
\hline$R 4$ & B-1113-109 & $4 K, 5 W$ \\
\hline$R 7$ & B-1113-105 & $43 K, 5 \%$ \\
\hline C1 & B-1114-13 & 0.1 MFD, 250V \\
\hline SCR & B-1120-3 & SCR 2A, 200V \\
\hline
\end{tabular}

The other components are the same as in 7546 a 11 resistors $10 \%, \frac{1}{2} \mathrm{~W}$ unless otherwise noted 
ML* PER REVOLUTION

\begin{tabular}{ll|ll}
\hline 7013 & 0.06 & 7015 & 1.67 \\
7014 & 0.21 & 7017 & 2.80 \\
7016 & 0.80 & 7018 & 3.80
\end{tabular}

*approximate flow

PUMP SYSTEMS

\begin{tabular}{|c|c|c|c|}
\hline $\begin{array}{l}\text { CATALOG } \\
\text { NUMBER }\end{array}$ & DESCRIPTION & $\begin{array}{l}\text { SPEED } \\
\text { RANGE } \\
\text { RPM }\end{array}$ & $\begin{array}{l}\text { MAXIMUM } \\
\text { NUMBER OF } \\
\text { PUMPS }\end{array}$ \\
\hline 7545 & $\begin{array}{l}\text { 115V-AC-MOTOR \& } \\
\text { CONTROLLER }\end{array}$ & 30 to 600 & 2 \\
\hline $7545-10$ & $\begin{array}{l}\text { 115V-AC-MOTOR \& } \\
\text { CONTROLLER }\end{array}$ & 5 to 100 & 10 \\
\hline 7546 & $\begin{array}{l}\text { 230V-AC-MOTOR \& } \\
\text { CONTROLLER }\end{array}$ & 30 to 600 & 2 \\
\hline $7546-10$ & $\begin{array}{l}\text { 230V-AC-MOTOR \& } \\
\text { CONTROLLER }\end{array}$ & 5 to 100 & 10 \\
\hline $7550-45$ & $\begin{array}{l}\text { KIT: } 7545 \& 4 \\
\text { PUMP HEADS }\end{array}$ & 30 to 600 & 2 \\
\hline $7550-46$ & $\begin{array}{l}\text { KIT: } 7546 \& 4 \\
\text { PUMP HEADS }\end{array}$ & 30 to 600 & 2 \\
\hline $7550-85$ & $\begin{array}{l}\text { KIT: } 7545 \& 8 \\
\text { PUMP HEADS }\end{array}$ & 30 to 600 & 2 \\
\hline $7550-86$ & $\begin{array}{l}\text { KIT: } 7546 \& 8 \\
\text { PUMP HEADS }\end{array}$ & 30 to 600 & 2 \\
\hline
\end{tabular}

A1] systems operate on 50 or $60 \mathrm{HZ}$ 
PUMP ROTOR REPLACEMENT

Each rotor assembly has three cylindrical rollers held between two circular discs. These rollers compress the tubing and force the liquid along the tubing as the rotor assembly rotates. The 7015 pump has a rotor which is different from the rotors in the other pump heads. The rollers of the 7015 rotor are flush with the outer edge of the circular discs. The rollers of the other pump heads extend approximately 1/16"beyond the outer edge of the discs. If the wrong rotor is used in any of the pump heads, improper tubing occlusion will occur.

MASTERFLEX PUMP HEAD MOUNTING HARDWARE

(Plated Steel)

For 7013 to 7018 Series Pumps

Part No.

Description

B-1238-3

For 1 channel

$B-1238-8$

For 2 channels

B-1238-6

For 3 channels

B-1238-7

For 4 channels

B-1238-16-CR

For 5 channels

$B-1238-17-C R$

For 6 channels

$B-1238-18-C R$

For 7 channels

B-1238-19-CR

For 8 channels

B-1238-20-CR

For 9 channels

B-1238-21-CR

For 10 channels

MASTERFLEX PUMP HEAD MOUNTING HARDWARE (Stainless Steel)

$B-1238-9$

For 1 channel

B-1238-10

For 2 channels 
MASTERFLEX PUMP REPLACEMENT PARTS

(Metai parts are plated steel)

\begin{tabular}{|c|c|c|c|}
\hline $\begin{array}{c}\text { STANDARD } \\
\text { PUMP } \\
\text { HEAD }\end{array}$ & $\begin{array}{c}\text { ADD-ON } \\
\text { PUMP } \\
\text { HEAD }\end{array}$ & $\begin{array}{c}\text { PLASTIC } \\
\text { PUPAP } \\
\text { HEAD } \\
\text { SECTION }\end{array}$ & $\begin{array}{c}\text { ROTOR } \\
\text { ASSEMBLY }\end{array}$ \\
\hline 7013 & & A-1106-2 & B-1061-1 \\
\hline & $7013-20$ & A-1106-2 & B-1289-1 \\
\hline 7014 & & $A-1106-3$ & $B-1061-1$ \\
\hline 7016 & $7014-20$ & $A-1106-3$ & $B-1289-1$ \\
\hline & $7016-20$ & $A-1106-5$ & $B-1289-1$ \\
\hline 7015 & & $A-1106-1$ & $B-1061$ \\
\hline & $7015-20$ & $A-1106-1$ & $B-1289-2$ \\
\hline 7017 & & $A-1106-4$ & $B-1061-1$ \\
\hline & $7017-20$ & $A-1106-4$ & $B-1289-1$ \\
\hline 7018 & & $A-1106-6$ & $B-1061-1$ \\
\hline & $7018-20$ & $A-1106-6$ & $B-1289-1$ \\
\hline & & & \\
\hline
\end{tabular}

A11 rotor assemblies use tefion thrust washers, A-1184. 
MASTERFLEX PUMP REPLACEMENT PARTS

(Metal parts are Stainless Steel)

\begin{tabular}{|c|c|c|c|}
\hline $\begin{array}{c}\text { STANDARD } \\
\text { PUMP } \\
\text { HEAD }\end{array}$ & $\begin{array}{c}\text { ADD-ON } \\
\text { PUMP } \\
\text { HEAD }\end{array}$ & $\begin{array}{c}\text { PLASTIC } \\
\text { PUMP } \\
\text { HEAD } \\
\text { SECTION }\end{array}$ & $\begin{array}{c}\text { ROTOR } \\
\text { ASSEMBLY }\end{array}$ \\
\hline $7013-10$ & & A-1400-1 & B-1290-1 \\
\hline & $7013-21$ & A-1400-1 & B-1291-1 \\
\hline $7014-10$ & & A-1400-2 & B-1290-1 \\
\hline $7016-10$ & $7014-21$ & A-1400-2 & B-1291-1 \\
\hline & $7016-21$ & A-1400-5 & B-1291-1 \\
\hline $7015-10$ & & A-1400-3 & B-1290-2 \\
\hline & $7015-21$ & A-1400-3 & B-1291-2 \\
\hline $7017-10$ & & A-1400-4 & B-1290-1 \\
\hline & $7017-21$ & A-1400-4 & B-1291-1 \\
\hline $7018-10$ & & A-1400-6 & B-1290-1 \\
\hline & $7018-21$ & A-1400-6 & B-1291-1 \\
\hline
\end{tabular}

A17 rotor assemblies use teflon thrust washers, A-1184. 
MOTOR REPAIR PARTS

\begin{tabular}{|c|c|c|}
\hline ITEM & PART NO. & DRIVE \\
\hline $\begin{array}{l}\text { MOTOR BRUSHES } \\
\text { (set of 2) }\end{array}$ & $A-1138-C R$ & $\begin{array}{l}7545,7545-10 \\
7546,7546-10\end{array}$ \\
\hline BRUSH CAP & $A-1791-C R$ & $\begin{array}{l}\text { ALL DRIVES NOTED } \\
\text { ABOVE }\end{array}$ \\
\hline $\begin{array}{l}\text { GEAR CASE } \\
\text { GASKET }\end{array}$ & B-1467 & $\begin{array}{l}\text { ALL DRIVES NOTED } \\
\text { ABOVE }\end{array}$ \\
\hline ARMATURE & $\begin{array}{l}A-1793-C R^{\star} \\
A-1808-C R^{* *}\end{array}$ & 7545 \\
\hline ARMATURE & $A-1808-C R$ & $7545-10$ \\
\hline ARMATURE & $\begin{array}{l}A-1792-C R^{*} \\
A-1809-C R^{* *}\end{array}$ & 7546 \\
\hline ARMATURE & $A-1809-C R$ & $7546-10$ \\
\hline $\begin{array}{l}\text { OUTPUT GEAR } \\
\text { ASSEMBLY }\end{array}$ & $7545-06$ & 7545,7546 \\
\hline $\begin{array}{l}\text { OUTPUT GEAR } \\
\text { ASSEMBLY }\end{array}$ & $B-1125$ & $7545-10,7546-10$ \\
\hline COMPOUND GEAR & $B-1127$ & $7545-10,7546-10$ \\
\hline
\end{tabular}

NOTE:

* VERSION A (OVERALL LENGTH $=6.453^{\prime \prime}$ )
* VERSION B (OVERALL LENGTH=6.143") 


\section{MAINTENANCE}

The speed control circuit has solid state comonents which do not require servicing. A tubing rupture may result in a motor overload which could cause some electrical parts to fail.

The rear motor bearing should be given two drops of \#20 non detergent oil every three months. Do not over-oil. Exact motor brush and communator life will depend on the speed and the number of pump heads. Brushes should be inspected and replaced when less than $0.300^{\prime \prime}$ long. The communator should be periodically inspected and cleaned if necessary. If preventive maintenance is not performed, excessive communator wear or 'bridging' between communator segments will cause excessive current through the controller circuit.

\section{WARRANTY}

The Cole-Parmer Instrument Company warrants the product to be free from defects in material and workmanship for a period of six months. If repair or adjustment is necessary and has not been the result of abuse or misuse within the six month period, please return, freight prepaid, and correction of the defect will be made without charge (see note on return of items.)

For your protection, items being returned must be carefully packed to prevent damage in shipment and insured against possible damage or loss. Cole-Parmer will not be responsible for damage resulting from careless or insufficient packing.

Out of warranty products will be repaired for a nominal charge. 


\section{RETURN OF ITEMS}

Authorization must be obtained from our Customer Service Department before returning items for any reason. When applying for authorization, please include data regarding the reason the items are to be returned. A $15 \%$ restocking charge will be made on all unauthorized returns.

\section{NOTE}

Technical information and advice on the use of the product in specific applications may be obtained. Modifications can be made to adapt the unit to special customer applications. Contact the Engineering Department for information.

The Cole-Parmer Instrument Company reserves the right to make improvements in design, construction and appearance of our products without notice. 

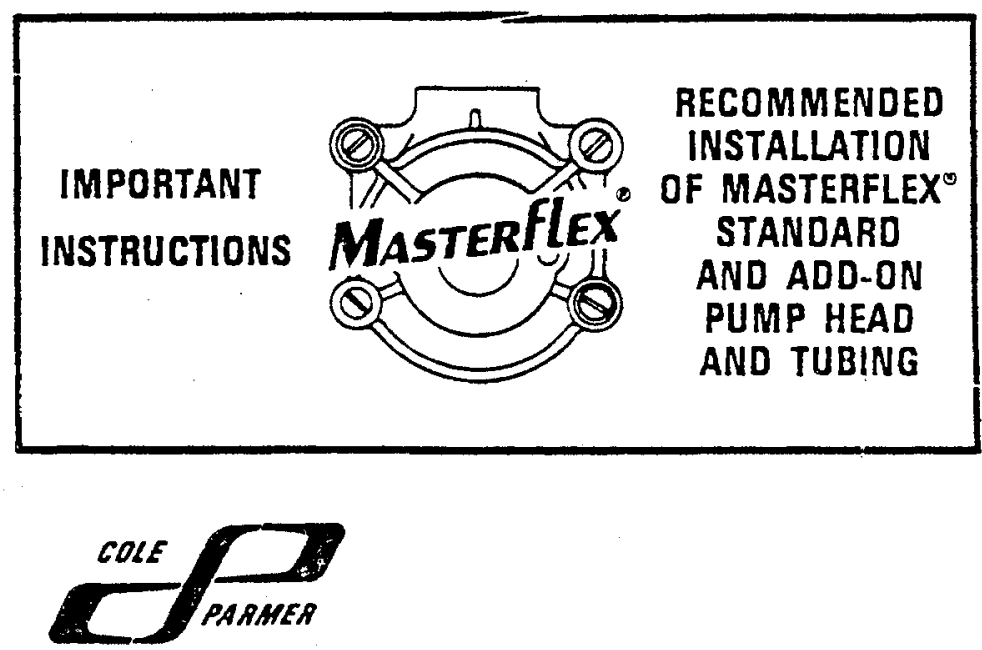

\section{COLE-PARMER INSTRUMENT COMPANY}

7425 NORTH OAK PARK AVE. CHICAGO, ILLNOIS 60648 312/647-0272

ERETM-COLE-PARMER

P306-75410

Standard Pump Head No. 7017

Add-On Pump Head No. 7017-20

Reprinted with Permission from cole Parmer Instrument co. 


\title{
MASTERFLEX ${ }^{\circledR}$ TUBING CHARACTERISTICS
}

\begin{abstract}
Proper performance of Masterflex Pumps requires correct tubing selection. Tubing listed below has been custom made to stringent specisications and is offered for its compatibility with these pumps. Use of tubing other than recommended may result in premature tubing failure, tubing slippage, decreased pressure and vacuum characteristics, and I or other malfunction.

Technical assistance in selecting the appropriate pump head size and correct tubing is available on request.

To select the tubing suited to your requirements, first check the applications table below for general characteristics of Masterflex tubing materials. Once the proper tubing material has been cetermined, specify that tubing from the lubing ordering information table for the pump head size to be used.

Operating temperature ranges for the various tubing materials are as follows: $\neq 6.408$ Tygor, $-20^{\circ}$ to $+165^{\circ} \bar{F}_{;}: 8401$ Tygon Soecial, $+10^{\circ}$ to $-180^{\circ} \mathrm{F}$; $\div 6419$ Tygon Focd and $\# 6415$ Tygon Sterile, $0^{\circ}$ to $+130^{\circ} \mathrm{F}:=6411$ Silicone, $-80^{\circ}$ to $+500^{\circ} \mathrm{F}$; and $\$ E 412$ Viton, $-10^{\circ}$ to $\div 400^{\circ} \mathrm{F}$.
\end{abstract}

Tygon Sterile tubing and Silicore tubing are medicai grade. Both are non-toxic and non-reactive to blcod, tissues, etc. The $\# 6408$ Tygon and $\# 6419$ Tygon Food tubirgis are non-toxic. Silicone tubing and all Tygon tubings (except Tygon Special) are autcclavable. Tygon Sterile tubing is supplied autoclaved, sterilized, and packageo in 10-foot lengths. \#6411 Silicone tubing provides maximum tubirg life (assuming circulant compatibitity) and most stable flow characteristics. Life of this tubing is consistently 150 hours or more at $550 \mathrm{rpm}$ (450 hours or more at $200 \mathrm{rpm}$ )".

Lite of $\# 6408$ Ty'gon tubing and \#6401 Tygon Special tubing is about 50 hours at $550 \mathrm{rpm}$. $\# 6419$ Tygon Food tubing and $\# 6415$ Tygon Sterile tubing life is about 40 nours at $550 \mathrm{rpm}$. Viton tubing life is about 30 hours at 550 rpm.

Life of a given section of tubing is inversely proportional to pump speed. In general, reducing the pump speed by $1 / 2$ will approximately double the tubing life.

-Except for $\$ 6411-09$ sillsone fubing with a 70 -hour life at 550 rom. 
Wear or fatigue of tubing is normal in any tubing pump; Masterflex Pump Heads are designed to minimize such wear and provide longer tubing life than competitive units. Assuming compatibility with fluid being pumped, three basic factors influence tubing life: (1) pump speed, (2) tubing material, and (3) tubing dimensional tolerances.

Pump Speed. Any given tubing is capable of undergoing a finite number of compressive cycles before fatiguing and eventual failure. Therefore, it is generally advisable to select a larger size Masterflex Pump Head to be run at lower speeds rather than a small size to be run at high speed.

Tubing Material. No. 6411 Silicone tubing provides about $300 \%$ greater tubing life than Tygon; No. 6412 Viton tubing may be expected to provide about $60 \%$ the life of Tygon tubing.

Tubing Dimensional Tolerances. Proper performance of Masterflex Pumps requires correct tubing selection. Loose tolerance tubing will cause overstress and premature failure of tubing. We strongly recommend use of Masterflex Tubing only.

\section{TUBING RECOMMENDATIONS FOR MASTERFLEX PUMPS}

NOTE: The applications table at right should be used to match tubing characteristics with the requirements of a specific application. Always specify catalog number suffix to indicate tubing size. Ratings in the table are generalized and based on average applications. A sample of tubing should always be subjected to immersion tests in the fluid to be pumped before ordering required quantities. If such tests indicate incompatibility, our engineering staff can assist you in selecting special tubing materials.

\begin{tabular}{|c|c|c|c|c|c|c|c|c|}
\hline \multicolumn{3}{|c|}{$\begin{array}{l}\text { TUBING TYPE } \\
\text { AND CATALOQ NUMBER }\end{array}$} & $\underset{6408}{\text { TrGON }}$ & $\begin{array}{c}\text { TYGON } \\
6401\end{array}$ & $\begin{array}{c}\text { TYGON } \\
\text { 6419 }\end{array}$ & $\begin{array}{c}\text { TYGON } \\
\text { 6415 }\end{array}$ & $\underset{\text { SA14 }}{\text { SILICONE }}$ & $\begin{array}{l}\text { VITON } \\
6412\end{array}$ \\
\hline \multirow{3}{*}{$\begin{array}{l}A \\
P \\
0\end{array}$} & \multicolumn{2}{|c|}{ PRESSURE } & 6 & $a$ & $a$ & a & $a$ & $E$ \\
\hline & \multicolumn{2}{|l|}{ VACUUM } & $a$ & a & $\mathbf{G}$ & G & $\bar{E}$ & $\bar{F}$ \\
\hline & CORPOSIVES & $A C I D$ & a & $\mathbf{F}$ & $=$ & $=$ & $\bar{F}$ & $\bar{E}$ \\
\hline \multirow{2}{*}{$\begin{array}{l}\mathbf{P} \\
\mathbf{L}\end{array}$} & COAHOSIVES & BASE & $\mathbf{a}$ & $\mathbf{P}$ & $=$ & - & $\mathbf{F}$ & $\bar{E}$ \\
\hline & \multirow[b]{2}{*}{ SOLVENTS } & GENEAAL & $\mathbf{a}$ & $\mathbf{G}$ & $=$ & $=$ & $\bar{F}$ & $\bar{E}$ \\
\hline $\begin{array}{l}1 \\
\text { c }\end{array}$ & & $\begin{array}{l}\text { HIGHLY } \\
\text { ACTIVE }\end{array}$ & $\mathbf{F}$ & $\mathbf{F}$ & - & - & $\mathbf{F}$ & G \\
\hline \multirow{3}{*}{$\begin{array}{l}\text { A } \\
\mathbf{T} \\
1\end{array}$} & \multirow{3}{*}{ TEMPERATUAE } & HIGH & $\bar{F}$ & $\bar{F}$ & FQA & FEA & EAA & $\bar{E}$ \\
\hline & & LOW & $\mathbf{G}$ & $F$ & $F$ & $F$ & $E$ & $F$ \\
\hline & & EXTRA LOW & N/A & $\mathrm{N} / \mathrm{A}$ & N/R & N/R & $E$ & N/R \\
\hline 0 & \multicolumn{2}{|l|}{ SPECIAL } & - & * & Food** & Medleal ** & $\begin{array}{l}\text { Food:*: } \\
\text { Modical }\end{array}$ & - \\
\hline $\mathbf{N}$ & \multicolumn{2}{|l|}{ TUBINO LIFE } & $\mathbf{G}$ & $\mathbf{a}$ & $\mathbf{a}$ & a & $E$ & $\bar{F}$ \\
\hline
\end{tabular}

Emexcellent $G=g o o d \quad P=p o o r \quad A=a u t o c l a v a b l e$

Especlally sulted for gesolines, fuels, olls and lubricants
$N / R=$ not recommended - Meet USDA apeciflcations

\begin{tabular}{|c|c|c|c|c|c|c|c|c|c|c|c|c|c|}
\hline \multirow{2}{*}{$\begin{array}{c}\text { FOR ALL } \\
\text { PUMP HEAD } \\
\text { PREFIX NOS. }\end{array}$} & \multirow{2}{*}{$\begin{array}{l}\text { TUBING } \\
\text { SIZE" } \\
\text { ID"XOD" }\end{array}$} & \multicolumn{2}{|c|}{ Tygon } & \multicolumn{2}{|c|}{ Tygon Speclal } & \multicolumn{2}{|c|}{ Tygon Food } & \multicolumn{2}{|c|}{ Tygon sterllo"* } & \multicolumn{2}{|c|}{ Slllcone"th } & \multicolumn{2}{|c|}{ Vitan } \\
\hline & & $\begin{array}{l}\text { Cat. } \\
\text { No. } \\
\end{array}$ & $\begin{array}{c}\text { Per } \\
50-F t .\end{array}$ & $\begin{array}{l}\text { Cat. } \\
\text { No. }\end{array}$ & $\begin{array}{l}\text { Per } \\
\text { 50-Ft. }\end{array}$ & $\begin{array}{l}\text { Cat. } \\
\text { No. }\end{array}$ & $\begin{array}{c}\text { Per } \\
50-\mathrm{Fl}\end{array}$ & $\begin{array}{l}\text { Cat. } \\
\text { No. }\end{array}$ & $\begin{array}{c}\text { Per } \\
10 . \mathrm{Ft}\end{array}$ & $\begin{array}{l}\text { Cat. } \\
\text { No. }\end{array}$ & $\begin{array}{c}\text { Per } \\
25 . \mathrm{Ft} \text {. }\end{array}$ & $\begin{array}{l}\text { Cat. } \\
\text { No. }\end{array}$ & $\begin{array}{l}\text { Per } \\
\text { Foot }\end{array}$ \\
\hline 7013 & $0.0315 \times 0.1625$ & $8408-41$ & $\$ 11.00$ & 6401.41 & $\$ 11.00$ & $5419-41$ & $\$ 11.00$ & - & - & $6411-41$ & $\$ 13.75$ & $6412-41$ & $\$ 0.90$ \\
\hline 7014- & $0.0655 \times 0.1945$ & $8408-43$ & 11.00 & $6401-43$ & 11.00 & $5419-43$ & 11.00 & - & $=$ & $6411-43$ & 15.00 & $6412-43$ & 1.75 \\
\hline $7015=$ & $0.1250 \times 0.2510$ & $6408-02$ & 12.00 & $5401-44$ & 12.00 & $6419-02$ & 12.00 & - & - & $6411-02$ & 17.50 & 6412.44 & 1.95 \\
\hline $7015-$ & $0.1925 \times 0.3920$ & $6408-45$ & 22.00 & $6401-45$ & 22.00 & $6 \overline{419-45}$ & 22.00 & $6415-30$ & 5.34 & $6411-45$ & 20.00 & $6412-45$ & 4.10 \\
\hline 7017. & $0.2550 \times 0.3900$ & $5408-05$ & 20.00 & 6401.47 & 20.00 & $\$ 419-06$ & 20.00 & 6415.40 & 4.88 & 6411.47 & 18.75 & 6412.47 & 3.30 \\
\hline $7018-$ & $0.3130 \times 0.4390$ & $5408-09$ & 23.50 & $6401-48$ & 23.50 & 6419.09 & 23.50 & - & - & $6411-09$ & 21.25 & $6412-48$ & 3.40 \\
\hline
\end{tabular}

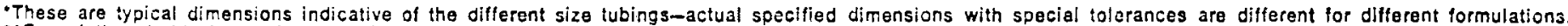
- Essecially stitable tor medical, surgical, and charmaceutical applications-Tygon Sterile is supplied in pre-sterilized io-foot lengths.

-..ilaximum continunus length of Silicone tubing is 25 feot. 


\section{INSTALLATION OF MASTERFLEX STANDARD PUMP HEAD AND TUBING}

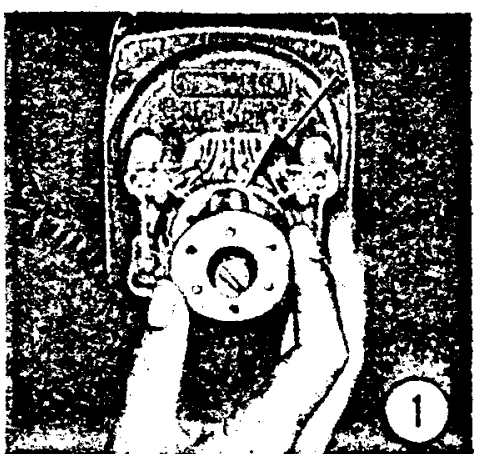

Aline either of the iwo interchange. able halves of the pump head with the two oins protruding from the face of the drive unit. Attach in position with the two fillister head screws provided, placing the screws through the iwo diagonally opposed recessed holes. install the longer end of the rotor assembly shaft through the pump head bearing and fully mate the shatt cross slot with the drive unit shear pin by rotating the shaft while exerting gentle pressure inwards; mating will bo indicated by complete seating of the rotor assembly within the head. Ro. tate the rotor assembly to position one of the rollers between the tubing intat and outlet recesses molded into itic head.

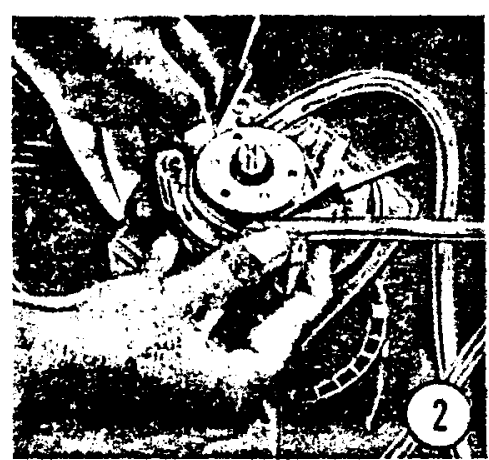

While maintaining the position of one of the rotor assembly rollers between the tubing recesses, position the tubing abou: the other two rollers and press the tubing cownwards with the thumbs until the tubing is fully seated within the pump head cavity and rollers. On large diameter tubing and tubings of higher Shore durometer ratings a tongua depressor or similar object may be used to assist full seating of the tubing. CAUTION: Use of hard or sharp objects such as screwdrivers may damaga both the tubing and the pump head.

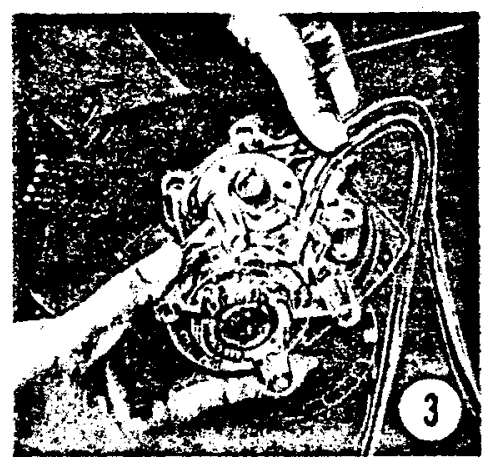

When the tubing has been fully seated within the pump head savity and the two rollers, hold the free ends of the tubing in the head inlet and outlet recesses and, while exerting a slight iension on the tubing ends, place the remaining half of the pump head over the rotor assembly shaft and against the installed pump head half. CAUTION: Failure to hold slight tension on the tubing may result in excess tubing slack within the pump head that may cause binding and shearing of the drive unit shear pin.

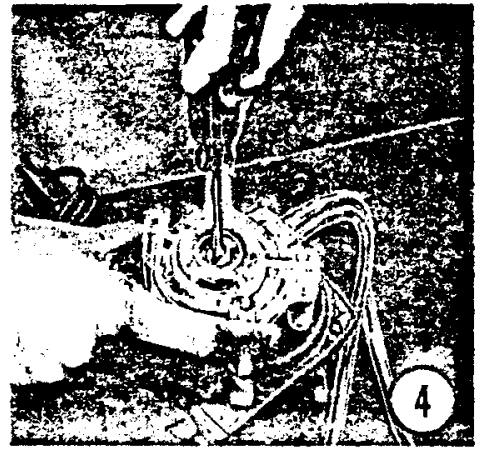

While pressing gently inward on the outer pump head half, rolate the rotor assembly shaft with a screwdrivor to ensure that the rotor assembly is fully seated with the drive unit shalt, that no gap remains between the intorfaces of the two pump head halves, and that there is no binding between the tubing and the rollers of the rotor assembly. CAUTION: Failure to ensure this proper seating before operating the pump may result in damage to both the drive unit gearing and shear pin.

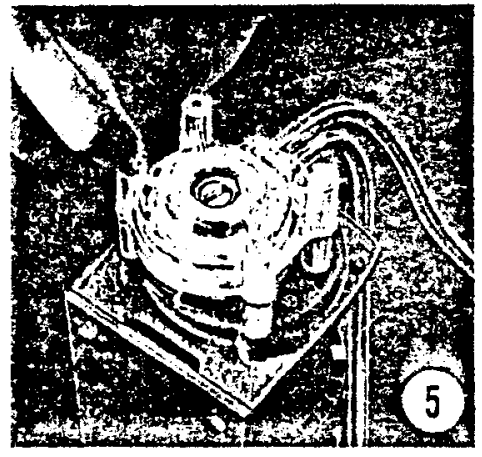

Using the two thumbscrews and flat washers provided, insert those attaching parts in the two mounting holes not occupled by the initially installed scrows and, using finger pressure only, attach the assembled pump hoad to the drive unit. CAUTION: Excessive torque on any of the four screws may cuuse distortion and cracking of the pump head.

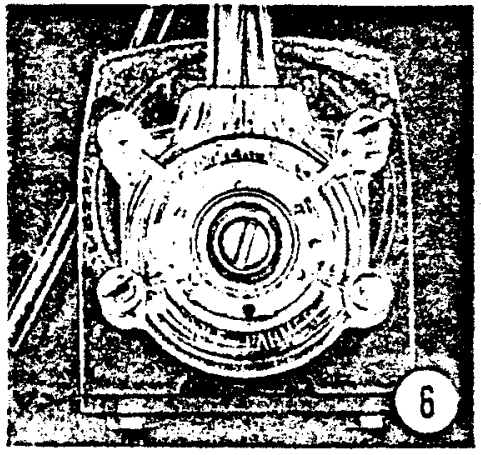

The pump head is now properly installed and ready for operation. If a subsequent change of tubing is de. sired, complete removal of the pump head is not necessary. Merely remove the two thumbscrows, washers, outer pump head half and tubing, and repeat steps one through five.

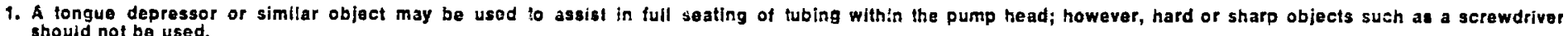

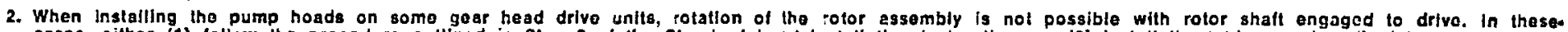

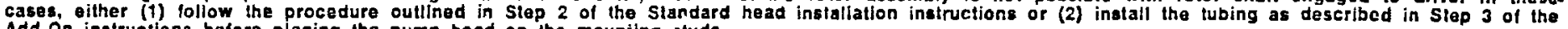
Add-On instructions betore placing the pump head on the mounilng studs. 


\section{INSTALLATION OF MASTERFLEX ${ }^{\circ}$ ADD-ON PUMP MEAD AND TUBING}
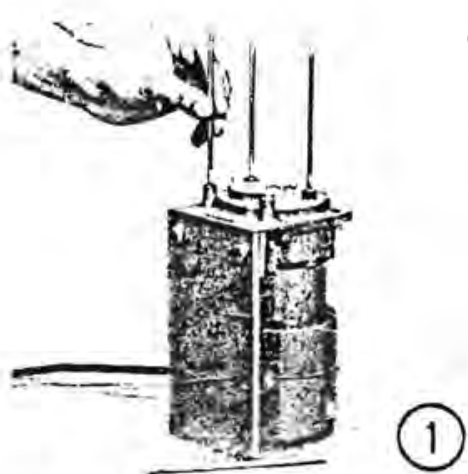

This Add-On head is packed complete with all hardware required for mounting on a Standard Masterflex head. For multi-channel applications, with more than one Add-On head. longer studs will be required. These will be supplied at no charge on request (please specify configuration i.e. three or four channel application).

To install, insert (finger-tight) each of the four studs inlo the motor face.

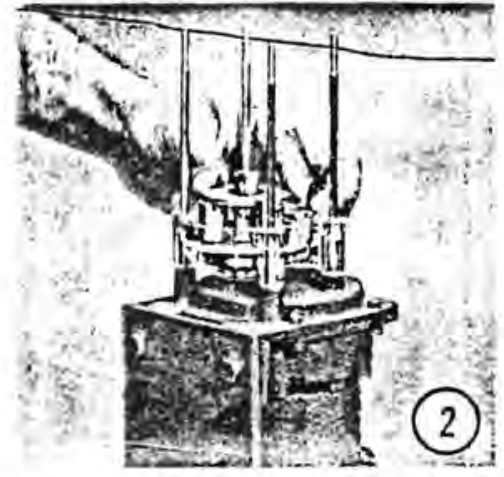

Place either of the two Interchangeable halves of the Standard pump head on the studs, alining the head with the two pins , alining the head face of the drive unit. Install the longer end of the Standard rotor assembly shaft through the pump head bearing and fully mate the shaft cross stot with the drive unit shear pin by rotating the shaft while exerting a slight prossuro inward. Mating will be indicated by complele soating of the rotor assembly within the head.

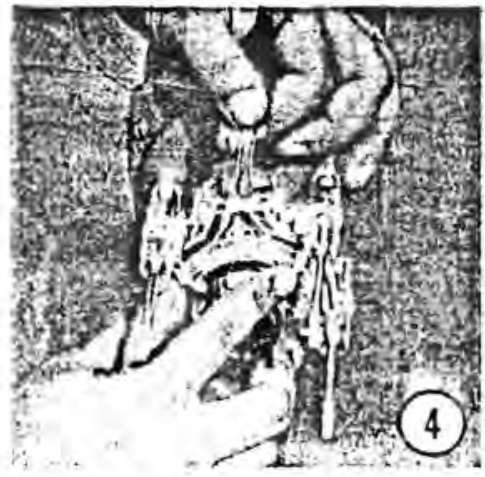

When the fubing has been fully seated, hold the free ends of tubing in the head inlet and outlet recesses and whlie exerting a slight tension on the tubing ends, place the remaining half of the Standard pump head over the rotor assembly shaft and against the installed pump head half. CAUTION: Failure to hold slight tension on the lubing may result in excess tublng slack within the pump head that may cause blnding and shearing of the drive unit shear pin.

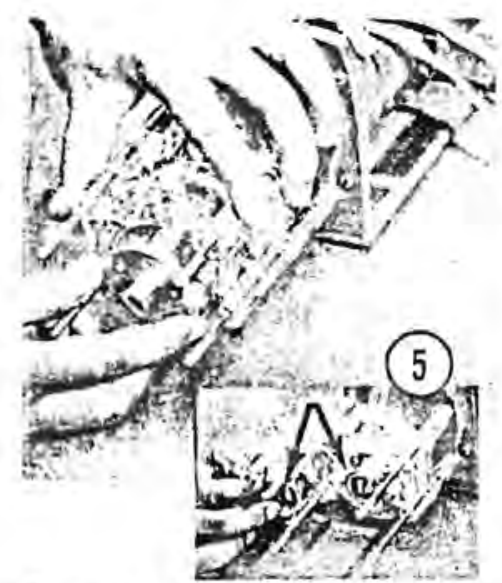

Place either of the two interchangeable halves of the "Add-On" pump head on the mounting studs, in contact with the Standard head already installed. Then place the non-slotted end of the "Add-On" rotor assembly into the pump head bearing and mate the shaft with the cross slot of the shaft previousiy installed by rotating with slight inward pressure. Then repeat steps (3) and (4).

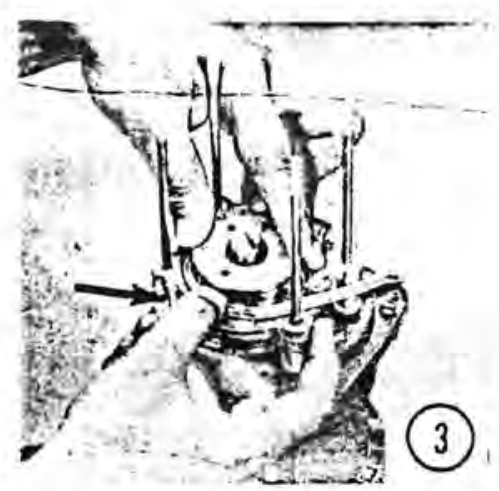

Install the tubing by positioning it around the roliers and rotating the rotor assembly with one hand while depressing the tubirg ahead of the rollers with the thumb of the other hand (see illustration above). Continue this rotation until the tubing is fully seated within the head cavity and rollers. A tongue depressor or similar object may bo used to assist full soating if necessary.

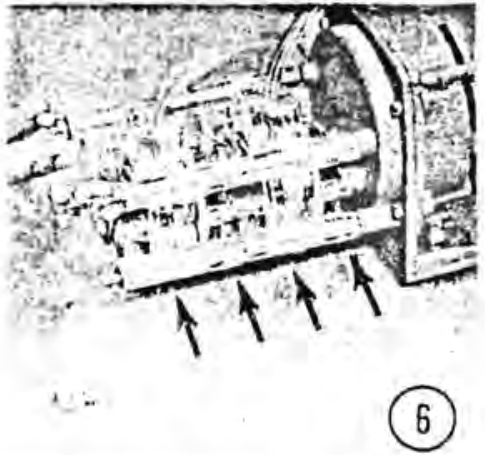

After chocking to be sure there is no space at any of the pump head interfaces, install the four wingnuts using finger pressure only. CAUTION: EXcessive tightening of any of the wingnuts may cause distortion of the pump heads.

NOTE: For multi-channel appl cations. repeat step (5) for as manv "Add-On" heads that are to be useo before attaching wingnuts. 


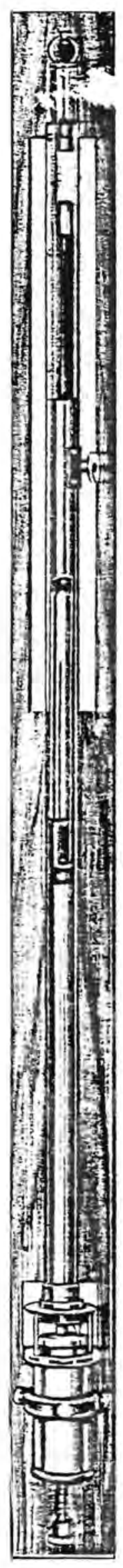

\title{
INSTRUCTION BOOKLET
}

for uso with

\section{U.S. SIGNAL CORPS TYPE BAROMHTERS}

\author{
Manujactured by \\ PRINCO INSTRUMENTS, INC. \\ 1020 Industrial Highway \\ Southampton, Pa. 18966
}

Reprinted with permission from Princo Instrunents, Inc. 


\section{THE "PRINCO" BAROMETER}

The "Princo" Standard Mercurial Barometer, U.S. Signal Corps type, is a Fortin type barometer. The glass tube is closed at the top, open at the bottom. The open end extends into the reservoir. The reservoir is so constructed that the level of the mercury within may be raised or lowered. A lower portion of the reservoir consists of a flexible chamois skin bag. Projecting from the bottom of the reservoir casing is a milled head adjusting screw. By means of the adjusting screw the mercury level is lowered or raised, permitting adjustment of the mercury level to the zero point. Further, the air in the reservoir can be expelled by means of the same screw. An ivory point projecting downward from the top of the cistern forms the fixed and definite zero point. It is to this zero point that the level of the mercury in the cistern is adjusted when taking readings.

The barometer tube is enclosed in a metal casing partially fenestrated at the upper end, exposing to view the glass tube and mercury column. The scale of the barometer is engraved on a separate metal strip attached to the metal casing opposite the fenestration. The scale is equipped with a vernier operated by a smoothly working rack and pinion movement. Attached to the metal casing is a thermometer.

The barometer is furnished with a mounting panel. The panel is equipped with white reflectors to facilitate observation of the cistern and mercury meniscus. A suspension post and a centering ring provide the means of mounting the barometer vertically on the panel.

\section{UNPACKING AND SETTING UP}

A barometer is a very delicate instrument and should be handled with great care. It is shipped with the glass tube completely full of mercury. Should the barometer arrive at its destination broken, notify the carrier at once so that their inspector may call to examine the damaged instrument and the manner in which it was packed and marked for shipment.

Keep the barometer in a horizontal position until the barometer board is prepared for its reception. Then carefully and slowly turn the barometer right side up. First place the reservoir through the centering ring at the lower end of the board before passing the suspension ring at the top of the case over the suspension post at the top of the board. Very gradually, release the adjusting screw at the bottom of the reservoir casing until the surface of the mercury in the reservoir is adjusted to zero; i.e., until the surface of the mercury exactly coincides with the tip of the ivory zero point. The mercury level should be lowered very slowly to permit sufficient time for the air to enter the reservoir through the chamois diaphragm at the top. Too sudden lowering of the mercury levei would cause a partial vacuum in the reservoir which would draw in air bubbles through the chamois bag, with the possibility that some air might enter the barometer tube.

\section{PREPARATION FOR SHIPMENT}

When the barometer is to be moved from one place to another, it should be inclined carefully and slowly to an angle of approximately $45^{\circ}$. The mercury in the barometer tube will, in so doing, slowly rise to the top of the tube and fill it completely. If the barometer is free of air and moisture, the mercury column will strike the top of the glass tube with an audible metallic sound or click. Care should be taken in tilting it slowly, since a sudden or violent movement may cause the mercury to rise quickly and with its impact break the top of the glass tube. The characteristic click may be heard plainly if the barometer is held close to the ear during the process. When the glass tube is completely filled with mercury, incline the barometer further to an angle of approximately $35^{\circ}$. While in this position turn the adjusting screw until mercury completely fills the reservoir. When the glass tube and the reservoir are thus completely filled with mercury, invert the barometer; i.e., turn it upside down. If the barometer is then held vertically in the inverted position, it may be carried about or prepared for shipment. If this position is not maintained, sudden sharp jars may cause the mercury to drop short distances in the tube and to rebound with sufficient force to break the top of the tube.

In shipping the barometer, be sure it is packed suitably in a strong box. In its packing box, the instrument should be in the horizontal position. When packed for shipment the instrument should be thoroughly imbedded on all sides and at both ends in at least four inches of resilient packing material. The packing box should be clearly marked "DO NOT STAND ON END." 
Table 1. TEMPERATURE CORRECTION, English Units

To reduce the reading of the barometer to standard temperature

\begin{tabular}{|c|c|c|c|c|c|c|c|c|c|c|c|c|}
\hline \multirow{3}{*}{$\begin{array}{c}\text { Tempera- } \\
\text { ture } \\
\text { F }\end{array}$} & \multicolumn{12}{|c|}{ Observed Reading of the Barometer in Inches } \\
\hline & $20^{\prime \prime}$ & $21^{\prime \prime}$ & $22^{\prime \prime}$ & $23^{\prime \prime}$ & $24^{\prime \prime}$ & $25^{\prime \prime}$ & $26^{\prime \prime}$ & $27^{\prime \prime}$ & $28^{\prime \prime}$ & $29^{\prime \prime}$ & $30^{\prime \prime}$ & $31 "$ \\
\hline & \multicolumn{12}{|c|}{ ALL CORRECTIONS SUBTRACTIVE } \\
\hline 30 & .002 & .003 & .003 & .003 & .003 & .003 & .003 & .003 & .003 & .004 & .004 & .004 \\
\hline 32 & .006 & .006 & .007 & .007 & .007 & .008 & .008 & .008 & .009 & .009 & .009 & .009 \\
\hline 34 & .010 & .010 & .011 & .011 & .012 & .012 & .013 & .013 & .014 & .014 & .015 & .015 \\
\hline 36 & .013 & .014 & .015 & .015 & .016 & .017 & .017 & .018 & .019 & .019 & .020 & .021 \\
\hline 38 & .017 & .018 & .019 & .020 & .020 & .021 & .022 & .023 & .024 & .025 & .026 & .026 \\
\hline 40 & .021 & .022 & .023 & .024 & .025 & .026 & .027 & .028 & .029 & .030 & .031 & .032 \\
\hline 42 & .024 & .025 & .027 & .028 & .029 & .030 & .032 & .033 & .034 & .035 & .036 & .038 \\
\hline 44 & .028 & .029 & .031 & .032 & .033 & .035 & .036 & .038 & .039 & .040 & .042 & .043 \\
\hline 46 & .031 & .033 & .035 & .036 & .038 & .039 & .041 & .043 & .044 & .046 & .047 & .049 \\
\hline 48 & .035 & .037 & .039 & .040 & .042 & .044 & .046 & .047 & .049 & .051 & .053 & .054 \\
\hline 50 & .039 & .041 & .043 & .045 & .046 & .048 & .050 & .052 & .054 & .056 & .058 & .060 \\
\hline 52 & .042 & .044 & .047 & .049 & i & .053 & .055 & .057 & .059 & .061 & .064 & .066 \\
\hline 54 & .046 & .048 & .051 & .053 & .055 & .057 & .060 & .062 & .064 & .067 & .069 & .071 \\
\hline 56 & .050 & .052 & .055 & .057 & .060 & .062 & .064 & .067 & .069 & .072 & .074 & .077 \\
\hline 58 & .053 & .056 & .059 & .061 & .064 & .066 & .069 & .072 & .074 & .077 & .080 & .082 \\
\hline 60 & .057 & .060 & .062 & .065 & .068 & .071 & .074 & .077 & .080 & .082 & .085 & .088 \\
\hline 62 & .060 & .063 & .066 & .069 & .073 & .076 & .079 & .082 & .085 & .088 & .091 & .094 \\
\hline 64 & .064 & .067 & .070 & .074 & .077 & .080 & .083 & .086 & .090 & .093 & .096 & .099 \\
\hline 66 & .068 & .071 & .074 & .078 & .081 & .085 & .088 & .091 & .095 & .098 & .101 & .105 \\
\hline 68 & . 071 & .075 & .078 & .082 & .085 & .089 & .093 & .096 & 100 & .103 & .107 & .110 \\
\hline 70 & .075 & .079 & .082 & .086 & .090 & .094 & .097 & .101 & .015 & .109 & .112 & .116 \\
\hline 72 & .078 & .082 & .086 & .09 & .05 & .098 & .102 & .106 & .110 & .114 & .118 & .122 \\
\hline 74 & .082 & .086 & .090 & .094 & .098 & .103 & 107 & 111. & .115 & .119 & .123 & .127 \\
\hline 76 & .086 & .090 & .094 & .098 & .103 & .107 & .111 & .116 & $: 120$ & .124 & .128 & 133 \\
\hline 78 & .089 & .094 & .098 & .103 & .107 & .112 & .116 & .120 & .125 & .129 & .134 & .138 \\
\hline 80 & .093 & .097 & .102 & .107 & .11 & .116 & .121 & .12 & .1 & .13 & .139 & .144 \\
\hline 82 & .096 & .101 & .106 & ווו. & .116 & .121 & .125 & .130 & .135 & .140 & .145 & .149 \\
\hline 84 & .100 & .105 & .110 & .115 & .120 & .125 & .130 & .135 & .140 & .145 & .150 & .155 \\
\hline 86 & .104 & 109 & .114 & .119 & .124 & .130 & .135 & .140 & ? 145 & .150 & 155 & 161. \\
\hline 88 & .107 & .113 & .118 & .123 & .129 & .134 & .139 & .145 & .150 & .155 & .161 & .166 \\
\hline 90 & 111 & .116 & .122 & .127 & .133 & .138 & .144 & .150 & .155 & .161 & .166 & .172 \\
\hline 92 & .114 & .120 & .126 & .132 & .137 & .142 & .149 & .154 & .160 & .166 & .172 & 177 \\
\hline 94 & .118 & .124 & .130 & .136 & 142 & .147 & .153 & .159 & .165 & 171. & .177 & .183 \\
\hline 96 & .122 & .128 & .134 & .140 & .146 & .152 & .158 & .164 & .170 & .176 & .182 & .188 \\
\hline 98 & .125 & .131 & .138 & .144 & .150 & .156 & .163 & .169 & .175 & .181 & .188 & .194 \\
\hline
\end{tabular}


Table 2. TEMPERATURE CORRECTION, Metric Units

To reduce the reading of the barometer to standard temperature

\begin{tabular}{|c|c|c|c|c|c|c|c|c|c|c|c|c|c|}
\hline \multirow{3}{*}{$\begin{array}{c}\text { Tempera- } \\
\text { ture } \\
\text { C }\end{array}$} & \multicolumn{13}{|c|}{ Observed Reading of the Borometer in Millimetres or Millibars } \\
\hline & 540 & 560 & 580 & 600 & 620 & 640 & 660 & 680 & 700 & 720 & 740 & 760 & 780 \\
\hline & \multicolumn{13}{|c|}{ ALL CORRECTIONS SUBTRACTIVE } \\
\hline 0 & 0.00 & 0.00 & 0.00 & 0.00 & 0.00 & 0.00 & 0.00 & 0.00 & 0.00 & 0.00 & 0.00 & 0.00 & 0.00 \\
\hline 1 & .09 & .09 & .09 & .10 & .10 & .10 & 11 & 11 & וו. & .12 & .12 & .12 & .13 \\
\hline 2 & .18 & .18 & .19 & .20 & .20 & .21 & .22 & .22 & .23 & .24 & .24 & .25 & .25 \\
\hline 3 & .26 & .27 & .28 & .29 & .30 & .31 & .32 & .33 & .34 & .35 & .36 & .37 & .38 \\
\hline 4 & .35 & .37 & .38 & .39 & .40 & .42 & .43 & .44 & .46 & .47 & .48 & .50 & .51 \\
\hline 5 & 0.44 & 0.46 & 0.47 & 0.49 & 0.51 & 0.52 & 0.54 & 0.56 & 0.57 & 0.59 & 0.60 & 0.62 & 0.64 \\
\hline 6 & .53 & .55 & .57 & .59 & .61 & .63 & .65 & .67 & .69 & .71 & .72 & .74 & .76 \\
\hline 7 & .62 & .64 & .66 & .69 & .71 & .73 & .75 & .78 & .80 & .82 & .85 & .87 & .89 \\
\hline 8 & .70 & .73 & .76 & .78 & .81 & .84 & .86 & .89 & .91 & .94 & $.9 ?$ & .99 & 1.02 \\
\hline 9 & .79 & .82 & .85 & .88 & .91 & .94 & .97 & 1.00 & 1.03 & 1.06 & 1.09 & 1.12 & 1.15 \\
\hline 10 & 0.88 & 0.91 & 0.95 & 0.98 & 1.01 & 1.04 & 1.08 & 1.11 & 1.14 & 1.17 & 1.21 & 1.24 & 1.27 \\
\hline 11 & .97 & 1.00 & 1.04 & 1.08 & 1.11 & 1.15 & 1.18 & 1.22 & 1.26 & 1.29 & 1.33 & 1.36 & 1.40 \\
\hline 12 & 1.06 & 1.10 & 1.13 & 1.17 & 1.21 & 1.25 & 1.29 & 1.33 & 1.37 & 1.41 & 1.45 & 1.49 & 1.53 \\
\hline 13 & 1.14 & 1.19 & 1.23 & 1.27 & 1.31 & 1.36 & 1.40 & 1.44 & 1.48 & 1.53 & 1.57 & 1.61 & 1.65 \\
\hline 14 & 1.23 & 1.28 & 1.32 & 1.37 & 1.41 & 1.46 & 1.51 & 1.55 & 1.60 & 1.64 & 1.69 & 1.73 & 1.78 \\
\hline 15 & 1.32 & 1.37 & 1.42 & 1.47 & 1.52 & 1.56 & 1.61 & 1.66 & 1.71 & 1.76 & 1.81 & 1.86 & 1.91 \\
\hline 16 & 1.41 & 1.46 & 1.51 & 1.56 & 1.62 & 1.67 & 1.72 & 1.77 & 1.82 & 1.88 & 1.93 & 1.98 & 2.03 \\
\hline 17 & 1.50 & 1.55 & 1.61 & 1.66 & 1.72 & 1.77 & 1.83 & 1.88 & 1.94 & 1.99 & 2.05 & 2.10 & 2.16 \\
\hline 18 & 1.58 & 1.64 & 1.70 & 1.76 & 1.82 & 1.88 & 1.93 & 1.99 & 2.05 & 2.11 & 2.17 & 2.23 & 2.29 \\
\hline 19 & 1.67 & 1.73 & 1.79 & 1.86 & 1.92 & 1.98 & 2.04 & 2.10 & 2.17 & 2.23 & 2.29 & 2.35 & 2.41 \\
\hline 20 & 1.76 & 1.82 & 1.89 & 1.95 & 2.02 & 2.08 & 2.15 & 2.21 & 2.28 & 2.34 & 2.41 & 2.47 & 2.54 \\
\hline 21 & 1.85 & 1.91 & 1.98 & 2.05 & 2.12 & 2.19 & 2.26 & 2.32 & 2.39 & 2.46 & 2.53 & 2.60 & 2.67 \\
\hline 22 & 1.93 & 2.01 & 2.08 & 2.15 & 2.22 & 2.29 & 2.36 & 2.43 & 2.51 & 2.58 & 2.65 & 2.72 & 2.79 \\
\hline 23 & 2.02 & 2.10 & 2.17 & 2.25 & 2.32 & 2.40 & 2.47 & 2.54 & 2.62 & 2.69 & 2.77 & 2.84 & 2.92 \\
\hline 24 & 2.11 & 2.19 & 2.26 & 2.34 & 2.42 & 2.50 & 2.58 & 2.66 & 2.73 & 2.81 & 2.89 & 2.97 & 3.05 \\
\hline 25 & 2.20 & 2.28 & 2.36 & 2.44 & 2.52 & 2.60 & 2.68 & 2.77 & 2.85 & 2.93 & 3.01 & 3.09 & 3.17 \\
\hline 26 & 2.28 & 2.37 & 2.45 & 2.54 & 2.62 & 2.71 & 2.79 & 2.88 & 2.96 & 3.04 & 3.13 & 3.21 & 3.30 \\
\hline 27 & 2.37 & 2.46 & 2.55 & 2.63 & 2.72 & 2.81 & 2.90 & 2.99 & 3.07 & 3.16 & 3.25 & 3.34 & 3.42 \\
\hline 28 & 2.46 & 2.55 & 2.64 & 2.73 & 2.82 & 2.91 & 3.00 & 3.10 & 3.19 & 3.28 & 3.37 & 3.46 & 3.55 \\
\hline 29 & 2.55 & 2.64 & 2.73 & 2.83 & 2.92 & 3.02 & 3.11 & 3.21 & 3.30 & 3.39 & 3.49 & 3.58 & 3.68 \\
\hline 30 & 2.63 & 2.73 & 2.83 & 2.93 & 3.02 & 3.12 & 3.22 & 3.32 & 3.41 & 3.51 & 3.61 & 3.71 & 3.80 \\
\hline 31 & 2.72 & 2.82 & 2.92 & 3.02 & 3.12 & 3.22 & 3.32 & 3.43 & 3.53 & 3.63 & 3.73 & 3.83 & 3.93 \\
\hline 32 & 2.81 & 2.91 & 3.02 & 3.12 & 3.22 & 3.33 & 3.43 & 3.54 & 3.64 & 3.74 & 3.85 & 3.95 & 4.05 \\
\hline 33 & 2.89 & 3.00 & 3.11 & 3.22 & 3.32 & 3.43 & 3.54 & 3.64 & 3.75 & 3.86 & 3.97 & 4.07 & 4.18 \\
\hline 34 & 2.98 & 3.09 & 3.20 & 3.31 & 3.42 & 3.53 & 3.64 & 3.75 & 3.87 & 3.98 & 4.09 & 4.20 & 4.31 \\
\hline
\end{tabular}


Table 2 Continued. TEMPERATURE CORRECTION, Metric Units

To reduce the reading of the barometer to standard temperature

\begin{tabular}{|c|c|c|c|c|c|c|c|c|c|c|c|c|c|}
\hline \multirow{3}{*}{$\begin{array}{c}\text { Tempera- } \\
\text { ture } \\
C\end{array}$} & \multicolumn{13}{|c|}{ Observed Reading of the Barometer in Millimetres or Millibars } \\
\hline & 800 & 820 & 840 & 860 & 880 & 900 & 920 & 940 & 960 & 980 & 1000 & 1020 & 1040 \\
\hline & \multicolumn{13}{|c|}{ ALL CORRECTIONS SUBTRACTIVE } \\
\hline 0 & 0.00 & 0.00 & 0.00 & 0.00 & 0.00 & 0.00 & 0.00 & 0.00 & 0.00 & 0.00 & 0.00 & 0.00 & 0.00 \\
\hline 1 & .13 & .13 & .14 & .14 & .14 & .15 & .15 & .15 & .16 & .16 & .16 & .17 & .17 \\
\hline 2 & .26 & .27 & .27 & .28 & .29 & .29 & .30 & .31 & .31 & .32 & .33 & .33 & .34 \\
\hline 3 & .39 & .40 & .41 & .42 & .43 & .44 & .45 & .46 & .47 & .48 & .49 & .50 & .51 \\
\hline 4 & .52 & .54 & .55 & .56 & .57 & .59 & .60 & .61 & .63 & .64 & .65 & .67 & .68 \\
\hline 5 & 0.65 & 0.67 & 0.69 & 0.70 & 0.72 & 0.73 & 0.75 & 0.77 & 0.78 & 0.80 & 0.82 & 0.83 & 0.85 \\
\hline 6 & .78 & .80 & .82 & .84 & .86 & .88 & .90 & .92 & .94 & .96 & .98 & 1.00 & 1.02 \\
\hline 7 & .91 & .94 & .96 & .98 & 1.01 & 1.03 & 1.05 & 1.07 & 1.10 & 1.12 & 1.14 & 1.17 & 1.19 \\
\hline 8 & 1.04 & 1.07 & 1.10 & I. 12 & 1.15 & 1.17 & 1.20 & 1.23 & 1.25 & 1.28 & 1.31 & 1.33 & 1.36 \\
\hline 9 & 1.17 & 1.20 & 1.23 & 1.26 & 1.29 & 1.32 & 1.35 & 1.38 & 1.41 & 1.44 & 1.47 & 1.50 & 1.53 \\
\hline 10 & 1.30 & 1.34 & 1.37 & 1.40 & 1.44 & 1.47 & 1.50 & 1.53 & 1.57 & 1.60 & 1.63 & 1.66 & 1.70 \\
\hline 11 & 1.44 & 1.47 & 1.51 & $\cdot 1.54$ & 1.58 & 1.51 & 1.65 & 1.69 & 1.72 & 1.76 & 1.79 & 1.83 & 1.87 \\
\hline 12 & 1.57 & 1.60 & 1.64 & 1.68 & 1.72 & 1.76 & 1.80 & 1.84 & 1.88 & 1.92 & 1.96 & 2.00 & 2.03 \\
\hline 13 & 1.70 & 1.74 & 1.78 & 1.82 & 1.86 & 1.91 & 1.95 & 1.99 & 2.03 & 2.08 & 2.12 & 2.16 & 2.20 \\
\hline 14 & 1.83 & 1.97 & 1.92 & 1.96 & 2.01 & 2.05 & 2.10 & 2.14 & 2.19 & 2.24 & 2.28 & 2.33 & 2.37 \\
\hline 15 & 1.96 & 2.00 & 2.05 & 2.10 & 2.15 & 2.20 & 2.25 & 2.30 & 2.35 & 2.40 & 2.44 & 2.49 & 2.54 \\
\hline 16 & 2.09 & 2.14 & 2.19 & 2.24 & 2.29 & 2.35 & $2 . .40$ & 2.45 & 2.50 & 2.55 & 2.61 & 2.66 & 2.71 \\
\hline 17 & 2.22 & 2.27 & 2.33 & 2.38 & 2.44 & 2.49 & 2.55 & 2.60 & 2.60 & 2.71 & 2.77 & 2.82 & 2.88 \\
\hline 18 & 2.35 & 2.40 & 2.46 & 2.52 & 2.58 & 2.64 & 2.70 & 2.76 & 2.81 & 2.87 & 2.93 & 2.99 & 3.05 \\
\hline 19 & 2.48 & 2.54 & 2.60 & 2.66 & 2.72 & 2.78 & 2.85 & 2.91 & 2.97 & 3.03 & 3.09 & 3.16 & 3.22 \\
\hline 20 & 2.60 & 2.67 & 2.74 & 2.80 & 2.87 & 2.93 & 3.00 & 3.06 & 3.13 & 3.19 & 3.26 & 3.32 & 3.39 \\
\hline $2 i$ & 2.73 & 2.80 & 2.87 & 2.94 & 3.01 & 3.08 & 3.14 & $3.2 ?$ & 3.28 & 3.35 & 3.42 & 3.49 & 3.56 \\
\hline 22 & 2.86 & 2.94 & 3.01 & 3.08 & 3.15 & 3.22 & 3.29 & 3.37 & 3.44 & 3.51 & 3.58 & 3.65 & 3.72 \\
\hline 23 & 2.99 & 3.07 & 3.14 & 3.22 & 3.29 & 3.37 & 3.44 & 3.52 & 3.59 & 3.67 & 3.74 & 3.82 & 3.89 \\
\hline 24 & 3.12 & 3.20 & 3.28 & 3.36 & 3.44 & 3.51 & 3.59 & 3.67 & 3.75 & 3.83 & 3.90 & 3.98 & 4.06 \\
\hline 25 & 3.25 & 3.33 & 3.42 & 3.50 & 3.58 & 3.66 & 3.74 & 3.82 & 3.90 & 3.99 & 4.07 & 4.15 & 4.23 \\
\hline 26 & 3.38 & 3.47 & 3.55 & 3.64 & 3.72 & 3.81 & 3.69 & 3.97 & 4.06 & 4.14 & 4.23 & 4.31 & 4.40 \\
\hline 27 & 3.51 & 3.60 & 3.69 & 3.78 & 3.86 & 3.95 & 4.04 & 4.13 & 4.21 & 4.30 & 4.39 & 4.48 & 4.57 \\
\hline 28 & 3.64 & 3.73 & 3.82 & 3.91 & 4.01 & 4.10 & 4.19 & 4.28 & 4.37 & 4.46 & 4.55 & 4.64 & 4.73 \\
\hline 29 & 3.77 & 3.87 & 3.96 & 4.05 & 4.15 & 4.24 & 4.34 & 4.43 & 4.53 & 4.62 & 4.71 & 4.81 & 4.90 \\
\hline 30 & 3.90 & 4.00 & 4.10 & 4.19 & 4.29 & 4.39 & 4.49 & 4.58 & 4.68 & 4.78 & 4.88 & 4.97 & 5.07 \\
\hline 31 & 4.03 & 4.13 & 4.23 & 4.33 & 4.43 & 4.53 & 4.63 & 4.73 & 4.84 & 4.94 & 5.04 & 5.14 & 5.24 \\
\hline 32 & 4.16 & 4.26 & 4.37 & 4.47 & 4.57 & 4.68 & 4.78 & 4.89 & 4.99 & 5.09 & 5.20 & 5.30 & 5.41 \\
\hline 33 & 4.29 & 4.40 & 4.50 & 4.61 & 4.72 & 4.82 & 4.73 & 5.04 & 5.15 & 5.25 & 5.36 & 5.47 & 5.57 \\
\hline 34 & 4.42 & 4.53 & 4.64 & 4.75 & 4.86 & 4.97 & 5.08 & 5.19 & 5.30 & 5.41 & 5.52 & 5.63 & 5.74 \\
\hline
\end{tabular}


Table 3. GRAVITY CORRECTION

To reduce the reading of the barometer to standard gravity

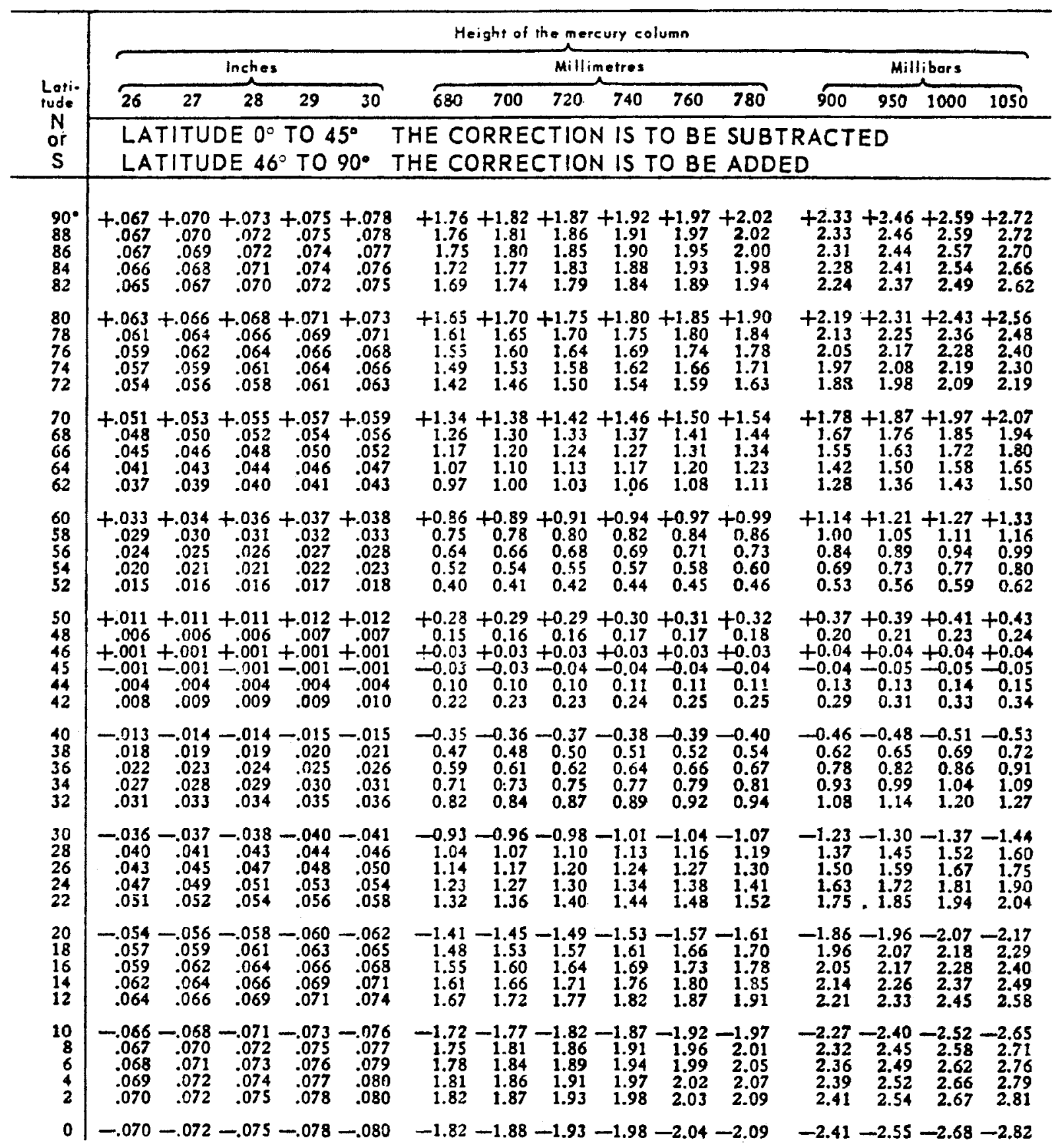

Tables 1 thru 3 are condensed from the "Smithsonian Meteorological Tables", Sixth Revised Edition 1949, Fifth Reprint 1971; and are corrected for consistancy with the recommendations contained in the "International Meteorological Tables", World Meteorological Organization, 1966, with amendments thru July 1973. 


\section{CARE OF THE BAROMETER}

The barometer should not be subjected to quick or sudden movements, nor should its position be shifted suddenly. All changes of position should be made slowly and steadily.

Do not handle or carry the barometer about in an upright position. Observe the directions for preparing the barometer for shipment, and transport the instrument in the horizontal position, with the mercury resting against the top of the glass tube.

Do not force or strain the adjusting screw.

The barometer should be handled as little as possible. It should be protected from the entrance of air, dust, moisture, etc.

If the mercury appears dull or tarnished, it is an indication that the mercury has become contaminated in some way. It frequently occurs that air, dirt, and moisture are admitted into the barometer tube. In such event the instrument will no longer give accurate readings. For proper cleaning of the tube and refilling with pure mercury, the instrument should be sent to the factory.

\section{DIRECTIONS FOR CLEANING A BAROMETER RESERVOIR}

Occasionally, mercury in a Fortin barometer reservoir becomes dusty or oxidized. If the mercury in the barometer tube is still nice and clean, it is sometimes possible, by exercising extreme care, to clean the mercury in the reservoir without the necessity of returning the barometer to the factory for repair. Use the following procedure:

1. Take and record several comparative readings with another barometer.

2. Provide two dry, clean cups or glasses. Avoid the use of damp, unclean or metal cups. Provide some clean cloths, tissue paper for cleaning the glass cistern and a few pieces of clean, white paper, 4" by 6" for use in filtering the mercury. A most convenient position for cleaning a barometer is to be seated in front of a desk, with a drawer at top and side partly open. This affords convenient corners in which the barometer can be rested in an upright position during the process. If the floor is very slippery, provide something to stand the barometer on so that it wiil not slip and fall down.

3. Screw up the adjusting screw until the mercury level rises to near the top of the barometer tube. Remove the barometer from its panel and invert it slowly to a position with the reservoir end up.

4. Without changing the position of the adjusting screw, unscrew the reservoir cover and remove it from the barometer. You will then see the kidskin reservoir and the two plastic cistern parts.

5. With the barometer in this inverted position with the reservoir end up, reach in and pull out the srnall wood button which is in the middle of the kidiskin reservoir. Pull this straight up to release any mercury which. may be trapped in it.

6. Unscrew the one portion of the plastic cistern. The other part is full of mercury.

7. Pour the mercury from the cistern into a clean porcelain cup. Do this slowly and steadily. Do not shake or jar the barometer. The important thing is not to lose any mercury from the barometer tube. It is not necessary to get the last drop sut of the cistern. In pouring the mercury out, do not elevate the barometer to more than a $45^{\circ}$ position because the pressure of atmosphere would not hoid the mercury in the barometer tube and some mercury would be lost.

8. Support the barometer in its inverted position against a desk drawer and remove the three cistern screws which hold together the two metal parts of the cistern on both sides of the glass cylinder.

9. Remove the glass cylinder of the barometer reservoir and catch the last few drops of mercury which may be left in it.

10. Clean the glass cylinder with cioth or tissue paper. If necessary, use soap and water but be careful to dry it well before reassembling it.

11. Be careful to preserve the washers which are on each end of the glass cylinder. If these become torn or badly creased, they can be replaced with new ones.

12. Reassemble the cistern, replacing first one washer, then the glass cylinder. Next, place the one plastic cistern part in the metal part of the cistern and attach it to the glass cylinder with a washer between the glass cylinder and the plastic flange. This should all be held together with the three cistern screws. Do not tighten them one at a vime. Place them together loosely at first and make sure the glass cylinder is seating properly between the two washers. Then tighten all three screws a little at a time so that the pressure around the glass cylinder is equally distributed. 
13. Clean the mercury by pouring it through a paper funnel. The paper funnel is made by using a piece of 4 by 6" white paper. It is coned into a funnel shape with only a small pin hole for an opening. I ne mercury will run through the pin hole and the dust or oxidized mercury will adhere to the paper. One or two pourings, using fresh paper each time, will usually restore the mercury to a nice clean, bright condition.

14. Pour the mercury back into the lower part of the barometer cistern. If a few drops of mercury have been lost, it will not affect the accuracy of the barometer because the zero point is adjusted before each reading is taken.

15. Screw on the half of the plastic cistern which contains the chamois bag.

16. Push the wood button back into the middle of the plastic cistern.

17. Replace the cistern cover, being careful to get the adjusting screw in the middle of the wood button.

18. Invert the barometer slowly to an upright position. Replace it on the barometer panel and lower the mercury until the level of mercury in the cistern coincides with the ivory point. The barometer is then in condition to be used again.

\section{READING THE BAROMETER}

Before reading the barometer be sure it is mounted securely in a vertical position. The most reliable readings are obtained when the temperature has not changed greatly over the past four hours. When reading the barometer the reader's eye should be in the same horizontal plane as the top of the mercury meniscus and the lower edge of the vernier plate. This position can be checked by getting the eye in line with the bottom of the vernier plate and the bottom of the metal guide in back of the mercury column directly in back of the vernier plate.

Readjustment to zero should be made whenever necessary in reading the barometer; i.e., the adjusting screw at the bottom of the reservoir casing should be manipulated until the surface of the mercury exactly coincides with the tip of the ivory zero point which is visible inside the reservoir.

The height of the meniscus will be greater for a rising mercury column than for a falling column. In order to bring the meniscus to its approximate, average height, tap the barometer lightly with your fingers before taking a reading.

The reading then observed should be corrected by use of the correction tables. For explanation of the tables, refer to the following section.

\section{CORRECTIONS TO BE APPLIED}

Barometers are adjusted at the factory as nearly as possible by comparison with a certified standard. The adjustment is so made that no further correction for capillarity need be made.

The standard temperature for the metric scales is $0^{\circ} \mathrm{C}$ and that of English scales is $62^{\circ} \mathrm{F}$. The standard temperature for the density of mercury is $0^{\circ} \mathrm{C}$ or $32^{\circ} \mathrm{F}$. Since the scales and the mercury have different coefficients of expansion, the pressure indications will be affected by variations in temperature; therefore, in order to obtain the true pressure every reading must be corrected for temperature. The Temperature Correction tables given in this pamphlet combine the corrections for the length of the scales and the density of mercury.

Further, the pressure indication will be affected by the gravity of the place at which the reading is taken. Latitudes from $0^{\circ}$ to $45^{\circ}$ have a subtractive correction; latitudes from $46^{\circ}$ to $90^{\circ}$ have an additive correction. More precise determinations of the true pressure may be made by using the Gravity Correction tables in conjunction with the observed readings corrected for temperature.

METRIC EXAMPLE: If the barometer reads $760.0 \mathrm{~mm}$ at $22.5^{\circ} \mathrm{C}$, the temperature correction (interpolating in Table 2 between 22 and $23^{\circ} \mathrm{C}$ ) is $-2.78 \mathrm{~mm}$, yielding a temperature corrected reading of $757.22 \mathrm{~mm}$. At $40^{\circ}$ latitude Table 3 gives a gravity correction of $-0.39 \mathrm{~mm}$, so that the true pressure rounded off to a tenth of a millimetre would be $756.8 \mathrm{~mm}$.

ENGLISH EXAMPLE: If the barometer reads $30.00^{\prime \prime}$ at a temperature of $71^{\circ} \mathrm{F}$, the temperature correction (interpolating in Table 1 between 70 and $72^{\circ} \mathrm{F}$ ) is $-.115^{\prime \prime}$, yielding a temperature corrected reading of $29.885^{\prime \prime}$. At $40^{\circ}$ latitude Table 3 gives a gravity correction of $-.015^{\prime \prime}$, so that the true pressure rounded off to a hundredth of an inch would be 29.87 '.

A barometer with a bore of 0.25 " diameter is suitable for readings to $0.2 \mathrm{~mm}$ or 0.01 ". A barometer with a bore of 0.5 " is suitable for readings of $0.05 \mathrm{~mm}$ or 0.002 ".

If it is desired to convert a metric reading to an English reading, or vice versa, always apply the temperature and gravity corrections before making the conversion.

To get a true barometer indication at the place of observation it is not necessary to correct for altitude. However, if you wish to correct to sea level pressure for comparison with National Weather Service values, a sea level differential (approximately $0.027 \mathrm{~mm}$ or 0.001 " per foot of elevation) would have to be added to the barometric pressure at your altitude. 


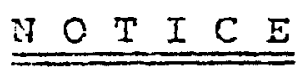

\section{BAROMETER SHIPPING DAMAGE}

Due to possible rough handing or temperature changes, a small quantity of mercury may be forced through the cistern seals of this barometer during shipnent. This small mercury loss does not normally indicate thet ais has gotten into the barometer tube and, thereforc, will not nomaliy affect the reading of the barometer. The small change in the quantity of mercury is automatically compensated for by the cistern adjusting screw, when the mercur: level is set to the ivory point prior to each reading.

However, if air has gotten into the barometer tube or if there is obvious shipping damage, the carrier should be notified at onse so that their inspector may exanine the isstrument and the manner in visich it ras packed and labeled.

Air in the barometer tuke will necessitate return of the barometer to the factory for repair, including replacement of the barometer tuie with a new vacuun filled and degassed baroneter tube.

GEECKING FOR AIR IIN THE BARONETER TUBE

You may check for air in the barometer tube in three ways.

(1) Fxamine the barometer tube for air bubbles which may have adhered to the walls.

(2) With the barcmeter in the upright position and the cistern screw adjusted so that mercury fills the cistem but does not come to the top of the small diameter barometer tube, slowly tilt the barometer until the mercury strikes the top of the barometer tube (atout $30^{\circ}$ off the vertical). A sharp click indicates a good vacuun, a dul? thud indicates a poor vacuum.

(3) Compare the barometer with another mexcurial baxometer known to be accurate. The barcmeters must be side by side for accurate comparison, in vihich case no temperature, gravity or altitude corrections reed to be applied.

\section{COIPARISON IVITH REPCRTFD BAROMETRTC PRESSURE}

The weether services aiways report barometric pressure adjusted to sea level. When reconciling your barometer with reported sea level barometric pressure, allowance must be made for the substantial decrease of pressure from sea level to your elevation (approzimately 0.027 millinetres or 0.001 inches per foot of elevation). Your barometer reads more accurately than the pressurs that can be obtained by this meinod. The scales of your barometer were adjusted at the factory for the life of the instrument and should not be tampered with. 
APPENDIX C

GENERAI INFORMATION 


\section{Conversion Chart}

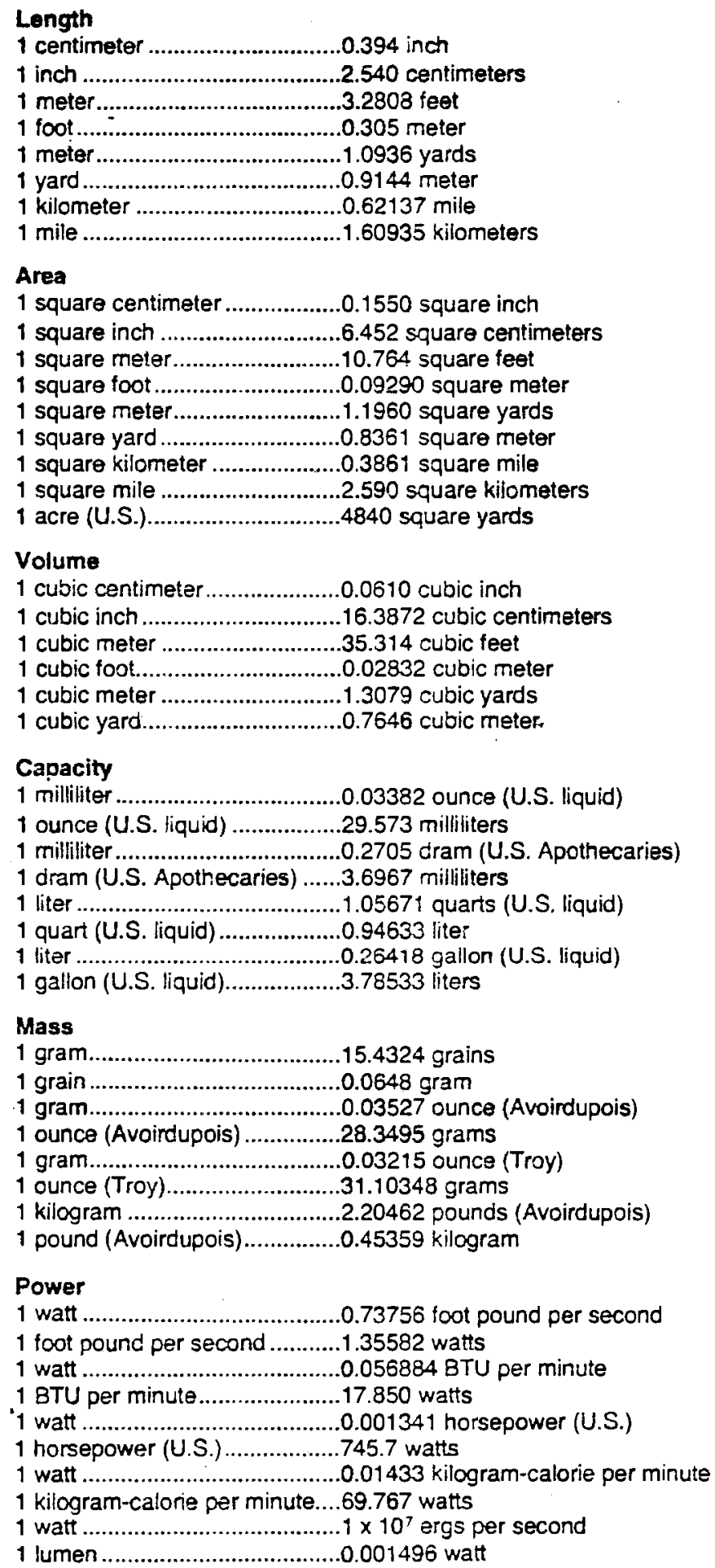


PEIIODIC: TABLE OF THE RLEMENTS

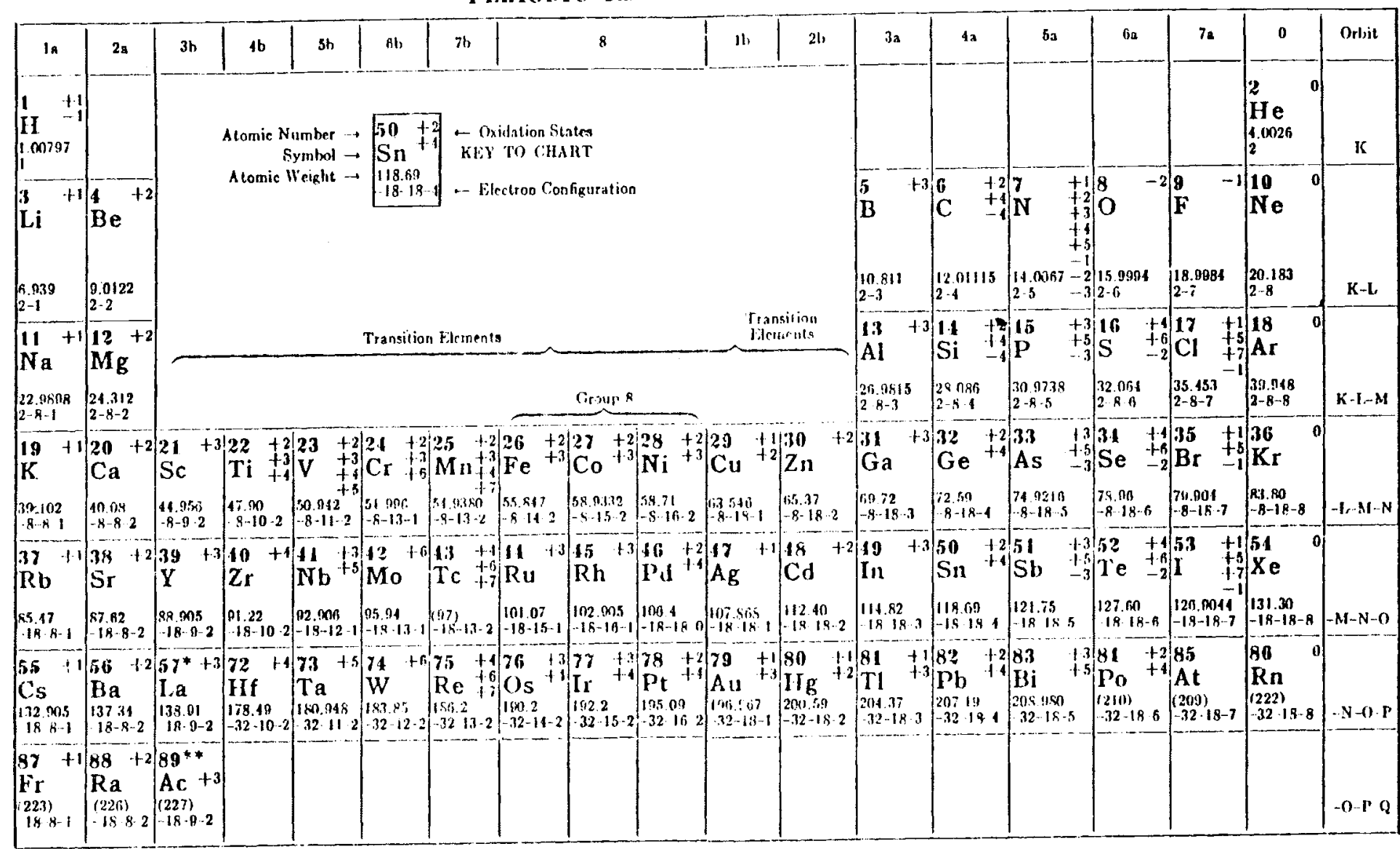

\begin{tabular}{|c|c|c|c|c|c|c|c|c|c|c|c|c|c|c|}
\hline • Lablthanilisa & $\left|\begin{array}{cc}58 & +3 \\
C & -14 \\
10 & 12 \\
19 & 9.2\end{array}\right|$ & $\left|\begin{array}{ll}59 & +3 \\
\mathrm{Pr} \\
140 \mathrm{mp} \\
20-9 \cdot 2\end{array}\right|$ & $\mid \begin{array}{l}60+3 \\
N d \\
114.24 \\
22 \& 2\end{array}$ & $\left|\begin{array}{ll}61 & +3 \\
\mathrm{Pm} \\
0151 \\
27.8 & 2\end{array}\right|$ & $\left|\begin{array}{l}62+2 \\
\operatorname{Sin}+3 \\
1: n .35 \\
21 \times \cdot 2\end{array}\right|$ & 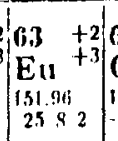 & 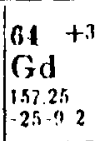 & $\left|\begin{array}{ll}65 & +3 \\
T b & \\
1569.924 \\
20.9 & 9\end{array}\right|$ & $\mid \begin{array}{ll}66 & +3 \\
D y \\
162.50 \\
-28 & 8.2\end{array}$ & 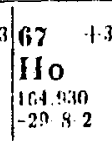 & $\mid \begin{array}{l}68 \\
\mathrm{Er} \\
16720 \\
-30 \times 2\end{array}$ & 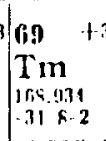 & $\begin{array}{l}70 \\
Y b \\
173.15 \\
-32 \times 2\end{array}$ & $\begin{array}{l}21 \\
\operatorname{Lin}_{11} \\
17197 \\
72 \cdot 92\end{array}$ \\
\hline Artimitirs & $\left|\begin{array}{l}90+1 \\
\mathrm{Th} \\
222.1138 \\
-19 \cdot 9-2\end{array}\right|$ & 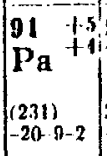 & $\mid \begin{array}{ll}92 & +1 \\
U & +1 \\
& 15 \\
238 & 103 \\
-21 & 92\end{array}$ & $\mid \begin{array}{cc}(2 ; 17) \\
-22 & 9-2\end{array}$ & {$\left[\begin{array}{lll}214 & 27 \\
27 & 2\end{array}\right.$} & 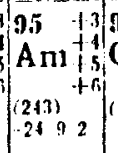 & $\left\{\begin{array}{l}96+3 \\
\mathrm{Cm} \\
(21 ;) \\
25 ! 12\end{array}\right.$ & $\mid \begin{array}{l}9 y+3 \\
B k+1 \\
3(21 \%) \\
2402\end{array}$ & 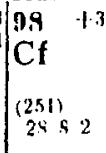 & $\begin{array}{l}99 \\
\text { Es } \\
(254) \\
29 \times 2\end{array}$ & $\begin{array}{l}100 \\
\text { Fn1 } \\
3: 77) \\
7 n-2\end{array}$ & $\left\{\begin{array}{l}101 \\
M d d \\
(256) \\
31 \cdot 5 \cdot 2\end{array}\right.$ & $\left\{\begin{array}{l}102 \\
(254) \\
32 \times 2\end{array}\right.$ & $\begin{array}{l}10.3 \\
\text { Lw }\end{array}$ \\
\hline
\end{tabular}

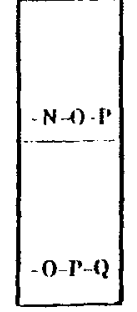

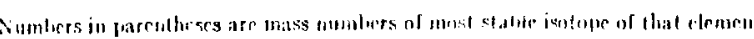

Reprinted with Permission from the Handbook of Chemistry and Physics (48th Edition). 


\section{DISTRIBUTION}

No. of

Copies

\section{OFFSITE}
A. A. Churm
Chicago Patent Group
Department of Energy
9800 South Cass Avenue
Argonne, IL 60439

27 DOE Technical Information Center

5 D. K. Walter

U.S. Department of Energy

20 Massachusetts Avenue

Washington, DC 20001

$5 \quad$ C. Rines

U.S. Department of Energy

20 Massachusetts Avenue

Washington, DC 20001

1 A. J. Shuckrow

Touhi11, Shuckrow, and Associates, Inc.

P. 0. Box 11022

Pittsburgh, PA 15237

1 E. Coppinger

Ecotope Group

2332 E. Madison

Seattle, WA 98122

1 H. E. McGuire

Rockwel 1 Hanford Operations

P. 0. Box 800

Richland, WA 99352

1 W. W. Pitt

Oak Ridge National Laboratory

P. 0. Box $X$

Oak Ridge, TN 37830

1 J. F. Ferguson

Department of Civil Engineering

University of Washington

Seattle, WA 98195

1 S. B. Ahlstrom

$\mathrm{CH} 2 \mathrm{M} \mathrm{Hill}$ Engineers

Box 8748

Boise, ID 83707 


\section{ONSITE}

$2 \quad$ DOE RL

H. E. Ransom

R. K. Stewart

$17 \quad$ PNL

D. B. Cearlock

G. W. Dawson

A. F. Gasperino

D. A. Long

B. W. Mercer

B. J. Sheldon

R. R. Spencer (10)

A. L. Wong

5 Technical Information

2 Publishing Coordination

5 Water and Land Resources Library 


\section{INSTALLATION OF MASTERFLEX ${ }^{\circ}$ STANDARD PUMP HEAD AND TUBING}

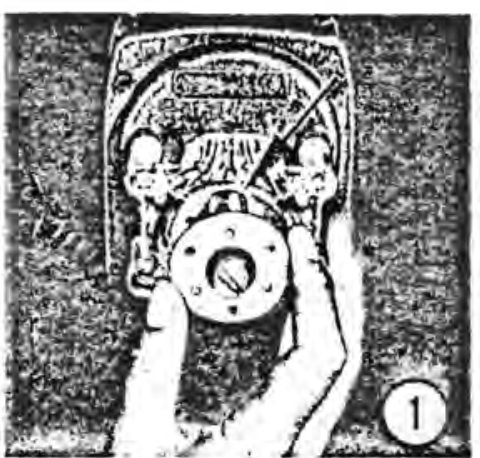

Aline either of the iwo interchangeable halves of the pump head with the two pins protruding from the face of the drive unit. Attach in position with the two fillister head screws provided, olacing the screws through the two diagonally opposed recessed holes. install the longer end of the rotor assembly shaft through the pump head bearing and fully mate the shaft cross slot with the drive unit shear pin by rotating the shaft while exerting gentle pressure inwards; mating will be indicated oy complete seating of the rotor assembly within the head. Rotate the rotor assembly to position one of the rollers botween the tubing niet and outlet recesses molded into tie bead.

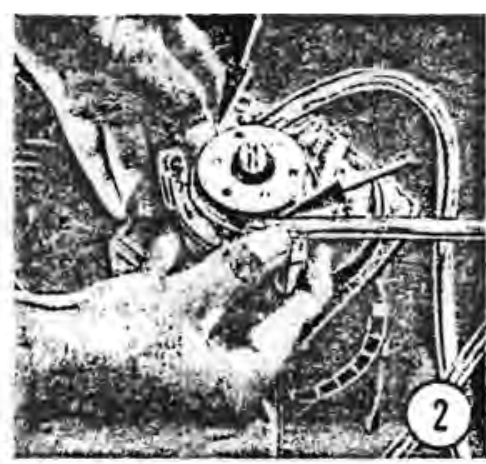

While maintaining the position of one of the rotor assembly rollers between the tubing recesses, position the tubing abou: the other two rollers and press the tubing downwards with the thumbs until the tubing is fully seated within the pump head cavity and rollers. On large dlameter tubing and tubings of higher Shore durometer ratings a tongue depressor or similar object may be usad to assist full seating of the tubing. CAUTION: Use of hard or sharp objects such as screwdrivers may damaga both the tubing and the pump head.

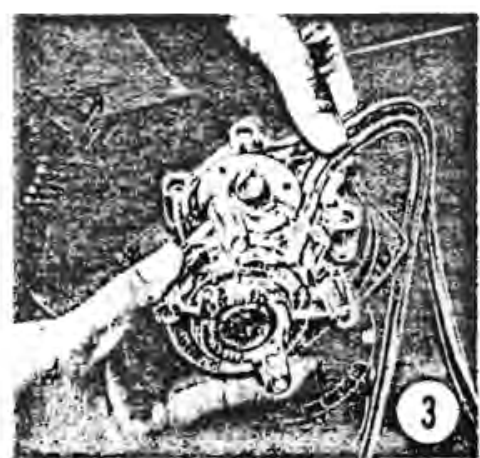

When the tubing has been fully seated within the pump head savity and the two rollers, hold the tree ends of the tubing in the head inlet and outlet recesses and while exerting a slight tension on the tubing ends, place the remaining half of the pump head over the rotor assembly shart and against the installed pump head halt. CAUTION: Failure to hold slight tension on the tubing may result in excess tubing slack within the pump head that may cause binding and shearing of the drive unit shear pin.

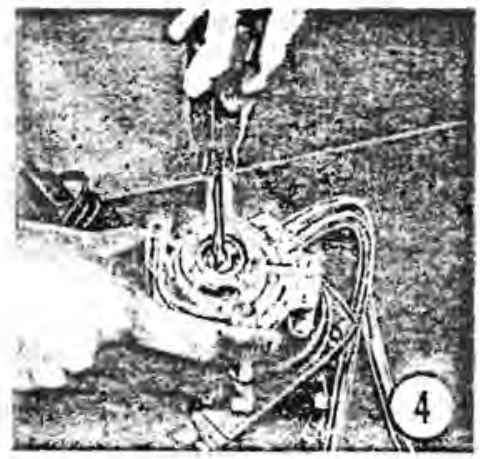

While pressing gently inward on the outor pump head half, rotata the rotor assembly shaft with a screwdrivor to ensure that the rotor assembly is fully seated with the drive unit shaft, that no gap remains between the infer. faces of the two pump head halves, and that there is no binding between the tubing and the rollers of the rotor assembly. CAUTION: Failurg to ensure this proper seating before operating the pump may result in damage to both the drive unit gearing and shear pin.

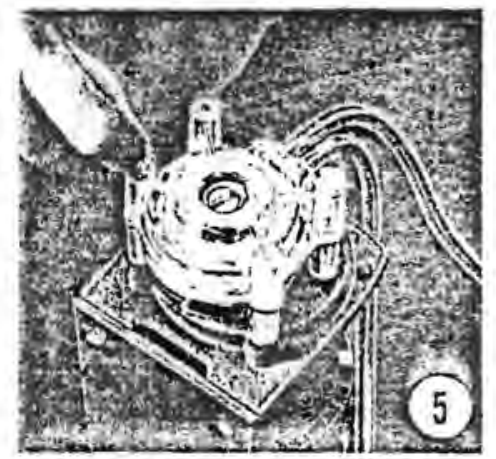

Using the two thumbscrews and flat washers provided, insert thuse attach. ing parts in the iwo mounting holes not occupiod by the initially installod screws and, using finger pressure only, attach the assembled pump hoad to the drive unit. CAUTION: Excessive torque on any of the lour screws may cause distortion and cracking of the pump head.

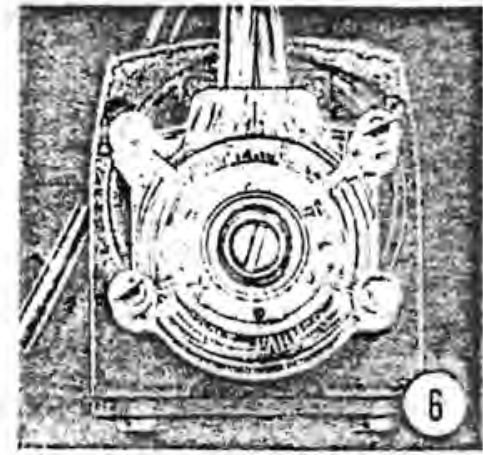

The pump head is now properiy in. stalled and ready for operation If subsequent change of tubing is desired. complete removal of the pump head is not necossary. Merely removo the swo thumbscrews, washers, outer pump head half and tubing, and repeat steps one through five.

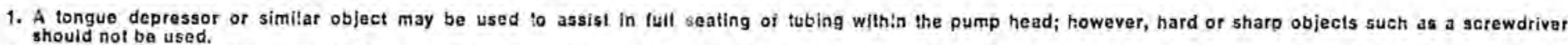

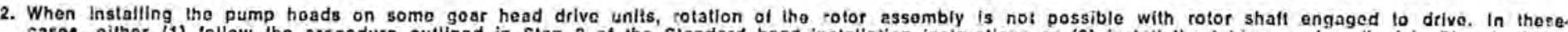

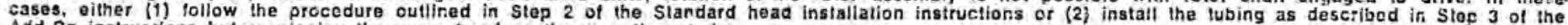
Add-On instructions belore placing the pump head on the mouniling studs. 